\title{
Waste Preparation and Transport Chemistry: Results of the FY 2002 Studies
}

June 2003

Prepared by

R. D. Hunt

J. S. Lindner

A. J. Mattus

J. C. Schryver

C. F. Weber 


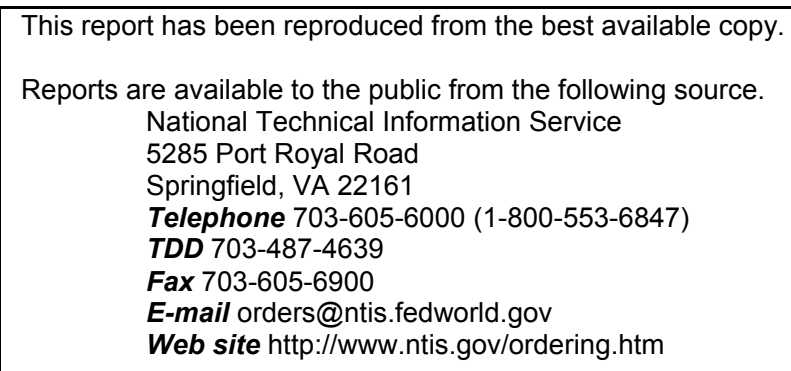

Reports are available to U.S. Department of Energy (DOE) employees, DOE contractors, Energy

Technology Data Exchange (ETDE) representatives, and International Nuclear Information

System (INIS) representatives from the following source.

Office of Scientific and Technical Information

P.O. Box 62

Oak Ridge, TN 37831

Telephone 865-576-8401

Fax 865-576-5728

E-mail reports@adonis.osti.gov

Web site http://www.osti.gov/products/sources.html

Reports produced after January 1, 1996, are generally available via the DOE Information Bridge. Web site http://www.doe.gov/bridge

This report was prepared as an account of work sponsored by an agency of the United States government. Neither the United States government nor any agency thereof, nor any of their employees, makes any warranty, express or implied, or assumes any legal liability or responsibility for the accuracy, completeness, or usefulness of any information, apparatus, product, or process disclosed, or represents that its use would not infringe privately owned rights. Reference herein to any specific commercial product, process, or service by trade name, trademark, manufacturer, or otherwise, does not necessarily constitute or imply its endorsement, recommendation, or favoring by the United States government or any agency thereof. The views and opinions of authors expressed herein do not necessarily state or reflect those of the United States government or any agency thereof. 
Nuclear Science and Technology Division

\title{
Waste Preparation and Transport Chemistry: Results of the FY 2002 Studies
}

\author{
R. D. Hunt \\ J. S. Lindner* \\ A. J. Mattus \\ J. C. Schryver ${ }^{\dagger}$ \\ C. F. Weber
}

Date Published: June 2003

Prepared for the Tanks Focus Area Office of Science and Technology

U.S. Department of Energy

\author{
Prepared by \\ OAK RIDGE NATIONAL LABORATORY \\ Oak Ridge, Tennessee 37831-6285 \\ managed by \\ UT-Battelle, LLC \\ for the \\ U.S. DEPARTMENT OF ENERGY \\ under contract DE-AC05-00OR22725
}

\footnotetext{
*Diagnostic Instrumentation and Analysis Laboratory, Mississippi State University

${ }^{\dagger}$ Computational Sciences and Engineering Division
} 



\section{CONTENTS}

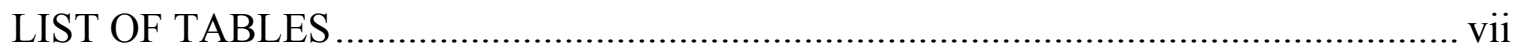

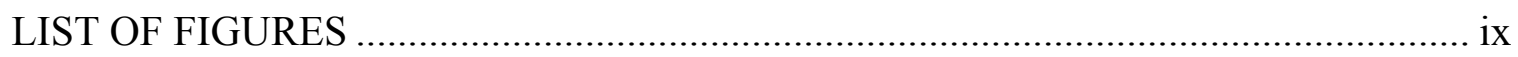

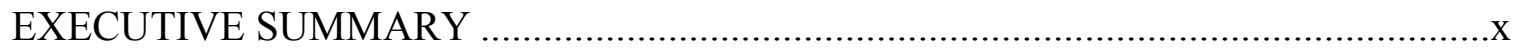

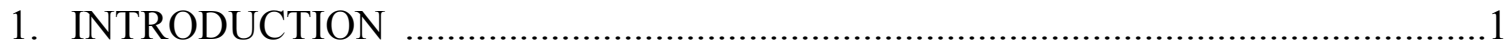

1.1 SOLID FORMATIONS DUE TO TEMPERATURE DROPS .............................

1.2 SOLID FORMATIONS DUE TO EVAPORATION ...........................................

2. SILICON SOLUBILITY AS A FUNCTION OF HYDROXIDE AND NITRATE .....2

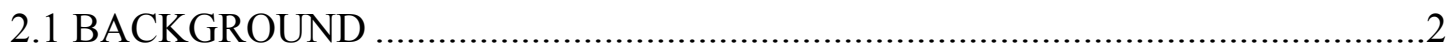

2.2 EXPERIMENTAL PROCEDURE ...............................................................

2.3 RESULTS AND DISCUSSION ............................................................... 7

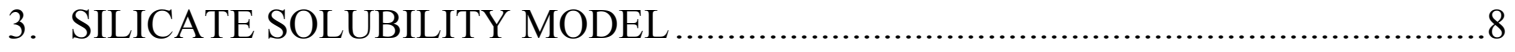

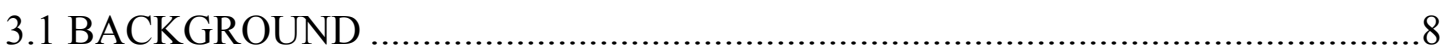

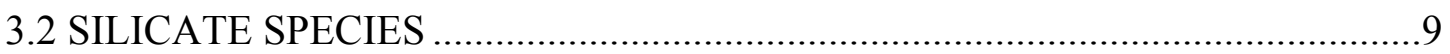

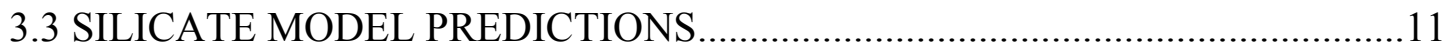

4. SIMULATIONS OF SLURRY TRANSFERS AT HANFORD ...............................17

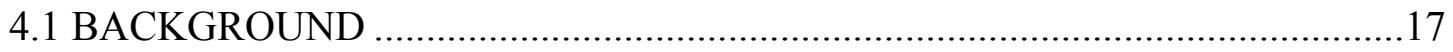

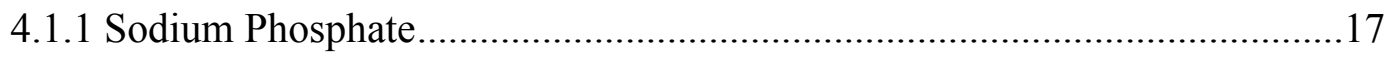

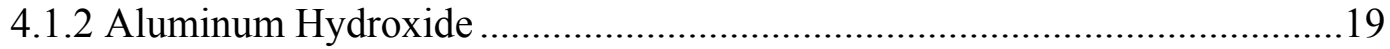

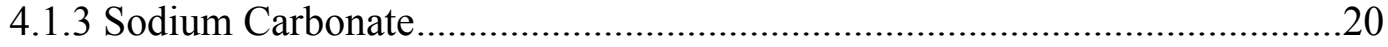

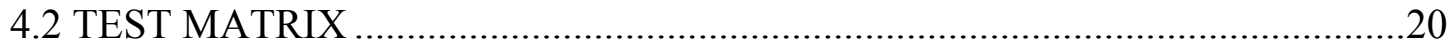

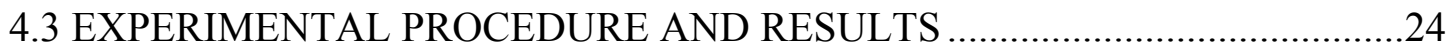

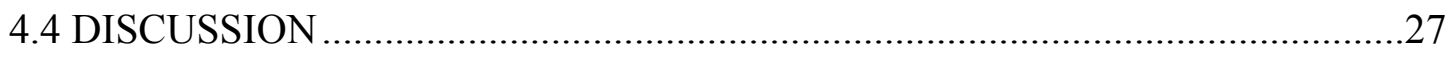

5. SIMULATIONS OF SALTWELL PUMPING TRANSFERS AT HANFORD .........28

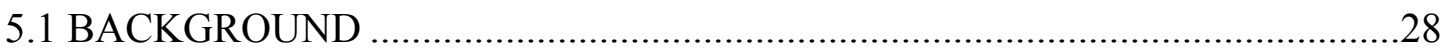

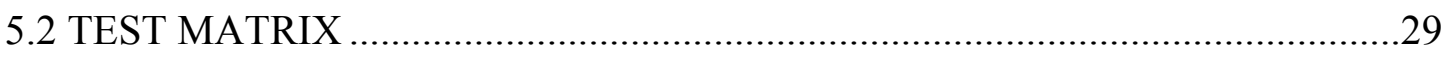

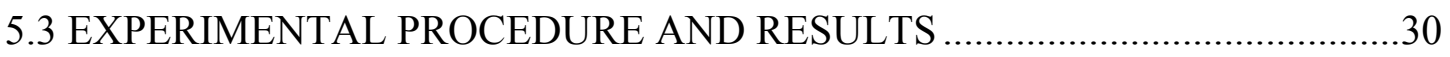

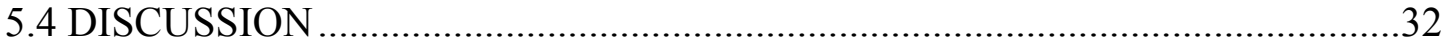

6. ENHANCEMENTS TO VISCOSITY PREDICTIONS ............................................33

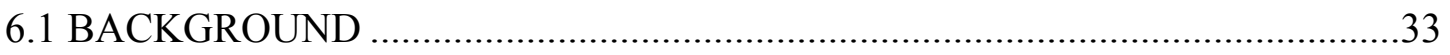

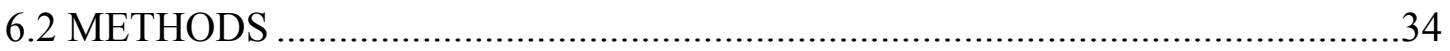

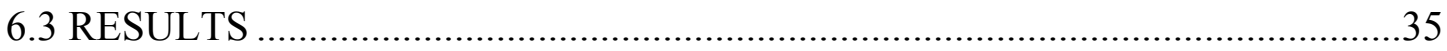

6.4 WEB-BASED ANN VISCOSITY MODEL FOR SALTWELL PUMPING........39 


\section{CONTENTS}

7. STRATEGIES TO REMOVE THE GIBBSITE PLUG AT HANFORD .....................40

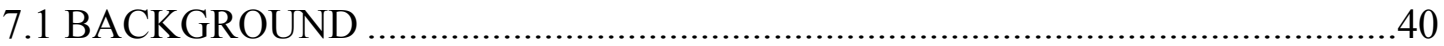

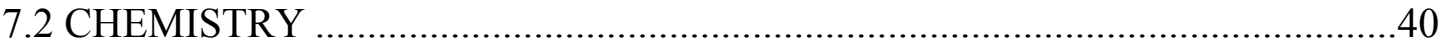

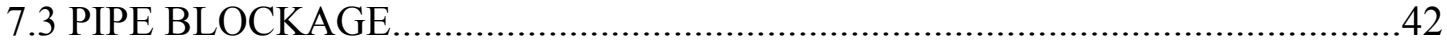

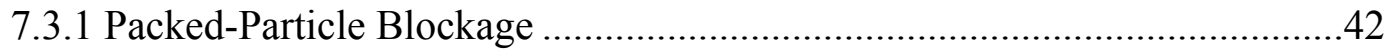

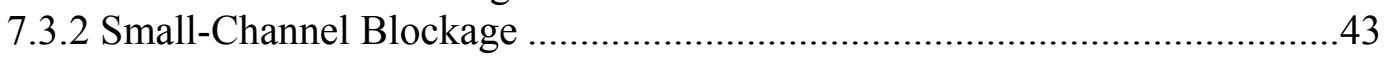

7.4 DISSOLUTION OF THE GIBBSITE PLUG .................................................4

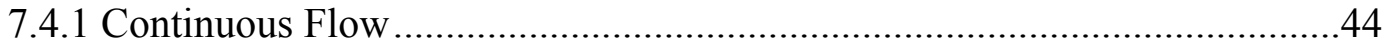

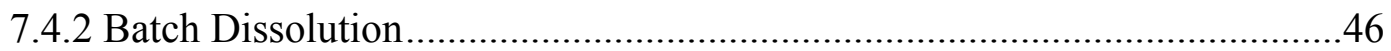

7.5 RECOMMENDATIONS AND CONCLUSIONS ………………….................4

8. POTENTIAL ALUMINUM SATURATION AT SAVANNAH RIVER....................47

8.1 SEEDING TESTS WITH SAVANNAH RIVER SUPERNATANTS...................47

8.2 SOLGASMIX PREDICTIONS OF ALUMINUM CONCENTRATIONS ...........48

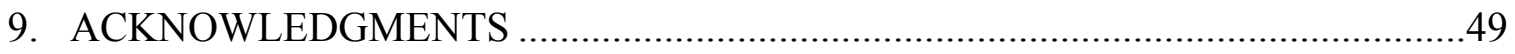

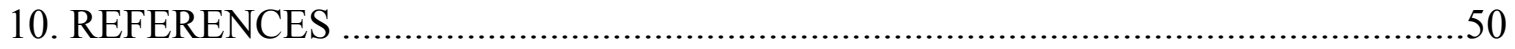




\section{LIST OF TABLES}

Table

Page

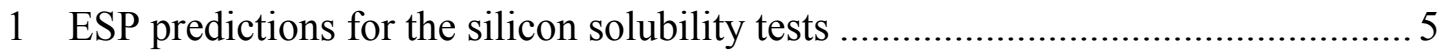

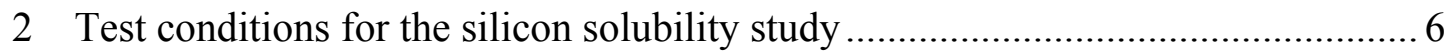

3 Silicon test results: soluble silicon concentration, $\mathrm{pH}$, and density ..................... 8

4 Silicate species and Gibbs energies of formation .........................................

5 Experimental results used to develop the silicate model ................................. 10

6 Pitzer parameters for the silicate species with sodium interactions.....................11

7 Pitzer parameters for the silicate species with nitrate interactions ..................... 11

8 Potentially problematic concentrations of phosphate and fluoride......................17

9 Hanford tanks susceptible to phosphate plugs without selective dissolution .......18

10 Quantities of major chemical components in the Hanford tanks .......................21

11 Range of concentrations for the main components in the Hanford tanks ............21

12 Chemical compositions of the Hanford slurry simulants.................................22

13 Hanford tanks with the largest quantities of sludge .......................................22

14 Types of waste in the selected Hanford tanks................................................23

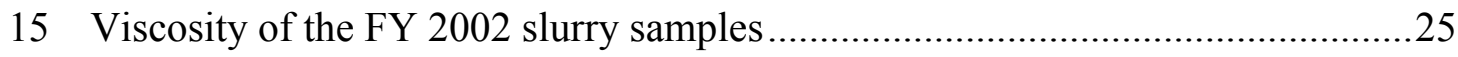

16 Volume percent of the gravity-settled solids prior to the slurry viscosity tests....26

17 Effects of water dilutions on the high-viscosity samples.................................27

18 Chemical compositions of the Hanford saltwell pumping simulants ...................30

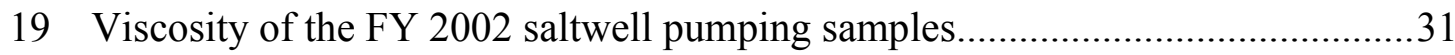

20 Volume percent of settled solids prior to the saltwell pumping tests ...................31

21 ANN performance on viscosity predictions for saltwell pumping simulants .......35 


\section{LIST OF TABLES}

Table

Page

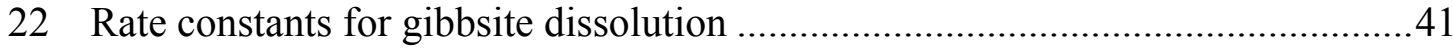

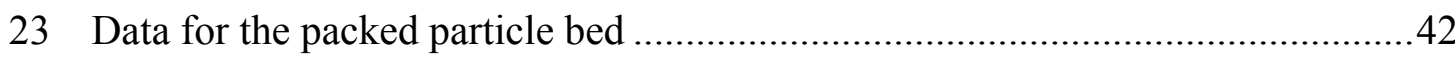

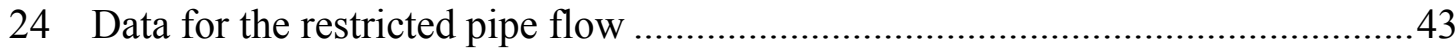

25 Dissolution results with a continuous flow of sodium hydroxide........................45

26 Dissolution results with batch additions of sodium hydroxide ..........................47

27 Chemical compositions and properties of Savannah River supernatants ............48

28 Test results and SOLGASMIX predictions for aluminum concentrations ...........49 


\section{LIST OF FIGURES}

Figure

Page

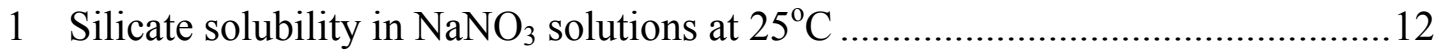

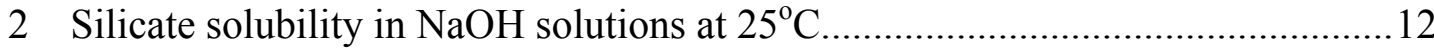

3 Silicate solubility in $\mathrm{NaOH}$ and $1 \mathrm{MNaNO}_{3}$ solutions at $25^{\circ} \mathrm{C} \ldots \ldots \ldots \ldots \ldots \ldots \ldots . . . . . . . . . . . .13$

4 Silicate solubility in $\mathrm{NaOH}$ and $3 \mathrm{MNaNO}_{3}$ solutions at $25^{\circ} \mathrm{C} \ldots \ldots \ldots \ldots \ldots \ldots \ldots . . . . . . . . . . .13$

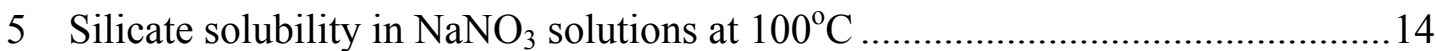

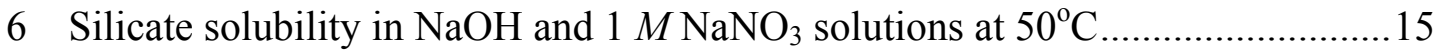

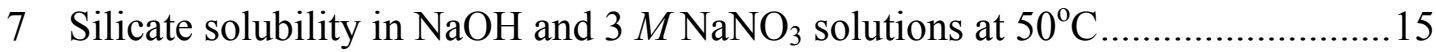

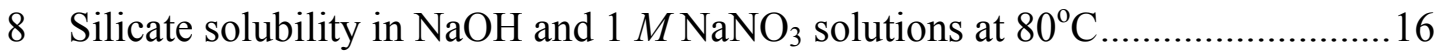

9 Silicate solubility in $\mathrm{NaOH}$ and $3 \mathrm{MNaNO}_{3}$ solutions at $80^{\circ} \mathrm{C} \ldots \ldots \ldots \ldots \ldots \ldots \ldots . . . . . . . . . . . .16$

10 Training performance: observed vs predicted viscosity for all samples...............36

11 Generalization performance: observed vs predicted viscosity for all samples .....37

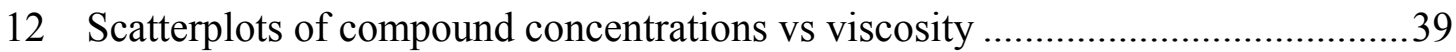




\section{EXECUTIVE SUMMARY}

As a result of both defense and commercial activities, the U.S. Department of Energy has accumulated millions of gallons of inorganic radioactive waste. The remediation plans for Hanford and the Savannah River Site (SRS) assume that decanted waste supernatants and slurries can be successfully transferred from one tank to another or to a treatment facility and that the filtered supernatants can easily pass through unit operations at a process facility. Unfortunately, these types of tank farm operations at Hanford and the SRS continued to be negatively impacted by the unintended formation of solids. Therefore, operating windows to avoid further problems with unwanted solid formation and removal methods for existing problematic solids are needed.

At Hanford, most of the current problems with solid formation have involved plugged pipes and pumps during the saltwell pumping activities of the interim stabilization program. These recent plugs have occurred when the filtered or decanted tank supernatants were transferred relatively short distances within one of the two Hanford tank farms. During the full-scale remediation, the treatment and immobilization facilities will be located close to one of the tank farms. Therefore, the waste in the other tank farm will have to be pumped through an $\sim 6$-mile-long cross-site transfer line. Previous transfers of supernatants and slurries through the cross-site lines have led to numerous plugs, and currently only two of the seven lines are usable. Should these two lines become permanently plugged, it would be impossible to meet the remediation schedule.

At the SRS, most of unwanted solid formation can be attributed to the introduction of a secondary waste stream into the tank farm. The recycle stream from the vitrifier was stored and mixed with wastes from previous canyon operations. The recycle stream is relatively rich in silicon, while the canyon operations typically produced wastes with high aluminum concentrations. As individual elements, aluminum and silicon have high solubilities in caustic. In sharp contrast, however, the solubilities of aluminosilicates are much lower. Therefore, it was expected that solid formation would occur when the waste streams were combined. However, when this combined waste stream was processed through the $2 \mathrm{H}$ evaporator system, aluminosilicate and sodium diuranate deposits firmly attached to the gravity drain line. After subsequent evaporations, deposits were also found in the evaporator pot and lift line. Because of the amount of enriched uranium in the evaporator pot, the $2 \mathrm{H}$ evaporator system was shut down, which led to a severe shortage of tank space. Therefore, the SRS tank farm was forced to transfer highly concentrated waste, leading to a plugged transfer pump in tank 32. More transfer problems can be expected as the number of secondary waste streams from the remediation efforts increases.

In response to these transfer problems, the Tanks Focus Area assembled a team of researchers from AEA Technology, Mississippi State University (MSU), and Oak Ridge National Laboratory (ORNL) to evaluate various aspects of the transport chemistry. AEA researchers have focused on agglomeration and deagglomeration processes, which are relevant to the Hanford waste tanks. Agglomeration is important because it controls the size of sludge particles during transfers and waste processing. Particle size is a key factor in pipe blockages and process times during liquid-solid separations. MSU researchers have used computational fluid dynamics to explore the effects of some physical and fluid dynamics parameters on operating windows for Hanford slurry transfers. In addition, they have studied 
the formation of sodium phosphate plugs and investigated ways to remove these plugs, such as by the addition of carbon dioxide. ORNL staff members have conducted experimental and theoretical studies on nearly all of solid formation problems at Hanford and the SRS. This report focuses on silicon solubility in caustic solutions for Hanford and the SRS, saltwell pumping and slurry transfers at Hanford, methods to remove the gibbsite plug at Hanford, and potential aluminum saturation at the SRS. Staff members at Hanford and the SRS had previously identified the need for a silicon solubility study conducted for appropriate concentrations of sodium hydroxide and sodium nitrate. These solubility results can then be used to evaluate strategies for the safe storage and treatment of silicon-rich waste streams from vitrification. For $\mathrm{pH}$ values of 6 to 9 , silicon solubilities are relatively constant on the order of few millimolars. However, for $\mathrm{pH}$ values of 9 to 11 , the silicon solubilities increase rapidly to $1 \mathrm{M}$. While the silicon solubilities at 25 and $50^{\circ} \mathrm{C}$ are comparable, those at $80^{\circ} \mathrm{C}$ are normally slightly higher. Therefore, filtration of glass frit from the recycle stream is feasible and should occur when the $\mathrm{pH}$ of the waste is 9 or lower and before the vitrifier waste is combined with a caustic and aluminum-rich waste stream. In addition, the solubility results were used to establish Pitzer parameters, which were added to a SOLGASMIX model. This model has accurately predicted solid formation and dissolution at Hanford and the SRS. The silicon solubility results can also be used to improve the predictive capabilities of other thermodynamic models such as the Environmental Simulation Program and the Geochemist's Workbench. The predictive capabilities of these models improve as more relevant experimental data are utilized. For example, the SOLGASMIX model with a refined database and the Geochemist's Workbench with its standard database were used to predict if the wastes in several SRS tanks were supersaturated with respect to aluminum. The SOLGASMIX model performed considerably better than the Geochemist's Workbench.

Recent viscosity tests on simulants of saltwell pumping confirmed earlier observations. Sodium phosphate needle crystals have been responsible for all, or nearly all, of the pipeline plugs during saltwell pumping. Wastes in five Hanford tanks are susceptible to phosphate plugs even without any increases in phosphate concentrations resulting from selective dissolution. Attempts to form pipeline plugs caused by aluminum hydroxide and sodium carbonate were not successful. Nitrate and nitrite anions have a comparable effect on the formation of sodium phosphate needle crystals, which typically appear as a solution is cooled from 30 to $25^{\circ} \mathrm{C}$. A sodium phosphate plug is more likely to occur if the rate of cooling is rapid. However, the presence of fluoride and sulfate significantly reduces the potential for a phosphate plug via the formation of double salts with the sodium phosphate. Potentially problematic concentrations of phosphate and fluoride were identified. The viscosity results were used as input for an artificial neural network (ANN), which predicts the highest viscosity of a solution with aluminum, carbonate, fluoride, hydroxide, nitrate, phosphate, silicon, sodium, and sulfate. Validation tests have indicated that the ANN model in conjunction with a simple table listing safe and potentially unsafe concentrations of phosphate and fluoride can be used to identify nearly all problematic waste transfers. This model can be accessed at http://www.ornl.gov/ViscosityANN/viscosityl.html.

A viscosity study was also conducted to evaluate potential slurry transfers at Hanford. Most of the slurry simulants were based on the waste compositions in 22 tanks, which contain approximately $50 \%$ of the total volume of sludge. The slurry simulants were comprised of aluminum, bismuth, calcium, carbonate, chromium, iron, nitrate, silicon, sodium, and zirconium. Because plugs caused by phosphate have been studied extensively, 
phosphate was not included in the slurry simulants. A maximum water dilution of $100 \%$ was needed to produce sludge slurries that could be safely transferred. Since the retrieval effort is expected to dilute the sludge by $300 \%$, pipeline plugs should not occur during the transfer if the sludge is sufficiently blended, if the slurry cannot form a phosphate plug, and if the solids in the slurry are small enough to be easily transported. In fact, the viscosity results clearly suggest that the $300 \%$ water dilution would be excessive. Prior to these tests, the perceived transfer limit for aluminum was $1 M$. However, the aluminum concentrations in 26 tanks are greater than 4 mol per liter of waste. Therefore, the aluminum concentration after the $300 \%$ dilution would still exceed the perceived limit. If the aluminum limit could be increased to $1.5 \mathrm{M}$, the amount of dilution water could be reduced by 5,100,000 gal, which should lead to significant cost savings. A further analysis clearly indicated that a high aluminum concentration with low concentrations of iron and silicon did not result in highviscosity slurries. In fact, the high-viscosity samples required only moderate concentrations of aluminum, iron, and silicon. However, it should be noted that relatively low concentrations of these three components can be problematic. For example, the concentrations of aluminum, iron, and silicon in the potentially problematic tank TY-103 slurry were $0.16,0.42$, and $0.20 \mathrm{M}$, respectively. Further evaluation of these test results and Hanford operational data are needed before any changes should be made in the waste transfer criteria for slurries.

Recent transfers at Hanford between the U and SY tank farms have resulted in significant blockage of a 3-in. transfer line. Attempts to remove the plug with water-back flushes have been only marginally successful. Because the transferred waste was high in aluminum and low in potentially complicating chemicals such as silicon, the Hanford tank farm operators believed that the plug is probably gibbsite and that a flush with caustic will be needed to improve the flow rate. The effects of various caustic dissolution strategies were examined. This analysis indicates that a continuous dissolution at high temperature and low flow rate is likely the best approach to the remediation of a gibbsite plug. The highest temperature that is practical will increase both the rate and the amount of dissolution. A flow of $1 \mathrm{~m}^{3}$ /day will likely yield the same dissolution rate as a flow of $10 \mathrm{~m}^{3} /$ day, while the slower flow rate will consume only a fraction of the caustic. However, a rate much below $1 \mathrm{~m}^{3} /$ day might significantly impact the dissolution rate. A continuous flow is recommended since it ensures that the caustic is replenished, maintains a higher temperature, and induces flow turbulence all of which enhances the dissolution rate. However, operational and regulatory considerations make implementation of this recommendation impractical at Hanford. 


\section{INTRODUCTION}

The initial step in the remediation of nuclear waste stored at Hanford and the Savannah River Site (SRS) involves the retrieval and transfer of the waste to another tank or to a treatment facility. The retrieved waste can range from a filtered supernatant to a slurry. Nearly all of the recent solid formation problems encountered during waste transfers and subsequent treatment steps have involved decanted or filtered supernatants. Problems with slurry transfers have not yet surfaced, because tank farm operations at Hanford and the SRS have focused primarily on supernatant transfers and treatment. For example, the interim stabilization program at Hanford continues to reduce the level of supernatants and interstitial liquids in its single-shell tanks through saltwell pumping of filtered liquid. In addition, at present, the cross-site transfer lines at Hanford can be used only to transfer liquids. Another reason for fewer problems with slurry transfers involves the additions of large quantities of dilution water prior to the transfer. When the waste is transferred, a drop in temperature is expected because most transfer lines are not heated. However, the dilution water reduces or eliminates solid formation caused by this temperature drop. In sharp contrast, decanted or filtered supernatants are near or at saturation for certain compounds. In such cases, tank farm operators must continue to evaporate their liquid waste since available tank space is quite limited. Solid formation can occur when the temperature of saturated solutions drops even slightly. The evaporation step can also lead to the formation of problematic solids. At the SRS, the evaporation of a relatively dilute waste stream was suspended due to the formation of deposits in the evaporator system. Therefore, small drops in temperature or evaporation can lead to problematic solid formations.

\subsection{SOLID FORMATIONS DUE TO TEMPERATURE DROPS}

Problematic solid formations, which can be attributed to small temperature drops, have been encountered at Hanford and the SRS. Several such instances have occurred since 2000. First, the transfer of 50,000 gal of filtered supernatant from tank U-103 was suspended for several weeks due to a plug in 02-A flex jumper. In an effort to avoid further plugs, modifications such as larger flex jumpers and additional heat tracing were made to the transfer system. Second, transfers of tank S-102 waste were suspended because of either a plugged pipeline or a mechanical problem with the transfer pump. The replacement pump failed within 2 weeks. In both cases, the problematic solid was most likely caused by sodium phosphate. Tests on actual supernatant from tank U-103 indicated that sodium phosphate solids could be observed even after a supernatant sample was diluted by $50 \%$ with water (Herting, 1999). Tests with other Hanford supernatants containing sodium phosphate have shown a dramatic increase in viscosity as the waste is cooled from 30 to $25^{\circ} \mathrm{C}$. According to the Best Basis Inventory (BBI), the phosphate concentration in tank S-102 is much higher than its counterpart in tank U-103. Therefore, the tank S-102 waste should be more likely to form a plug. At the SRS, the waste from tank 32 could not be moved to the $3 \mathrm{H}$ evaporator because of a plug in the tank 32 transfer system. An analysis of the tank 32 supernatant indicated that the plug was probably due to sodium nitrate, which is water soluble. Attempts to use high pressure air failed to remove the plug. Eventually, the discharge line to the pump 
was disconnected, and cold water was used to dissolve the plug. When the pump is not in use, the temperature of the waste in the discharge line is slightly cooler than the temperature of the waste in the tank, because the tank contents are heated via radiolysis. In water, the solubility of sodium nitrate is directly related to temperature and nearly doubles as the temperature increases from 25 to $100^{\circ} \mathrm{C}$. Therefore, in the future, the discharge line will be more thoroughly flushed to prevent plugging. These plugged lines and pumps encountered at Hanford and the SRS have led to schedule delays, higher remediation costs, and increases in personnel exposures.

\subsection{SOLID FORMATIONS DUE TO EVAPORATION}

While most cases of unwanted solid formations have been attributed to temperature drops, such problems can also occur when the waste is concentrated during evaporation. At the SRS, a dilute recycle stream from its vitrifier continues to be sent to the tank farm and subsequent evaporation. Because of limited tank space, this silicon-rich waste was combined with an aluminum-rich waste stream from canyon operations. This combined waste was processed through the $2 \mathrm{H}$ evaporator, which reduced the volume of the aluminum-rich waste by $25-30 \%$ and the volume of the recycle stream by $90 \%$. Unfortunately, this evaporation produced sodium aluminosilicate solids, which deposited at various locations in the evaporator system. In 1997, the gravity drain line from the evaporator became plugged. This plug was subsequently removed with high-pressure water. In 1999, the evaporator operations were suspended due to poor performance. The lift line in the evaporator was plugged, and a large quantity of aluminosilicate deposits was observed in the pot of the evaporator. Sodium diuranate was also found in the deposits, and the evaporator was shut down because the amount of ${ }^{235} \mathrm{U}$ in the deposits was a criticality concern. In 2001, the tank farm operators used 1.5 $\mathrm{M}$ nitric acid to remove the deposits in the pot while high-pressure water was used to clear the lift line. This nitric acid solution was neutralized with sodium hydroxide before it was returned to a storage tank. The shutdown of the $2 \mathrm{H}$ evaporator produced a severe shortage of tank space, which could have stopped other major operations, such as vitrification.

\section{SILICON SOLUBILITY AS A FUNCTION OF HYDROXIDE AND NITRATE}

\subsection{BACKGROUND}

The waste remediation effort at Hanford utilizes the Environmental Simulation Model (ESP) to predict the effects of water additions on saltcake dissolution and waste transfers. Therefore, the Tanks Focus Area and the Office of River Protection have funded a number of efforts to validate and/or improve the ESP predictions. Previous studies have demonstrated the need for special databases for individual components. For example, the TRONA and $\mathrm{Na} 2$ snacl databases should be used for relatively high concentrations of carbonate and sulfate, respectively. In other cases, the ESP could not adequately predict the solubility of important double salts such as sodium-fluoride-phosphate and sodium-fluoride-sulfate. 
Therefore, to enhance the ESP database, solubility tests on these salts have been performed at Mississippi State University (MSU).

During the most recent evaluation of the ESP and its database, staff members at MSU and Oak Ridge National Laboratory (ORNL) noted the lack of silicon solubility data for high $\mathrm{pH}$ values and high sodium nitrate concentrations. The single-shell tanks at Hanford contain over 700 metric tons of silicon, and the amount of silicon in the Hanford tank farm will increase significantly if the waste from vitrification is sent to the tank farm. In addition, researchers at the SRS identified a similar research need. The SRS has already encountered processing problems when the silicon-rich recycle stream from its vitrifier, the Defense Waste Processing Facility (DWPF), was mixed with its aluminum-rich tank supernatants. When this combined waste stream was evaporated due to limited tank space, aluminosilicate and sodium diuranate deposits formed in the evaporator system, which led to the shutdown of the evaporator. The tank farm operators at the SRS are currently segregating the silicon-rich waste from the aluminum-rich supernatant in an effort to prevent further deposits in the evaporator. According to the BBI, silicon segregation has already occurred in two Hanford tanks. Hanford tank SX-113 contains $6.4 \mathrm{~mol}$ of silicon and $0.7 \mathrm{~mol}$ of aluminum per liter of sludge, while the sludge in tank TY-106 consists of $6.1 \mathrm{~mol}$ of silicon and $0.3 \mathrm{~mol}$ of aluminum per liter of waste. Even though the waste volumes in tanks SX-113 and TY-106 are only 31,000 and 21,000 gal, respectively, the feed tank to the SRS evaporator contains less silicon than in these Hanford tanks. Therefore, the aluminosilicate problem observed at the SRS could also occur at Hanford if these high-silicon wastes are mixed with a highaluminum waste and then evaporated. In fact, Hanford tanks BX-102 and BY-111 contain 96,000 and 460,000 gal of waste with silicon-to-aluminum molar ratios of 1 to 1 . An earlier study (Hunt et al., 2002) has demonstrated that comparable molar ratios of silicon to aluminum will lead to aluminosilicate deposits when the waste is heated above $50^{\circ} \mathrm{C}$.

Because Hanford and the SRS will continue to encounter high-silicon waste streams, a series of silicon solubility tests was performed at ORNL. The initial $\mathrm{pH}$ of the samples ranged from 9 to 14.7 , and the sodium nitrate concentration was either 1 or $3 M$. Three temperatures, 25,50 , and $80^{\circ} \mathrm{C}$, were selected for these tests. The solubility results were used to determine suitable Pitzer's parameters for the test conditions. The results were provided to researchers at MSU and the SRS to make any necessary modifications to the databases of their thermodynamic models.

\subsection{EXPERIMENTAL PROCEDURE}

Each solubility sample consisted of deionized water, sodium nitrate (Aldrich Chemical Company), sodium hydroxide (VWR), and silicon dioxide in the form of fumed silica (Alfa Aesar). Fumed silica was selected as the source of silicon due to its very small particle size, which should permit faster equilibration. All samples were prepared and adjusted at $25^{\circ} \mathrm{C}$. It should be noted that the $\mathrm{pH}$ and density of an aqueous solution are inversely related to its temperature and that the temperature has a greater effect on $\mathrm{pH}$ than on density. The densities of water at 25,50 , and $80^{\circ} \mathrm{C}$ are $0.997,0.988$, and $0.972 \mathrm{~g} / \mathrm{mL}$, respectively. In contrast, an aqueous solution with a $\mathrm{pH}$ of 14 at $25^{\circ} \mathrm{C}$ will have $\mathrm{pH}$ values of 13.1 and 12.2 at 50 and $80^{\circ} \mathrm{C}$, respectively. The samples were prepared in a graduated polyethylene cylinder. After the required amount of sodium nitrate was weighed and 
transferred to the cylinder, nearly all of the required water was then added. After the sodium nitrate was dissolved, the $\mathrm{pH}$ of the sample was adjusted by using $0.1 \mathrm{M}, 1 \mathrm{M}$, or $50 \mathrm{wt} \%$ sodium hydroxide. The $\mathrm{pH}$ of the sample was monitored with a $\mathrm{pH}$ meter (Orion 920A). The solutions were then transferred and sealed in a high-density polyethylene bottle. The salt solutions for the 50 and $80^{\circ} \mathrm{C}$ experiments were then heated to the test temperature in an oven. After the heated salt solutions had reached equilibrium, fumed silica, which is acidic, was added. Finally, a small amount of deionized water, which had been also heated in the oven, was then added to a few of the samples to increase the volume to the desired level. If an excessive amount of water was required to make the final volume adjustment, another sample was prepared with a more suitable initial amount of water.

Researchers at MSU used the test conditions in Table 1 and the ESP to estimate the amount of fumed silica that would be required in most of the solubility tests. The ESP also provided estimates for the final $\mathrm{pH}$ and density, which are also shown in Table 1. The amount of silicon dioxide in the samples with an initial $\mathrm{pH}$ of 13 or less was equal to the amount used in the ESP model plus 20\%. The amount of fumed silica used in each sample was considerably more than the predicted silicon solubility. In each case, no additions of silicon dioxide were required, because small amounts of silicon solids could be observed. When significantly lower concentrations of fumed silica were used in the samples, solids could not be detected visually in the polyethylene bottles. With the highest-pH samples, another thermodynamic model, which uses SOLGASMIX, was also used to predict the required addition of fumed silica. The use of SOLGASMIX to model silicon species has been discussed in detail earlier (Hunt et al., 1999). For nearly all of the samples with $\mathrm{pH}$ values above 13, the initial addition of silicon dioxide was based on an ESP or SOLGASMIX prediction plus $20 \%$. If no silicon solids could be observed, then a small amount of silicon dioxide, on the order of $10-20 \%$ of the predicted amount, was added to the samples. This addition was repeated until solids were observed. With a few samples, the amount of fumed silica was reduced because of an excess amount of solids. The amount of fumed silica that was used in each sample is provided in Table 2, along with other test conditions.

After the final addition of fumed silica, the samples were sealed and heated for 1 week to a temperature that was $10^{\circ} \mathrm{C}$ above the final test temperature. After the initial equilibration period, the temperature of the samples was reduced $10^{\circ} \mathrm{C}$ to the test temperature $\left(25,50\right.$, or $\left.80^{\circ} \mathrm{C}\right)$. The $\mathrm{pH}$ of the solution was used to monitor the progress toward equilibrium. The final equilibration period was approximately 6 weeks. The $\mathrm{pH}$ of each equilibrated sample was determined at the time of equilibration. Because the final $\mathrm{pH}$ is a function of the concentration of soluble and insoluble silicon, an effort was made to limit the amount of insoluble silicon. In addition, the effects of temperature on the $\mathrm{pH}$ electrode were determined for 50 and $80^{\circ} \mathrm{C}$ so that the actual $\mathrm{pH}$ of the solution could be determined from the electrode.

Most samples were then filtered using two syringe filters, which were $0.8 / 0.2-\mu \mathrm{m}$ Supor ${ }^{\circledR}$ membrane (Gelman Laboratory) and 0.02- $\mu$ m Anotop 25 inorganic membrane (Whatman). The samples with an initial $\mathrm{pH}$ of 14 and higher could be filtered only with the $0.8 / 0.2-\mu \mathrm{m}$ Supor ${ }^{\circledR}$ membranes. The syringes and filters were preheated to the temperature of the samples in order to prevent precipitation. After the density of the filtered solution was determined, the sample was diluted at the temperature of the solubility tests. The soluble silicon concentration was measured through the use of inductively coupled plasma emission spectroscopy (ICP). The ICP for this silicon analysis was a Model 61E trace analyzer 
(Thermo Jarrell Ash), which is a simultaneous plasma emission spectrometer. The silicon concentrations were determined through direct analysis and standard silicon additions. The silicon concentrations from the two methods were comparable for nearly all of the samples. The reported silicon concentrations were based on the standard silicon additions.

Table 1. ESP predictions for the silicon solubility tests

\begin{tabular}{|c|c|c|c|c|c|c|c|}
\hline e & & & $1 \mathrm{MNaNO}_{3}$ & & & $3 \mathrm{MNaNO}_{3}$ & \\
\hline $\begin{array}{c}\text { Temperature } \\
\left({ }^{\circ} \mathrm{C}\right)\end{array}$ & $\begin{array}{c}\text { Initial } \\
\mathrm{pH}\end{array}$ & $\begin{array}{c}\text { Final } \\
\mathrm{pH}\end{array}$ & $\begin{array}{l}\text { Soluble } \mathrm{Si} \\
\qquad(M)\end{array}$ & $\begin{array}{l}\text { Density } \\
(\mathrm{g} / \mathrm{mL})\end{array}$ & $\begin{array}{c}\text { Final } \\
\mathrm{pH}\end{array}$ & $\begin{array}{l}\text { Soluble } \mathrm{Si} \\
\qquad(M)\end{array}$ & $\begin{array}{l}\text { Density } \\
(\mathrm{g} / \mathrm{mL})\end{array}$ \\
\hline 25 & 8 & 5.5 & 0.00178 & 1.050 & 5.3 & 0.00154 & 1.144 \\
\hline 25 & 8.7 & 5.7 & 0.00178 & 1.050 & 5.4 & 0.00154 & 1.144 \\
\hline 25 & 9 & 5.8 & 0.00178 & 1.050 & 5.6 & 0.00154 & 1.144 \\
\hline 25 & 10.7 & 7.5 & 0.00223 & 1.050 & 7.2 & 0.00203 & 1.144 \\
\hline 25 & 11 & 7.8 & 0.00277 & 1.050 & 7.5 & 0.00253 & 1.144 \\
\hline 25 & 11.7 & 8.5 & 0.00676 & 1.051 & 8.2 & 0.00653 & 1.144 \\
\hline 25 & 12 & 8.8 & 0.0118 & 1.051 & 8.5 & 0.0115 & 1.145 \\
\hline 25 & 13 & 9.8 & 0.102 & 1.059 & 9.5 & 0.102 & 1.152 \\
\hline 25 & 13.7 & 10.5 & 0.501 & 1.092 & 10.2 & 0.501 & 1.183 \\
\hline 25 & 14 & 10.8 & 1.00 & 1.133 & 10.5 & 1.00 & 1.221 \\
\hline 50 & 8 & 5.4 & 0.00276 & 1.038 & 5.2 & 0.00239 & 1.126 \\
\hline 50 & 8.7 & 5.5 & 0.00276 & 1.038 & 5.3 & 0.00239 & 1.126 \\
\hline 50 & 9 & 5.7 & 0.00276 & 1.038 & 5.4 & 0.00240 & 1.126 \\
\hline 50 & 10.7 & 7.3 & 0.00325 & 1.038 & 7.0 & 0.00288 & 1.126 \\
\hline 50 & 11 & 7.6 & 0.00375 & 1.039 & 7.3 & 0.00338 & 1.126 \\
\hline 50 & 11.7 & 8.3 & 0.00774 & 1.039 & 8.0 & 0.00738 & 1.127 \\
\hline 50 & 12 & 8.6 & 0.0127 & 1.039 & 8.3 & 0.0124 & 1.127 \\
\hline 50 & 13 & 9.6 & 0.102 & 1.047 & 9.3 & 0.102 & 1.134 \\
\hline 50 & 13.7 & 10.3 & 0.501 & 1.079 & 10.0 & 0.502 & 1.164 \\
\hline 50 & 14 & 10.5 & 1.00 & 1.119 & 10.3 & 1.00 & 1.201 \\
\hline 80 & 8 & 5.3 & 0.00434 & 1.021 & 5.1 & 0.00376 & 1.105 \\
\hline 80 & 8.7 & 5.4 & 0.00434 & 1.021 & 5.2 & 0.00376 & 1.105 \\
\hline 80 & 9 & 5.5 & 0.00434 & 1.021 & 5.3 & 0.00376 & 1.105 \\
\hline 80 & 10.7 & 7.0 & 0.00483 & 1.021 & 6.7 & 0.00425 & 1.105 \\
\hline 80 & 11 & 7.3 & 0.00532 & 1.021 & 7.0 & 0.00474 & 1.105 \\
\hline 80 & 11.7 & 8.0 & 0.00929 & 1.021 & 7.7 & 0.00873 & 1.106 \\
\hline 80 & 12 & 8.3 & 0.0143 & 1.022 & 8.0 & 0.0137 & 1.106 \\
\hline 80 & 13 & 9.3 & 0.104 & 1.029 & 9.0 & 0.103 & 1.113 \\
\hline 80 & 13.7 & 10.0 & 0.501 & 1.060 & 9.7 & 0.502 & 1.142 \\
\hline 80 & 14 & 10.2 & 0.999 & 1.098 & 10.0 & 1.00 & 1.177 \\
\hline
\end{tabular}


Table 2. Test conditions for the silicon solubility study

\begin{tabular}{|c|c|c|c|c|c|}
\hline Sample number & Temperature $\left({ }^{\circ} \mathrm{C}\right)$ & $\mathrm{NaNO}_{3}(M)$ & Initial $\mathrm{pH}$ at $25^{\circ} \mathrm{C}$ & Volume (mL) & Fumed silica $(\mathrm{g})$ \\
\hline Si1-1-25 & 25 & 1 & 9.0 & 250 & 0.0614 \\
\hline Si1-3-25 & 25 & 3 & 9.0 & 250 & 0.0481 \\
\hline $\mathrm{Si} 2-1-25$ & 25 & 1 & 9.7 & 250 & 0.0621 \\
\hline $\mathrm{Si} 2-3-25$ & 25 & 3 & 9.7 & 250 & 0.0488 \\
\hline Si3-1-25 & 25 & 1 & 10.0 & 100 & 0.0252 \\
\hline $\mathrm{Si} 3-3-25$ & 25 & 3 & 10.0 & 100 & 0.0198 \\
\hline $\mathrm{Si} 4-1-25$ & 25 & 1 & 10.7 & 50 & 0.0140 \\
\hline $\mathrm{Si} 4-3-25$ & 25 & 3 & 10.7 & 50 & 0.0112 \\
\hline Si5-1-25 & 25 & 1 & 11.0 & 50 & 0.0157 \\
\hline Si5-3-25 & 25 & 3 & 11.0 & 50 & 0.0128 \\
\hline Si6-1-25 & 25 & 1 & 11.7 & 30 & 0.0178 \\
\hline Si6-3-25 & 25 & 3 & 11.7 & 30 & 0.0155 \\
\hline Si7-1-25 & 25 & 1 & 12.0 & 30 & 0.0282 \\
\hline Si7-3-25 & 25 & 3 & 12.0 & 30 & 0.0254 \\
\hline Si8-1-25 & 25 & 1 & 13.0 & 30 & 0.362 \\
\hline Si8-3-25 & 25 & 3 & 13.0 & 30 & 0.280 \\
\hline Si9-1-25 & 25 & 1 & 13.7 & 30 & 1.61 \\
\hline Si9-3-25 & 25 & 3 & 13.7 & 30 & 1.45 \\
\hline Si10-1-25 & 25 & 1 & 14.0 & 30 & 5.28 \\
\hline Si10-3-25 & 25 & 3 & 14.0 & 30 & 4.65 \\
\hline Sil-1-50 & 50 & 1 & 9.0 & 250 & 0.0789 \\
\hline Si $1-3-50$ & 50 & 3 & 9.0 & 250 & 0.0571 \\
\hline $\mathrm{Si} 2-1-50$ & 50 & 1 & 9.7 & 250 & 0.0790 \\
\hline $\mathrm{Si} 2-3-50$ & 50 & 3 & 9.7 & 250 & 0.0572 \\
\hline $\mathrm{Si} 3-1-50$ & 50 & 1 & 10.0 & 100 & 0.0316 \\
\hline $\mathrm{Si} 3-3-50$ & 50 & 3 & 10.0 & 100 & 0.0229 \\
\hline $\mathrm{Si} 4-1-50$ & 50 & 1 & 10.7 & 50 & 0.0174 \\
\hline $\mathrm{Si} 4-3-50$ & 50 & 3 & 10.7 & 50 & 0.0128 \\
\hline Si5-1-50 & 50 & 1 & 11.0 & 50 & 0.0191 \\
\hline Si5-3-50 & 50 & 3 & 11.0 & 50 & 0.0142 \\
\hline Si6-1-50 & 50 & 1 & 11.7 & 30 & 0.0322 \\
\hline Si6-3-50 & 50 & 3 & 11.7 & 30 & 0.0255 \\
\hline $\mathrm{Si} 7-1-50$ & 50 & 1 & 12.0 & 30 & 0.0486 \\
\hline $\mathrm{Si} 7-3-50$ & 50 & 3 & 12.0 & 30 & 0.0396 \\
\hline Si8-1-50 & 50 & 1 & 13.0 & 30 & 0.345 \\
\hline Si8-3-50 & 50 & 3 & 13.0 & 30 & 0.294 \\
\hline Si9-1-50 & 50 & 1 & 13.7 & 30 & 1.67 \\
\hline Si9-3-50 & 50 & 3 & 13.7 & 30 & 1.44 \\
\hline Si10-1-50 & 50 & 1 & 14.0 & 30 & 5.47 \\
\hline Si10-3-50 & 50 & 3 & 14.0 & 30 & 4.10 \\
\hline Sil-1-80 & 80 & 1 & 9.0 & 50 & 0.0146 \\
\hline Sil-3-80 & 80 & 3 & 9.0 & 50 & 0.0115 \\
\hline $\mathrm{Si} 2-1-80$ & 80 & 1 & 9.7 & 50 & 0.0148 \\
\hline Si2-3-80 & 80 & 3 & 9.7 & 50 & 0.0117 \\
\hline Si3-1-80 & 80 & 1 & 10.0 & 50 & 0.0151 \\
\hline Si3-3-80 & 80 & 3 & 10.0 & 50 & 0.0119 \\
\hline $\mathrm{Si} 4-1-80$ & 80 & 1 & 10.7 & 50 & 0.0163 \\
\hline $\mathrm{Si} 4-3-80$ & 80 & 3 & 10.7 & 50 & 0.0130 \\
\hline Si5-1-80 & 80 & 1 & 11.0 & 50 & 0.0180 \\
\hline Si5-3-80 & 80 & 3 & 11.0 & 50 & 0.0144 \\
\hline Si6-1-80 & 80 & 1 & 11.7 & 50 & 0.0313 \\
\hline Si6-3-80 & 80 & 3 & 11.7 & 50 & 0.0267 \\
\hline Si7-1-80 & 80 & 1 & 12.0 & 50 & 0.0483 \\
\hline Si7-3-80 & 80 & 3 & 12.0 & 50 & 0.0420 \\
\hline Si8-1-80 & 80 & 1 & 13.0 & 50 & 0.353 \\
\hline Si8-3-80 & 80 & 3 & 13.0 & 50 & 0.317 \\
\hline Si9-1-80 & 80 & 1 & 13.7 & 50 & 1.44 \\
\hline Si9-3-80 & 80 & 3 & 13.7 & 50 & 1.31 \\
\hline Si10-1-80 & 80 & 1 & 14.0 & 50 & 4.17 \\
\hline Si10-3-80 & 80 & 3 & 14.0 & 50 & 2.65 \\
\hline
\end{tabular}




\subsection{RESULTS AND DISCUSSION}

The results, which include filtered silicon solubility, final $\mathrm{pH}$, and filtered density, are presented in Table 3. The experimental results support the general trends of the ESP predictions on soluble silicon concentrations. The soluble silicon concentration is relatively stable at the lower $\mathrm{pHs}$ and increases dramatically as the $\mathrm{pH}$ increases. The ESP predicts that the initial increase in solubility should occur between a $\mathrm{pH}$ of 6 and 7 . In contrast, these experimental results clearly demonstrate that the transition to higher silicon solubility occurs between a $\mathrm{pH}$ of 8 and 9 . Therefore, in order to minimize the addition of silicon from its vitrifier to its tank farm, the SRS should filter the DWPF recycle stream before the $\mathrm{pH}$ of the recycle stream is increased to 8 . The ESP also overestimates the amount of hydroxide that will be consumed during the conversion of silicon dioxide to a variety of silicates. The predicted final $\mathrm{pH}$ was typically 0.4 to $1 \mathrm{pH}$ unit lower than the experimental result. Since an excess amount of fumed silica was used in the experiments, the observed difference should be considered a minimum. At the SRS, sodium hydroxide will be added to convert the DWPF waste stream to a high-caustic waste that can be safely stored in the carbon steel tanks. If the ESP predictions were used, the required amount of sodium hydroxide would be significantly overestimated. In addition, the amount of low-level waste that must be immobilized in saltstone and stored will be partially determined by the amount of sodium that is added to the DWPF recycle stream.

In general, the experimental solubility results were in good agreement with the ESP predictions. With both methods, the silicon solubility concentrations increased from $0.001 \mathrm{M}$ to $0.002 \mathrm{M}$ as the initial $\mathrm{pH}$ increased from 9 to 14 . The experimental results confirmed the ESP predictions that silicon solubility at an initial $\mathrm{pH}$ of 14 or lower will always be greater with $1 M$ sodium nitrate than with $3 M$ sodium nitrate. The SOLGASMIX model predicted that silicon solubility with $3 \mathrm{M}$ sodium nitrate would be greater than its $1 M$ sodium nitrate counterparts at higher pHs. However, a direct comparison of the model predictions and the experimental results cannot be made. The samples with an initial $\mathrm{pH}$ of 14 were filtered only through a $0.2-\mu \mathrm{m}$ filter. Therefore, these samples probably contained colloids, which would lead to an overestimate of the soluble silicon. Chemical analyses of the SRS supernatants (Wilmarth and Peterson, 2000) have indicated that silicon colloids were present in the $2 \mathrm{H}$ evaporator system. A few small differences between the ESP predictions and the experimental solubility results were observed. The ESP predictions at the lower $\mathrm{pH}$ range indicated that the silicon solubility increased by approximately $50 \%$ when the temperature was increased from 25 to $50^{\circ} \mathrm{C}$. For the samples with low $\mathrm{pH}$, the experimental solubility results at 25 and $50^{\circ} \mathrm{C}$ were comparable. The experimental results and the ESP predictions exhibited a significant increase in silicon solubility from 50 to $80^{\circ} \mathrm{C}$. 
Table 3. Silicon test results: soluble silicon concentration, $\mathrm{pH}$, and density

\begin{tabular}{|c|c|c|c|c|c|c|c|}
\hline $\begin{array}{c}\text { Sample } \\
\text { ID }\end{array}$ & $\begin{array}{l}\text { Soluble Si } \\
(M)\end{array}$ & $\begin{array}{c}\text { Final } \\
\mathrm{pH}\end{array}$ & $\begin{array}{l}\text { Density } \\
(\mathrm{g} / \mathrm{mL})\end{array}$ & $\begin{array}{c}\text { Sample } \\
\text { ID }\end{array}$ & $\begin{array}{c}\text { Soluble Si } \\
\qquad(M)\end{array}$ & $\begin{array}{c}\text { Final } \\
\mathrm{pH}\end{array}$ & $\begin{array}{l}\text { Density } \\
(\mathrm{g} / \mathrm{mL})\end{array}$ \\
\hline Sil-1-25 & 0.00223 & 6.17 & 1.052 & Sil-3-25 & 0.00140 & 5.97 & 1.157 \\
\hline $\mathrm{Si} 2-1-25$ & 0.00200 & 7.12 & 1.052 & Si2-3-25 & 0.00124 & 6.88 & 1.157 \\
\hline $\mathrm{Si} 3-1-25$ & 0.00192 & 7.25 & 1.052 & $\mathrm{Si} 3-3-25$ & 0.00123 & 7.05 & 1.157 \\
\hline Si4-1-25 & 0.00214 & 8.13 & 1.052 & Si4-3-25 & 0.00150 & 7.92 & 1.157 \\
\hline Si5-1-25 & 0.00206 & 8.40 & 1.052 & $\mathrm{Si} 5-3-25$ & 0.00136 & 8.16 & 1.157 \\
\hline Si6-1-25 & 0.00243 & 9.34 & 1.052 & Si6-3-25 & 0.00165 & 9.06 & 1.157 \\
\hline Si7-1-25 & 0.00469 & 9.70 & 1.052 & Si7-3-25 & 0.00286 & 9.46 & 1.157 \\
\hline Si8-1-25 & 0.0634 & 10.94 & 1.058 & Si8-3-25 & 0.0267 & 10.76 & 1.162 \\
\hline Si9-1-25 & 0.253 & 11.12 & 1.077 & $\mathrm{Si} 9-3-25$ & 0.190 & 11.10 & 1.179 \\
\hline Si10-1-25 & $1.42^{a}$ & 11.58 & 1.138 & Si10-3-25 & $1.08^{a}$ & 11.61 & 1.233 \\
\hline Sil-1-50 & 0.00200 & 6.98 & 1.039 & Sil-3-50 & 0.00134 & 6.89 & 1.145 \\
\hline Si2-1-50 & 0.00212 & 7.31 & 1.039 & $\mathrm{Si} 2-3-50$ & 0.00138 & 7.25 & 1.145 \\
\hline Si3-1-50 & 0.00207 & 7.56 & 1.039 & $\mathrm{Si} 3-3-50$ & 0.00137 & 7.40 & 1.145 \\
\hline Si4-1-50 & 0.00120 & 7.84 & 1.039 & $\mathrm{Si} 4-3-50$ & 0.00128 & 7.75 & 1.145 \\
\hline Si5-1-50 & 0.00198 & 7.96 & 1.040 & Si5-3-50 & 0.00092 & 7.90 & 1.146 \\
\hline Si6-1-50 & 0.00203 & 8.46 & 1.040 & Si6-3-50 & 0.00151 & 8.42 & 1.146 \\
\hline Si7-1-50 & 0.00463 & 9.31 & 1.045 & Si7-3-50 & 0.00328 & 9.24 & 1.146 \\
\hline Si8-1-50 & 0.0353 & 10.31 & 1.051 & Si8-3-50 & 0.0253 & 10.16 & 1.149 \\
\hline Si9-1-50 & 0.335 & 10.53 & 1.068 & $\mathrm{Si} 9-3-50$ & 0.114 & 10.47 & 1.164 \\
\hline Si10-1-50 & $1.60^{a}$ & 10.75 & 1.128 & Si10-3-50 & $1.25^{a}$ & 10.73 & 1.212 \\
\hline Sil-1-80 & 0.00339 & 6.97 & 1.022 & Sil-3-80 & 0.00211 & 6.88 & 1.128 \\
\hline Si2-1-80 & 0.00447 & 7.47 & 1.022 & Si2 $-3-80$ & 0.00182 & 7.34 & 1.128 \\
\hline Si3-1-80 & 0.00374 & 7.55 & 1.022 & Si3-3-80 & 0.00272 & 7.44 & 1.129 \\
\hline Si4-1-80 & 0.00341 & 7.78 & 1.022 & Si4-3-80 & 0.00263 & 7.64 & 1.129 \\
\hline Si5-1-80 & 0.00377 & 7.89 & 1.023 & Si5-3-80 & 0.00199 & 7.82 & 1.129 \\
\hline Si6-1-80 & 0.00389 & 8.58 & 1.023 & Si6-3-80 & 0.00295 & 8.43 & 1.129 \\
\hline Si7-1-80 & 0.00823 & 9.29 & 1.028 & Si7-3-80 & 0.00425 & 9.04 & 1.130 \\
\hline Si8-1-80 & 0.0109 & 9.84 & 1.034 & Si8-3-80 & 0.00709 & 9.77 & 1.132 \\
\hline Si9-1-80 & 0.0150 & 10.19 & 1.042 & Si9-3-80 & 0.0137 & 10.01 & 1.142 \\
\hline Si10-1-80 & $1.86^{a}$ & 10.98 & 1.127 & Si10-3-80 & $0.254^{a}$ & 10.68 & 1.173 \\
\hline
\end{tabular}

${ }^{a}$ May contain colloidal silicon species, because the samples were filtered only with a $0.2-\mu \mathrm{m}$ filter.

\section{SILICATE SOLUBILITY MODEL}

\subsection{BACKGROUND}

During the past few years, a general model using the SOLGASMIX code has been developed for silicate behavior. An initial modeling effort (Hunt et al., 1999) was able to describe most major phenomena such as increasing solubility with increasing $\mathrm{pH}$, polymerization in the $\mathrm{pH}$ region of 10.6 to 12.2 , and solubility in neutral solutions at $25^{\circ} \mathrm{C}$. This model was modified to include temperatures up to $100^{\circ} \mathrm{C}$ so that the model could be used to predict the formation of aluminosilicates (Weber, 2001a) and to evaluate other waste processing issues at the SRS (Weber, 2001b). This work represents additional refinement of the basic silicate model between 25 and $100^{\circ} \mathrm{C}$ and its adaptation to solutions with sodium 
nitrate as well as sodium hydroxide. This refined model can more accurately evaluate strategies for the safe storage and treatment of silicon-rich waste streams from vitrification.

\subsection{SILICATE SPECIES}

Possible silicate species and the shapes of the different polymers are discussed in detail elsewhere (Hunt et al., 1999). In this study, the choice of species was altered slightly, and additional data were used to characterize behavior of individual species and the properties of the overall solution. The species in this study are listed in Table 4. The silicate species will be referred to using the shorthand notation shown in Eq. (1),

$$
(i, j)=\mathrm{Si}_{j} \mathrm{O}_{m}(\mathrm{OH})_{n}{ }^{i-},
$$

where $m$ and $n$ are determined by the geometrical shape of the polymer. The nuclear magnetic resonance (NMR) connectivity group associated with each species is noted in Table 4. NMR results and connectivity groups have been discussed earlier (Hunt et al., 1999; Weber, 2001a; Weber, 2001b).

For each of the species in Table 4, a useful model requires parameters that describe interactions in solution. These parameters can be obtained through the regression of the data on solution behavior and phase equilibria. The experimental results used in these regressions are shown in Table 5. Some of the results were used in previous studies, while others had not been used before. As in previous studies, the primary focus of the regression is for Gibbs energies of formation and Pitzer parameters, which were used to calculate activity

Table 4. Silicate species and Gibbs energies of formation

\begin{tabular}{lllcccc}
\hline \multicolumn{1}{c}{ Species } & \multicolumn{1}{c}{ Formula } & \multicolumn{1}{c}{ Name } & $\begin{array}{c}\text { NMR } \\
\text { group }\end{array}$ & $D^{\mathrm{a}}$ & $E \times 10^{-5}$ a & $F^{\mathrm{a}}$ \\
& & & & & \\
\hline$(0,1)$ & $\mathrm{Si}(\mathrm{OH})_{4}$ & Monomer & $\mathrm{Q}^{0}$ & -528.318 & 1.637327 & 43.5 \\
$(1,1)$ & $\mathrm{Si}(\mathrm{OH})_{3}{ }^{-}$ & Monomer & $\mathrm{Q}^{0}$ & -504.633 & 1.654941 & \\
$(2,1)$ & $\mathrm{SiO}_{2}(\mathrm{OH})_{2}{ }^{2-}$ & Monomer & $\mathrm{Q}^{0}$ & -469.704 & 1.681643 & \\
$(2,2)$ & $\mathrm{Si}_{2} \mathrm{O}_{3}(\mathrm{OH})_{4}{ }^{2-}$ & Dimer & $\mathrm{Q}^{1}$ & -451.519 & 1.509723 & \\
$(4,2)$ & $\mathrm{Si}_{2} \mathrm{O}_{5}(\mathrm{OH})_{2}{ }^{4-}$ & Dimer & $\mathrm{Q}^{1}$ & -420.494 & 1.497499 & \\
$(6,3)$ & $\mathrm{Si}_{3} \mathrm{O}_{6}(\mathrm{OH})_{3}{ }^{3-}$ & Cyclic trimer & $\mathrm{Q}_{\Delta}{ }^{2}$ & -372.594 & 1.318080 & \\
$(2,4)$ & $\mathrm{Si}_{4} \mathrm{O}_{6}(\mathrm{OH})_{6}{ }^{2-}$ & Cyclic tetramer & $\mathrm{Q}^{2}$ & -417.945 & 1.326586 & \\
$(4,4)$ & $\mathrm{Si}_{4} \mathrm{O}_{8}(\mathrm{OH})_{4}{ }^{4-}$ & Cyclic tetramer & $\mathrm{Q}^{2}$ & -406.861 & 1.424412 & \\
$(6,6)$ & $\mathrm{Si}_{6} \mathrm{O}_{15}{ }^{6-}$ & Prismatic hexamer & $\mathrm{Q}_{\Delta}{ }^{3}$ & -361.081 & 1.242837 & \\
$(4,8)$ & $\mathrm{Si}_{8} \mathrm{O}_{16}(\mathrm{OH})_{4}{ }^{4-}$ & Prismatic octamer & $\mathrm{Q}^{3}$ & -372.149 & 1.196639 & \\
$(8,8)$ & $\mathrm{Si}_{8} \mathrm{O}_{20}{ }^{8-}$ & Prismatic octamer & $\mathrm{Q}^{3}$ & -356.300 & 1.172717 & \\
$\mathrm{SiO}_{2}$ & $\mathrm{SiO}_{2}$ & Amorphous solid & & -343.128 & 1.114171 & \\
$(\mathrm{amorphous)}$ & & & & & & \\
& & & & -95.667 & 0.355206 & -3.82631 \\
$\mathrm{Water}^{+}$ & & & & 0.0 & 0.0 & 0.0 \\
$\mathrm{H}^{+}$ & & & -105.642 & 0.292040 & -1.16439 \\
$\mathrm{Na}^{+}$ & & & -44.707 & 0.203373 & 15.17588 \\
$\mathrm{NO}_{3}{ }^{-}$ & & & & -63.446 & 0.219727 & 15.17588 \\
$\mathrm{OH}^{-}$ & & & & & \\
\hline
\end{tabular}

${ }^{\mathrm{a}} \mu^{\mathrm{o}} / \mathrm{RT}$ coefficients. 
coefficients. The estimation of parameter values is simplified through the separation of the overall process into a series of smaller steps, which were performed as follows:

1. Using solubility data and NMR data at $25^{\circ} \mathrm{C}$, determine Gibbs energies and binary Pitzer parameters at $25^{\circ} \mathrm{C}$ for each of the silicate anions interacting with sodium cations.

Determine the Gibbs energy of formation for the amorphous silicate solid.

2. Using solubility data in the sodium hydroxide and sodium nitrate solutions at $25^{\circ} \mathrm{C}$, determine the interaction parameters for the nitrate anion and each of the aqueous silicate species.

3. Using solubility data and NMR data at elevated temperatures, determine temperature coefficients for the binary Pitzer parameters and the Gibbs energies.

4. Using solubility data in the sodium hydroxide and sodium nitrate solutions at 50 and $80^{\circ} \mathrm{C}$, calculate temperature coefficients for the interaction parameters determined in step 2.

For NMR data and solubility in either sodium hydroxide or sodium nitrate solutions, the data analysis and regressions are similar to those performed in previous work (Hunt et al., 1999; Weber, 2001a; Weber, 2001b). The measured densities were used to convert the equilibrium concentrations to molal units so that they could be used in the regressions and the model predictions. The average negative charge per silicon atom in solution $(Z)$ was calculated by dividing the initial hydroxide concentration by the soluble silicon concentration. It is assumed that all of the initial hydroxide was consumed by the ionization of silica. The optimal parameters in Tables 4, 6, and 7 can be described by the functional form in Eq. (2):

$$
x(T)=A+B \ln \left(T / T_{0}\right)+C\left(1 / T_{0}-1 / T\right),
$$

where $T_{0}=298 \mathrm{~K}$.

Table 5. Experimental results used to develop the silicate model

\begin{tabular}{|c|c|c|c|}
\hline Reference & Type of data & Temperature $\left({ }^{\circ} \mathrm{C}\right)$ & Comment \\
\hline Svensson et al., 1986 & NMR & 25 & $\begin{array}{l}\text { Very concentrated - up to } \\
20 M \text { silicon }\end{array}$ \\
\hline McCormick et al., 1987 & NMR & 25 & \\
\hline $\begin{array}{l}\text { Kinrade and Swaddle, } \\
1988\end{array}$ & NMR & $25-105$ & No pH data \\
\hline Marshall, 1980 & Solubility & $0-300$ & $\begin{array}{l}\text { Neutral sodium nitrate } \\
\text { solutions }\end{array}$ \\
\hline Alexander et al., 1954 & Solubility & 25 & Sodium hydroxide solutions \\
\hline This work & Solubility & 25,50 , and 80 & $\begin{array}{l}\text { Sodium hydroxide and } \\
\text { sodium nitrate solutions }\end{array}$ \\
\hline
\end{tabular}


Table 6. Pitzer parameters for the silicate species with sodium interactions

\begin{tabular}{|c|c|c|c|c|}
\hline \multirow[t]{2}{*}{ Species of $\mathrm{Na}^{+}$} & \multicolumn{2}{|c|}{$\beta^{(0)}$ coefficients } & \multirow[t]{2}{*}{$\beta^{(1)}$} & \multirow[t]{2}{*}{$\mathrm{C}$} \\
\hline & $D$ & $E$ & & \\
\hline$(0,1)$ & 0.0000 & & & \\
\hline$(1,1)$ & 0.7924 & 28,859 & -4.2020 & 0.0488 \\
\hline$(2,1)$ & -0.1145 & -807.3 & -9.1375 & -0.0102 \\
\hline$(2,2)$ & -0.0893 & 852.6 & -7.3034 & -0.0273 \\
\hline$(4,2)$ & -0.0204 & -477.7 & -12.0415 & -0.0185 \\
\hline$(6,3)$ & 0.0050 & -200.4 & -12.2557 & -0.0192 \\
\hline$(2,4)$ & 0.0268 & 1585 & -6.7390 & -0.0418 \\
\hline$(4,4)$ & -0.3131 & -1370.1 & -3.4868 & -0.0161 \\
\hline$(6,6)$ & -0.2922 & -807.2 & -0.2316 & -0.0159 \\
\hline$(4,8)$ & -0.4775 & 422.3 & -2.3039 & -0.0150 \\
\hline$(8,8)$ & -0.3233 & 2031 & -8.4712 & 0.0453 \\
\hline
\end{tabular}

Table 7. Pitzer parameters for the silicate species with nitrate interactions

\begin{tabular}{ccc}
\hline Species of $\mathrm{NO}_{3}{ }^{-}$ & \multicolumn{2}{c}{$\Theta$ coefficients } \\
\cline { 2 - 3 } & $D$ & $E$ \\
\hline$(0,1)$ & 0.05 & -24.75 \\
$(1,1)$ & 0.0 & $9.869 \times 10^{7}$ \\
$(2,1)$ & 0.4 & 584.8 \\
$(2,2)$ & 0.4 & 270.5 \\
$(4,2)$ & 0.4 & 254 \\
$(6,3)$ & 0.4 & 322.6 \\
$(2,4)$ & 1.2 & 4853 \\
$(4,4)$ & 0.6 & 1054 \\
$(6,6)$ & 1.6 & 632.4 \\
$(4,8)$ & 1.0 & 3290 \\
$(8,8)$ & 0.8 & 13.38 \\
\hline
\end{tabular}

\subsection{SILICATE MODEL PREDICTIONS}

The calculations of the current silicate model were in good agreement with the experimental NMR results for each connectivity group at $25^{\circ} \mathrm{C}$ (Svensson et al., 1986; McCormick et al., 1987; Kinrade and Swaddle, 1988). With a few exceptions, the new silicate model was also able to predict the $\mathrm{pH}$ values of the NMR samples (Svensson et al., 1986; McCormick et al., 1987). Figures $1-4$ show the solubility of amorphous silica at $25^{\circ} \mathrm{C}$ in hydroxide and nitrate solutions. The model calculation generally matches the data within the experimental error. At $25^{\circ} \mathrm{C}$, the predictions of the new silicate model are better than the calculations of the earlier versions of the silicate model (Hunt et al., 1999; Weber, 2001a; Weber, 2001b). 


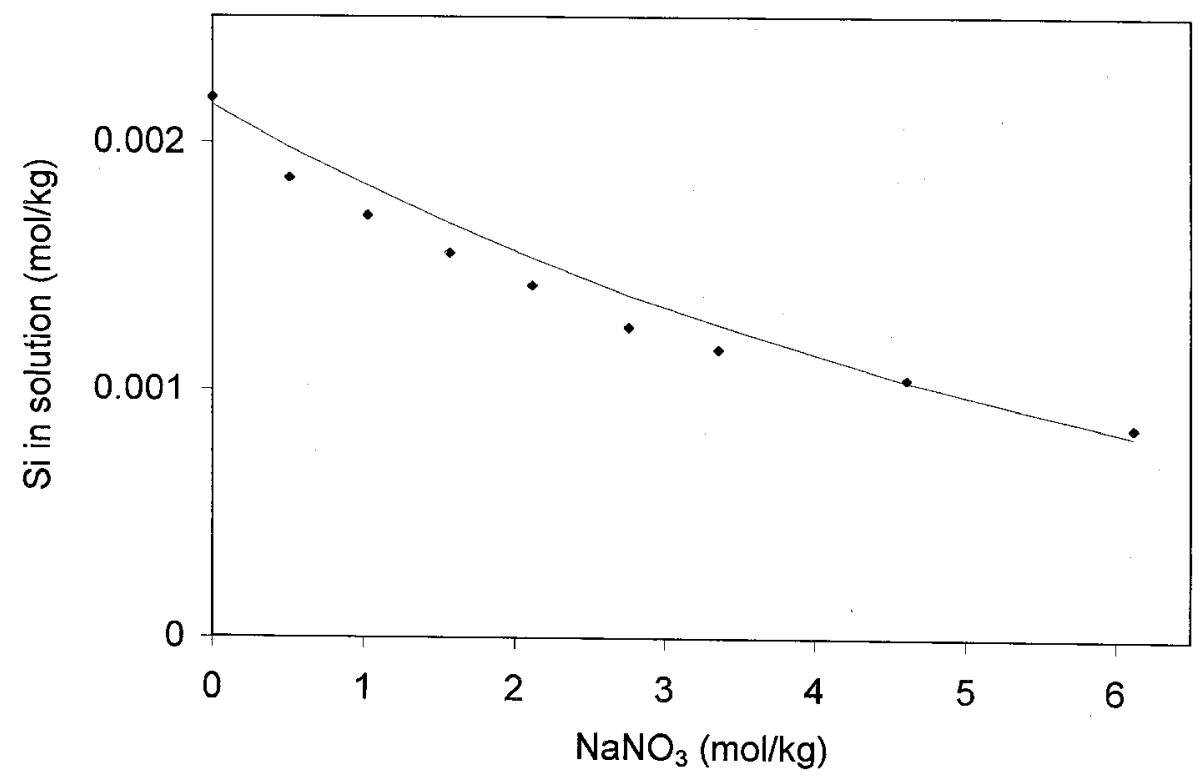

Fig. 1. Silicate solubility in $\mathrm{NaNO}_{3}$ solutions at $\mathbf{2 5}^{\circ} \mathrm{C}$. (Based on Marshall, 1980.)

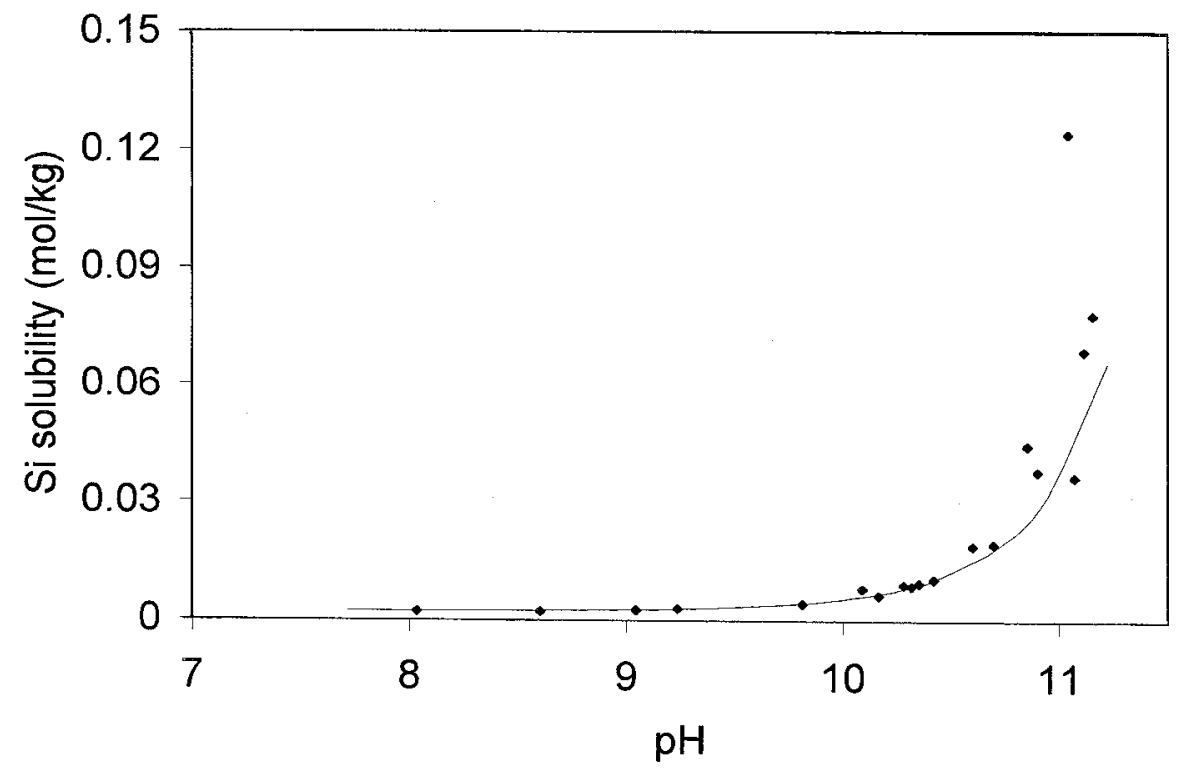

Fig. 2. Silicate solubility in $\mathrm{NaOH}$ solutions at $\mathbf{2 5}^{\circ} \mathrm{C}$. (Based on Alexander et al., 1954.) 


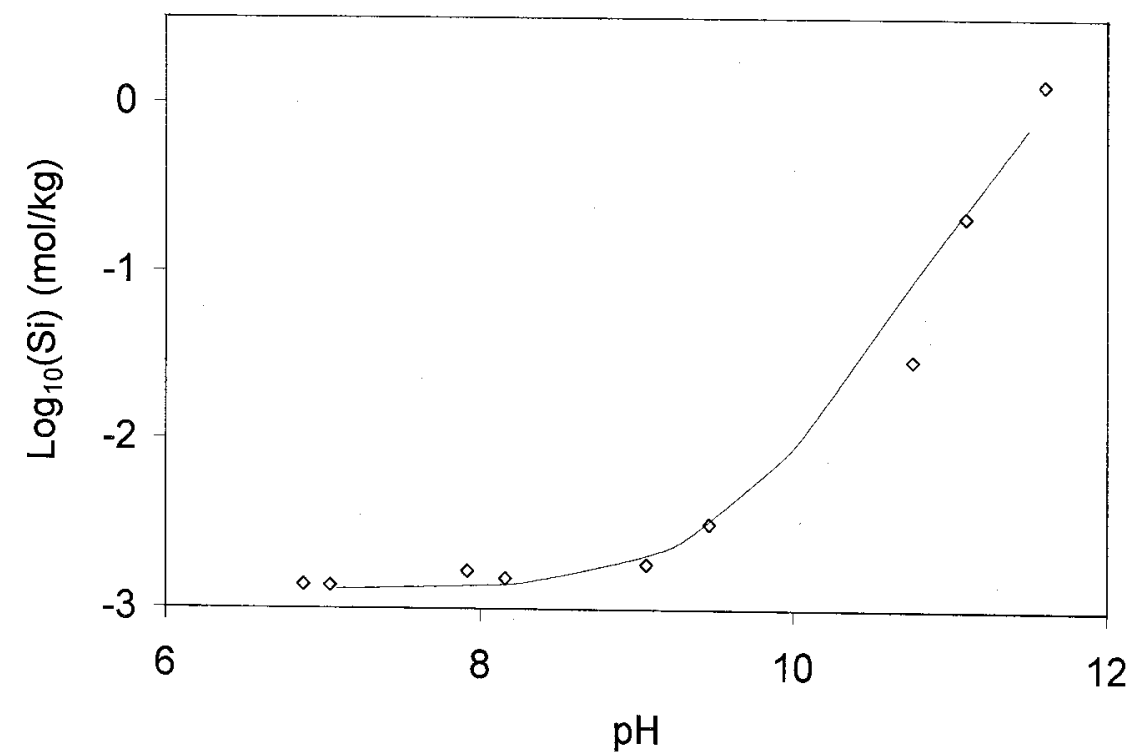

Fig. 3. Silicate solubility in $\mathrm{NaOH}$ and $1 M \mathrm{NaNO}_{3}$ solutions at $25^{\circ} \mathrm{C}$.

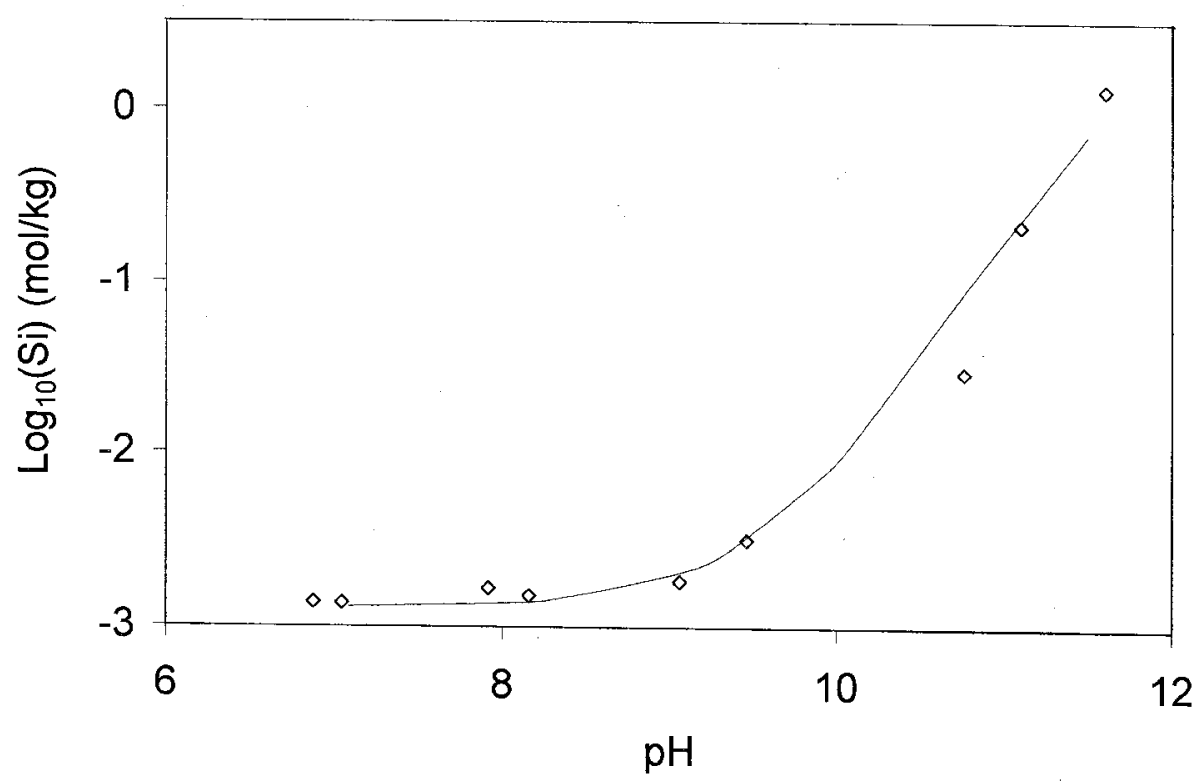

Fig. 4. Silicate solubility in $\mathrm{NaOH}$ and $3 M \mathrm{NaNO}_{3}$ solutions at $25^{\circ} \mathrm{C}$. 
The silicate model was then tested at elevated temperatures to determine its applicability to the SRS evaporator system. NMR samples with a maximum silicate concentration of 2.5 $M$ (Kinrade and Swaddle, 1988) were tested between the temperatures of 30 and $105^{\circ} \mathrm{C}$. The new model predictions were in good agreement with nearly all of the experimental NMR results. As shown in Fig. 5, the model predictions were very close to solubility results at $100^{\circ} \mathrm{C}$ in sodium nitrate solutions (Marshall, 1980). However, the predicted solubility is noticeably higher than the solubility results in sodium hydroxide and sodium nitrate solutions, as displayed in Figs. 6-9. Most of the error is likely due to the value of the average negative charge per silicon atom in solution $(Z)$.

The amount of hydroxide consumed is known from $\mathrm{pH}$ measurements before and after equilibration with silica. If this amount of charge is assigned to the measured silicate in solution, then the value of $Z$ can be determined. A $Z$ value of 2 is an absolute maximum, because no individual species have been observed with a charge greater than 2 . However, all of the $\mathrm{Z}$ values of the experimental results in Figs. 6-9 appear to be large and several exceed 2 by a significant amount. Therefore, it appears that the measured silica concentrations are too low. However, the error is not exceedingly great, and it is probably on the order of $30-40 \%$ of the measured solubility values. Thus, the calculations do reflect the general trend of the experimental results, which is increasing solubility with increasing $\mathrm{pH}$ and decreasing concentration of neutral salts.

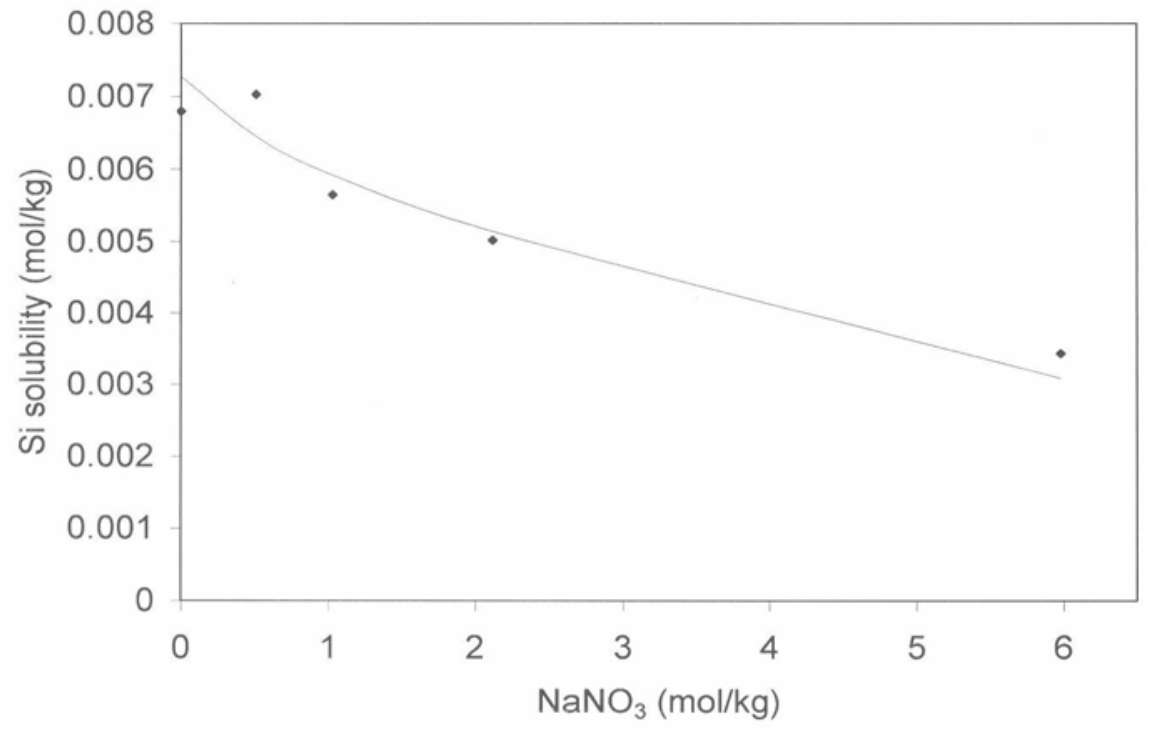

Fig. 5. Silicate solubility in $\mathrm{NaNO}_{3}$ solutions at $100^{\circ} \mathrm{C}$. 


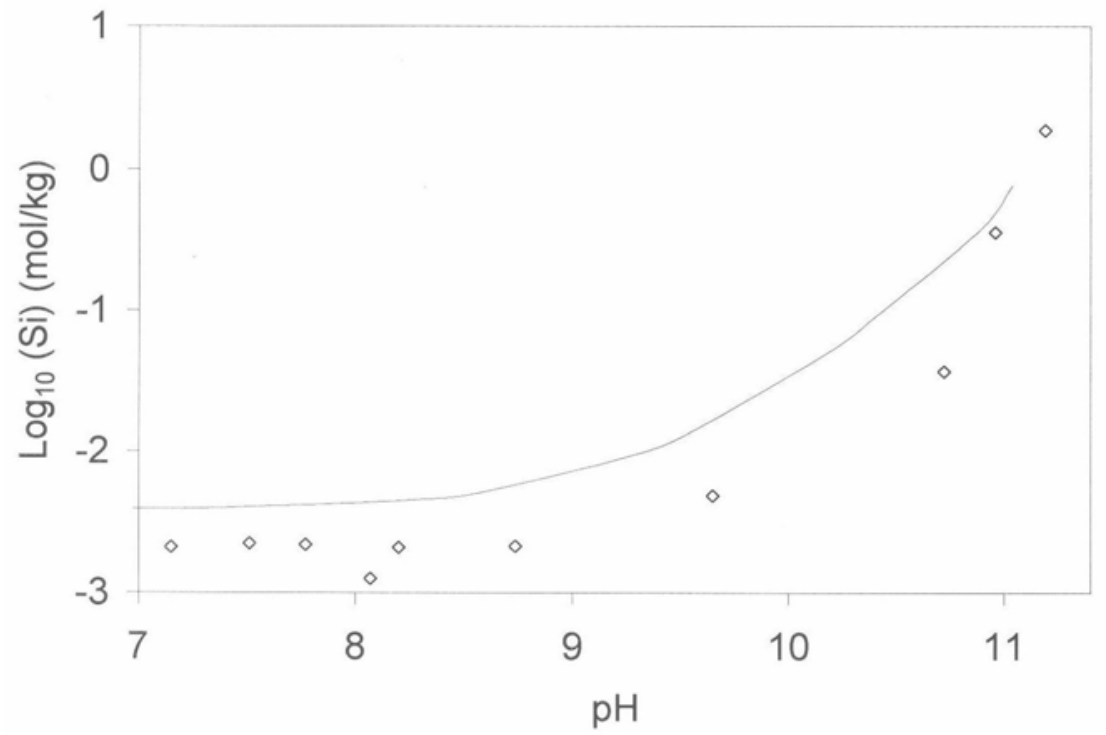

Fig. 6. Silicate solubility in $\mathrm{NaOH}$ and $1 M \mathrm{NaNO}_{3}$ solutions at $50^{\circ} \mathrm{C}$.

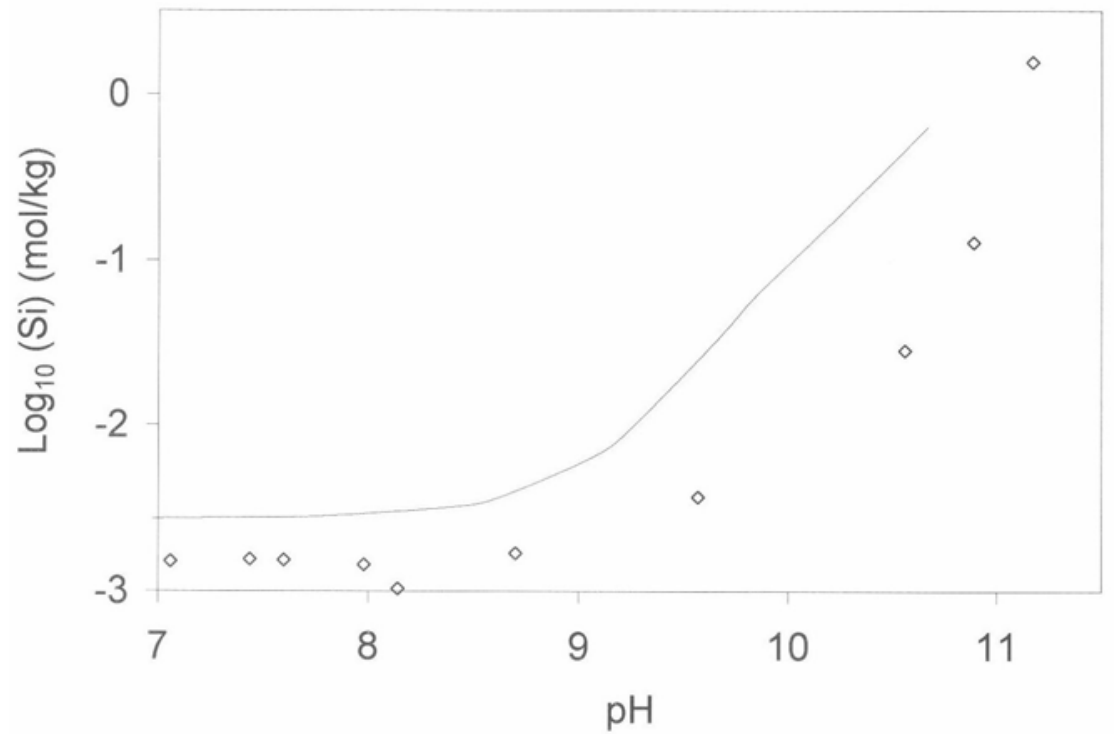

Fig. 7. Silicate solubility in $\mathrm{NaOH}$ and $3 M \mathrm{NaNO}_{3}$ solutions at $50^{\circ} \mathrm{C}$. 


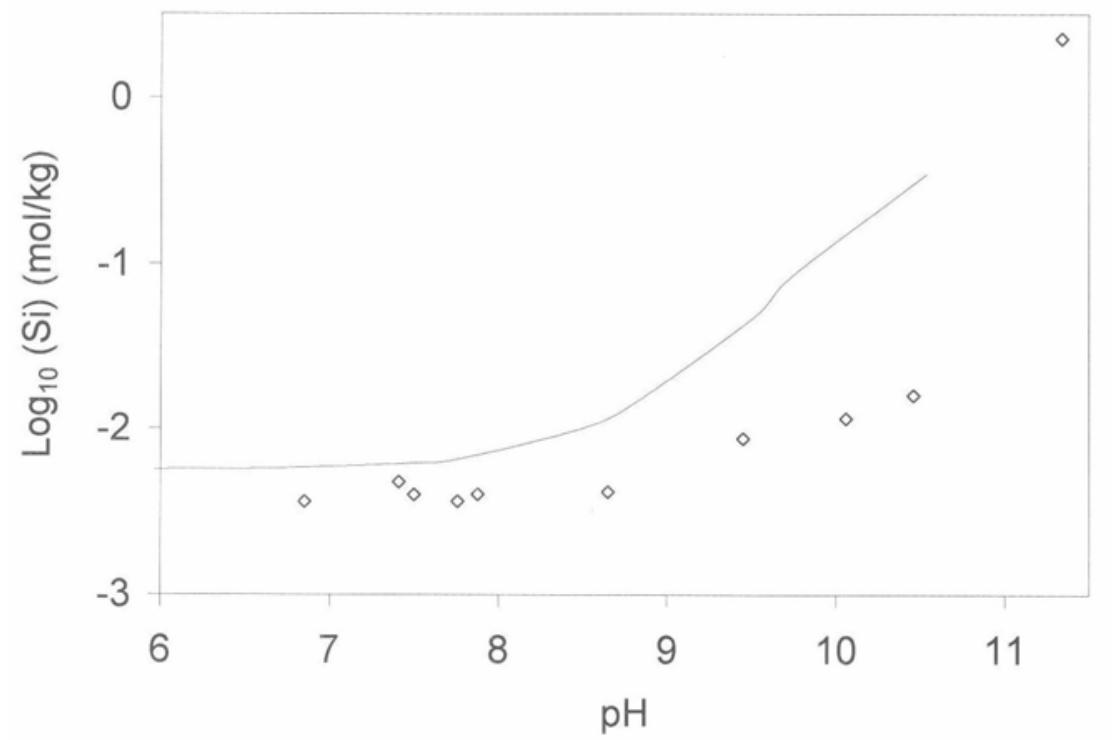

Fig. 8. Silicate solubility in $\mathrm{NaOH}$ and $1 M \mathrm{NaNO}_{3}$ solutions at $80^{\circ} \mathrm{C}$.

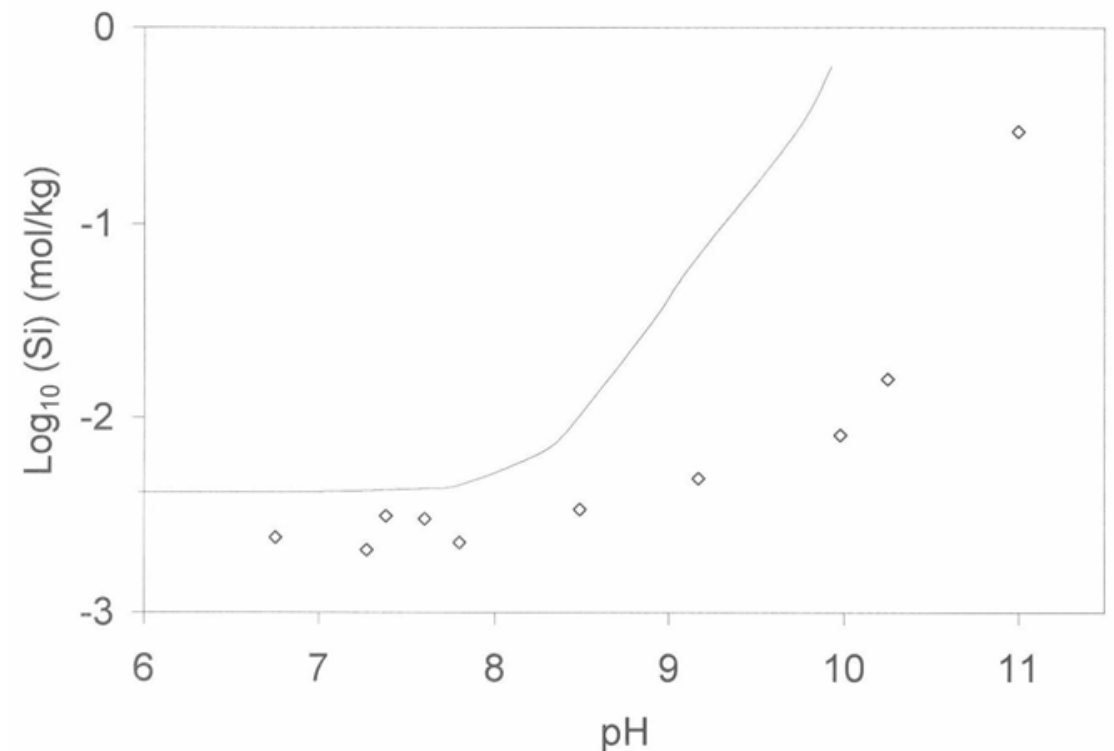

Fig. 9. Silicate solubility in $\mathrm{NaOH}$ and $3 M \mathrm{NaNO}_{3}$ solutions at $80^{\circ} \mathrm{C}$. 


\section{SIMULATIONS OF SLURRY TRANSFERS AT HANFORD}

\subsection{BACKGROUND}

At Hanford, the tank farms in the 200 East and 200 West Areas are connected by cross-site transfer lines, which are approximately 6 miles long. During the past 4 decades of waste transfers, four lines have become permanently plugged while a fifth line has been abandoned. The sixth transfer line is still in use, and a seventh transfer line was recently built at a cost of several millions of dollars. In an effort to prevent further pipeline plugs, the Waste Feed Delivery Project commissioned a literature review on events, phenomena, and studies pertinent to the technical risks of its project in FY 1998. The literature (Colton et al., 1998) indicated that an extensive amount of information was already available on the behavior and transport of Hanford tank waste. However, information on problematic solids and chemical compositions is very limited. In the literature review, 19 tank waste samples that formed gels were identified from process aids and laboratory notebooks. However, the problematic solid was identified in only 10 of the 19 samples. Sodium phosphate needle crystals formed in five samples under a variety of conditions, which include waste cooling, waste evaporation, and the addition of phosphoric acid. In two samples, the precipitation of aluminum hydroxide produced a hard brittle solid rather than a gel. The formation of silica gel was observed during the acidification of two samples. Finally, the precipitation of sodium carbonate occurred after the addition of sodium hydroxide to a waste simulant. Of the four problematic solids, only sodium phosphate, aluminum hydroxide, and sodium carbonate could have been responsible for the plugged transfer lines, because acidic wastes have not been transferred cross-site.

\subsubsection{Sodium Phosphate}

With respect to the sodium phosphate solids, the literature review (Colton et al., 1998) indicated that phosphate and fluoride concentrations are important because of the possibility of saturation of the sodium-fluoride-phosphate double salts. Subsequent research (Hunt et al., 2000b; Hunt et al., 2002) has demonstrated that the formation of the sodiumfluoride-phosphate double salt actually reduces the potential for pipeline plugs. The chemical compositions and temperatures that can produce high-viscosity solids due to sodium phosphate have been determined. Problematic concentrations of phosphate and fluoride are shown in Table 8.

Table 8. Potentially problematic concentrations of phosphate and fluoride

\begin{tabular}{ccc}
\hline $\begin{array}{c}\text { Phosphate } \\
\text { concentration }(M)\end{array}$ & $\begin{array}{c}\text { Safe fluoride } \\
\text { concentration }(M)\end{array}$ & $\begin{array}{c}\text { Potentially unsafe } \\
\text { fluoride concentration }(M)\end{array}$ \\
\hline 0.5 & $>0.2$ & $<0.2$ \\
0.4 & $>0.13$ & $<0.1$ \\
0.3 & $>0.1$ & $<0.05$ \\
0.2 & $>0.1$ & $<0.05$ \\
\hline
\end{tabular}


The potential for a sodium phosphate plug during the proposed retrieval operations was evaluated. The water or caustic added by the retrieval operation was assumed to be equal to three times the volume of saltcake and sludge. In addition, it was assumed that the supernatant would not be diluted prior to the waste transfer. The BBI was used to determine the phosphate and fluoride concentrations in 177 storage tanks at Hanford. In previous tests, the lowest phosphate concentration that led to high-viscosity solids was $0.06 \mathrm{M}$ (Hunt et al., 2000a). Prior to any dilution due to retrieval activities, 86 tanks had a phosphate concentration of $0.06 \mathrm{M}$ or greater. In 46 of these 86 tanks, the molar ratio of phosphate to fluoride was less than 2 , which is a safe transfer condition regardless of temperature or dilution. In 16 of the remaining 40 tanks, the molar ratio of phosphate to fluoride was greater than 6 , which would normally be a concern. However, for 10 of the 16 tanks, the dilution during retrieval should reduce the phosphate concentration to less than $0.06 \mathrm{M}$. After the retrieval operations, the final phosphate concentrations will be greater or equal to $0.06 \mathrm{M}$ for the remaining six tanks: $0.15 M$ for tank AP-106; $0.13 M$ for tank TY-105; $0.07 M$ for tank U-107; and 0.06 $M$ for tanks AP-104, BX-109, and TY-103. In tanks AP-104 and TY-103, however, the fluoride concentrations should be sufficient to prevent a transfer problem. It should also be noted that part of the waste in tank U-107 must be transferred before all of the retrieval liquid can be added. Further information on these potentially problematic tanks is provided in Table 9. For the final 24 tanks, which have a minimum phosphate concentration of $0.06 \mathrm{M}$, the molar ratio of phosphate to fluoride is between 2 and 6. Dilution should reduce the phosphate concentration to $0.05 M$ or less in 20 tanks. After the dilution during retrieval, the final phosphate concentration will be greater than $0.06 \mathrm{M}$ for four tanks: $0.18 M$ for tank BY-101, 0.13 $M$ for tank TX-117, and $0.07 M$ for tanks S-108 and SY-102. After dilution, the fluoride concentrations in tanks SY-102, TX-117, and S-108 should be sufficient to prevent a transfer problem. Of these three tanks, tank SY-102 presents the greatest risk because the molar ratio of phosphate to fluoride is nearly 6 and because part of the waste must be transferred prior to the completion of the dilution. Because the waste in tank BY-101 is potentially problematic, this tank was added to the list in Table 9. For all of the waste listed in Table 9, no transfer problems should occur if the waste is transferred at $50^{\circ} \mathrm{C}$. However, sodium phosphate plugs may occur as the waste is cooled from 30 to $25^{\circ} \mathrm{C}$ in a static environment.

Table 9. Hanford tanks susceptible to phosphate plugs without selective dissolution

\begin{tabular}{lcccccc}
\hline Tank & $\begin{array}{c}\text { Waste } \\
\text { volume } \\
(\mathrm{kgal})\end{array}$ & $\begin{array}{c}\text { Current values } \\
\begin{array}{c}\text { Phosphate } \\
\text { concentration }\end{array}\end{array}$ & $\begin{array}{c}\text { Fluoride } \\
\text { concentration }\end{array}$ & $\begin{array}{c}\text { Waste } \\
\text { volume } \\
(M)\end{array}$ & $\begin{array}{c}\text { After retrieval } \\
\text { Phosphate } \\
\text { concentration }\end{array}$ & $\begin{array}{c}\text { Fluoride } \\
\text { concentration }\end{array}$ \\
\hline AP-106 & 621 & 0.15 & 0.01 & 621 & 0.15 & $(M)$ \\
TY-105 & 231 & 0.50 & 0.00 & 924 & 0.13 & 0.01 \\
U-107 & 408 & 0.26 & 0.02 & 1533 & 0.07 & 0.00 \\
BX-109 & 193 & 0.23 & 0.00 & 772 & 0.06 & 0.00 \\
BY-101 & 387 & 0.72 & 0.25 & 1548 & 0.18 & 0.06 \\
\hline
\end{tabular}


A key assumption in the identification of potentially problematic waste tanks is that no selective dissolution occurs. However, selective dissolution will occur due to limited tank space or by design to assist in the separation of radionuclides. The volume of saltcake in 30 Hanford tanks ranges from 380 to $653 \mathrm{kgal}$. Therefore, it would be impossible to add all of the retrieval solution at one time. For example, tank TX-113 contains $653 \mathrm{kgal}$ of saltcake, which is $0.40 \mathrm{M}$ phosphate and $0.33 \mathrm{M}$ fluoride. The previous viscosity tests indicate that this molar ratio of phosphate to fluoride does not lead to high-viscosity solids. Dissolution tests have been performed on an actual saltcake sample from tank TX-113 at 25 and $50^{\circ} \mathrm{C}$ (Herting, 2000). At $25^{\circ} \mathrm{C}$, the maximum dissolution of phosphate and fluoride occurred after a water dilution of $300 \mathrm{wt} \%$, producing phosphate and fluoride concentrations of $0.06 \mathrm{M}$. Therefore, no problems should be encountered if the dissolution and waste transfer occur at $25^{\circ} \mathrm{C}$. Unfortunately, the dissolution profile for phosphate changes considerably as the temperature is increased from 25 to $50^{\circ} \mathrm{C}$. The maximum fluoride concentration of $0.10 \mathrm{M}$ occurred after the water dilution of $200 \mathrm{wt} \%$. In contrast, the maximum phosphate concentration of $0.23 \mathrm{M}$ was detected after the water dilution of $100 \mathrm{wt} \%$. The fluoride concentration after the water dilution of $100 \mathrm{wt} \%$ was only $0.02 \mathrm{M}$. As the temperature was increased from 25 to $50^{\circ} \mathrm{C}$, similar increases in phosphate solubility were observed with saltcake samples from tanks A-101 and S-102 (Herting et al., 1999). Since the free space in tank TX-113 is limited and the temperature inside the tank is $22^{\circ} \mathrm{C}$, the final composition of the initial dissolution solution should be comparable to the experimental results with 50 or $100 \mathrm{wt} \%$ dilution at $25^{\circ} \mathrm{C}$. However, if the solution temperature is increased to $50^{\circ} \mathrm{C}$ during the dissolution process, a sodium phosphate plug is likely to occur if the waste is permitted to cool in the transfer line. A potential phosphate problem will be encountered in many other tanks if selective dissolution is performed at an elevated temperature. The saltwell pumping activities utilize selective dissolution at the temperature of the saltcake, which has led to several plugged lines. Finally, most ESP predictions have significantly overestimated phosphate and fluoride solubilities during the initial saltcake dissolutions. This problem probably resulted from the lack of solubility data on the sodium phosphate-sodium fluoride double salt, which were only recently obtained by MSU researchers. In order to prevent sodium phosphate plugs, it is extremely important to accurately know and control the phosphate and fluoride concentrations.

\subsubsection{Aluminum Hydroxide}

With respect to the aluminum hydroxide precipitation, the maximum aluminate solubility in a saturated waste solution is approximately $1.3 \mathrm{M}$. However, the aluminate solubility can be much higher in solutions comprised of the three primary chemicals in the Hanford tank supernatants. For example, the ESP predicts that the aluminate solubility is greater than $5.3 \mathrm{M}$ in a solution of $4.1 \mathrm{M}$ sodium hydroxide, $2.5 \mathrm{M}$ sodium nitrate, and $1.2 \mathrm{M}$ sodium nitrite. Even though high concentrations of soluble aluminum are possible, due to previous transfer problems, Hanford tank farm operators typically will not transfer waste if the concentration of aluminum is greater than $1 M$ (McKay, 1993). Because some of the previous transfer problems have been attributed to aluminum, this component was included in the tests of slurry transfers. For example, based on the chemical composition of the waste in the feed tank, Hanford tank farm personnel believe that the current blockage in the 3-in. 
transfer line between the SY and U tank farms is due to aluminum. Treatment options for the aluminum blockage are discussed in a subsequent section.

\subsubsection{Sodium Carbonate}

With respect to the precipitation of sodium carbonate, the waste that was responsible for the last cross-site line plug contained very little phosphate and a considerable amount of carbonate (Hunt et al., 2000a). Subsequent tests have shown that sodium carbonate can improve the stability of the sodium phosphate plugs (Hunt et al., 2000b). However, samples with sodium carbonate concentrations as high as $0.6 \mathrm{M}$ failed to produce high-viscosity solids. Since one of the plugged transfer lines was attributed to carbonate, it was included in the tests of slurry transfers.

\subsection{TEST MATRIX}

The initial step was a detailed analysis of the chemical inventories for each of the 177 Hanford tanks based on the BBI. Even though the Hanford tanks contain $5.6 \times 10^{7}$ mol of phosphate, it was not considered since phosphate plugs had already been studied extensively (Hunt et al., 2002). Every chemical simulant of a Hanford tank waste contains water, sodium $\left(2.1 \times 10^{9} \mathrm{~mol}\right)$, hydroxide $\left(1.9 \times 10^{9} \mathrm{~mol}\right)$, and nitrate $\left(8.7 \times 10^{8} \mathrm{~mol}\right)$. Researchers at Hanford have estimated that the hydroxide value is overestimated by a factor of two or three. Hanford simulants will typically contain nitrite $\left(2.7 \times 10^{8} \mathrm{~mol}\right)$, but this investigation has shown that the primary contribution of nitrate and nitrite is usually to the ionic strength. Since sodium nitrite can lead to the formation of poisonous $\mathrm{NO}_{x}$ gases, the nitrate concentration was increased to account for the combined nitrate and nitrite concentrations. The other elements and compounds that were evaluated included aluminum, bismuth, calcium, carbonate, chromium, iron, lanthanum, manganese, nickel, silicon, strontium, and zirconium. The total quantity in kilograms and moles for each chemical is provided in Table 10. Several of the major chemicals were eliminated so that the number of initial samples could be kept to a reasonable number. Lanthanum, lead, and strontium were eliminated because their total quantities of moles were less than $5.0 \times 10^{5}$. Nickel was also eliminated because it had the fourth-lowest number of total moles and because the most likely source of nickel for the waste simulant is nickel nitrate, which is a known carcinogen. Manganese was not selected because its high concentration was only $0.04 M$. In contrast, the high concentration of the chosen chemicals was a minimum of $0.1 \mathrm{M}$. Finally, zirconium was not selected because only nine tanks have a zirconium concentration of $0.01 \mathrm{M}$ or greater. Therefore, the primary chemicals that were selected for the initial set of slurry samples were aluminum, bismuth, calcium, carbonate, chromium, iron, and silicon. The high and low concentrations of each component in the Hanford tanks (based on the BBI) are shown in Table 11. The slurry simulants were made from aluminum hydroxide, bismuth nitrate, calcium nitrate, sodium carbonate, chromium nitrate, iron(III) nitrate, iron(III) oxide, sodium metasilicate, sodium hydroxide, sodium nitrate, and deionized water. The concentrations of hydroxide and nitrate were fixed at 2 and $5 M$, respectively. The sodium concentration varied with the simulant compositions. 
Table 10. Quantities of major chemical components in the Hanford tanks

\begin{tabular}{|c|c|c|c|c|c|}
\hline Chemical & Total (kg) & Total (mol) & Chemical & Total $(\mathrm{kg})$ & Total (mol) \\
\hline Aluminum ${ }^{\mathrm{a}}$ & $7.8 \times 10^{6}$ & $2.9 \times 10^{8}$ & Lead & $7.9 \times 10^{4}$ & $3.8 \times 10^{5}$ \\
\hline Bismuth $^{\mathrm{a}}$ & $5.7 \times 10^{5}$ & $2.7 \times 10^{6}$ & Manganese & $1.6 \times 10^{5}$ & $3.0 \times 10^{6}$ \\
\hline Calcium $^{\mathrm{a}}$ & $2.4 \times 10^{5}$ & $6.1 \times 10^{6}$ & Nickel & $1.2 \times 10^{5}$ & $2.0 \times 10^{6}$ \\
\hline Carbonate $^{a}$ & $5.9 \times 10^{5}$ & $9.9 \times 10^{6}$ & Silicon $^{\mathrm{a}}$ & $8.1 \times 10^{5}$ & $2.9 \times 10^{7}$ \\
\hline Chromium $^{\mathrm{a}}$ & $6.1 \times 10^{5}$ & $1.2 \times 10^{7}$ & Strontium & $4.0 \times 10^{4}$ & $4.6 \times 10^{5}$ \\
\hline Iron $^{\mathrm{a}}$ & $1.2 \times 10^{6}$ & $2.2 \times 10^{7}$ & Zirconium & $4.1 \times 10^{5}$ & $4.5 \times 10^{6}$ \\
\hline Lanthanum & $3.9 \times 10^{4}$ & $2.8 \times 10^{5}$ & & & \\
\hline
\end{tabular}

${ }^{\mathrm{a}}$ Selected for the initial slurry tests.

Table 11. Range of concentrations for the main components in the Hanford tanks

\begin{tabular}{lcllllll}
\hline Concentration $(M)$ & $\mathrm{Al}$ & \multicolumn{1}{c}{$\mathrm{Bi}$} & $\mathrm{Ca}$ & $\mathrm{CO}_{3}$ & $\mathrm{Cr}$ & $\mathrm{Fe}$ & \multicolumn{1}{c}{$\mathrm{Si}$} \\
\hline High & 4 & 0.1 & 0.1 & 1.2 & 0.15 & 0.3 & 0.3 \\
Low & 1 & 0.001 & 0.01 & 0.3 & 0.01 & 0.01 & 0.001 \\
\hline
\end{tabular}

Two approaches were used in the development of the Hanford slurry test matrix. First, an experimental design with a two-level seven-factor partial factorial experimental design was used to select the concentrations for the first eight viscosity samples. With this test matrix, only two concentrations of each chemical variable were used. Initially, the high and low concentrations in Table 10 were used. However, the densities of some of the slurry simulants were too high. Therefore, the high concentrations of aluminum and carbonate were reduced to 3 and $1 M$, respectively. Even with the reduced aluminum and carbonate concentrations, the densities of the eight samples ranged from 1.31 to $1.49 \mathrm{~g} / \mathrm{mL}$. For comparison, the administrative control limit for waste transfers at Hanford is currently $1.41 \mathrm{~g} / \mathrm{mL}$, due to the potential for flammable gases. Because an effort is under way to increase this control limit on the densities, viscosity measurements were performed on these simulated slurry samples. In addition, the samples were diluted with deionized water when high-viscosity conditions were encountered. The compositions of these viscosity samples are shown in Table 12.

The second approach involved an evaluation of the tanks that contain primarily sludge. In the Hanford tanks, $1.2 \times 10^{7}$ gal of the total $5.4 \times 10^{7}$ gal of nuclear waste is classified as sludge. The slurries will be composed primarily of sludge, supernatant, and a retrieval liquid such as inhibited water. The Hanford tanks with the largest quantities of sludge are listed in Table 13. Tanks AW-103, S-101, and AY-102 were excluded from this evaluation, since the sludge in these tanks will be a minor component during the retrieval operations. The other 22 tanks contain $6.0 \times 10^{6}$ gal of sludge, which is approximately $50 \%$ of the total sludge volume. These 22 tanks contain a wide variety of the Hanford waste types (Colton, 1996). Tanks B-104, B-110, B-111, BX-107, BX-112, C-107, T-104, T-107, T-110, $\mathrm{T}-111$, and $\mathrm{U}-110$ contain waste from the first and second decontamination cycles of the bismuth phosphate process. Sludges from the uranium recovery process are found in tanks BX-109, C-110, TY-103, and TY-105, while those in tanks A-103 and TX-108 are from the evaporator bottoms. The sludges in tanks C-102 and C-104 are the results of the PUREX 
Table 12. Chemical compositions of the Hanford slurry simulants

(Concentrations in molarity)

\begin{tabular}{|c|c|c|c|c|c|c|c|c|c|c|}
\hline $\begin{array}{l}\text { Sample } \\
\text { number }\end{array}$ & $\mathrm{Al}(\mathrm{OH})_{3}$ & $\mathrm{Bi}\left(\mathrm{NO}_{3}\right)_{3}$ & $\mathrm{Ca}\left(\mathrm{NO}_{3}\right)_{3}$ & $\mathrm{Na}_{2} \mathrm{CO}_{3}$ & $\mathrm{Cr}\left(\mathrm{NO}_{3}\right)_{3}$ & $\mathrm{Fe}\left(\mathrm{NO}_{3}\right)_{3}$ & $\mathrm{Fe}_{2} \mathrm{O}_{3}$ & $\mathrm{Na}_{2} \mathrm{SiO}_{3}$ & $\mathrm{ZrO}\left(\mathrm{NO}_{3}\right)_{3}$ & $\mathrm{ZrO}_{2}$ \\
\hline H1 & 1.0 & 0.001 & 0.01 & 0.3 & 0.01 & 0.01 & 0.00 & 0.001 & 0.00 & 0.00 \\
\hline $\mathrm{H} 2$ & 1.0 & 0.001 & 0.10 & 0.3 & 0.15 & 0.30 & 0.00 & 0.300 & 0.00 & 0.00 \\
\hline H3 & 1.0 & 0.100 & 0.01 & 1.0 & 0.01 & 0.30 & 0.00 & 0.300 & 0.00 & 0.00 \\
\hline $\mathrm{H} 4$ & 1.0 & 0.100 & 0.10 & 1.0 & 0.15 & 0.01 & 0.00 & 0.001 & 0.00 & 0.00 \\
\hline H5 & 3.0 & 0.001 & 0.01 & 1.0 & 0.15 & 0.30 & 0.00 & 0.001 & 0.00 & 0.00 \\
\hline H6 & 3.0 & 0.001 & 0.10 & 1.0 & 0.01 & 0.01 & 0.00 & 0.300 & 0.00 & 0.00 \\
\hline H7 & 3.0 & 0.100 & 0.01 & 0.3 & 0.15 & 0.01 & 0.00 & 0.300 & 0.00 & 0.00 \\
\hline H8 & 3.0 & 0.100 & 0.10 & 0.3 & 0.01 & 0.30 & 0.00 & 0.001 & 0.00 & 0.00 \\
\hline A-103 & 1.20 & 0.00 & 0.04 & 1.44 & 0.03 & 0.02 & 0.00 & 0.40 & 0.00 & 0.00 \\
\hline AW-105 & 0.08 & 0.01 & 0.05 & 0.12 & 0.00 & 0.24 & 0.00 & 0.06 & 0.33 & 0.33 \\
\hline B-104 & 0.09 & 0.07 & 0.01 & 0.25 & 0.01 & 0.25 & 0.00 & 0.27 & 0.00 & 0.00 \\
\hline B-110 & 0.06 & 0.12 & 0.03 & 0.10 & 0.02 & 0.44 & 0.00 & 0.45 & 0.00 & 0.00 \\
\hline B-111 & 0.04 & 0.11 & 0.02 & 0.37 & 0.03 & 0.36 & 0.00 & 0.44 & 0.00 & 0.00 \\
\hline BX-107 & 0.77 & 0.17 & 0.04 & 0.03 & 0.03 & 0.29 & 0.00 & 0.35 & 0.00 & 0.00 \\
\hline $\mathrm{BX}-109^{a}$ & 0.06 & 0.00 & 0.05 & 0.02 & 0.00 & 0.29 & 0.00 & 0.02 & 0.00 & 0.00 \\
\hline BX-112 & 0.59 & 0.11 & 0.04 & 0.23 & 0.04 & 0.19 & 0.00 & 0.42 & 0.00 & 0.00 \\
\hline C-102 & 2.56 & 0.01 & 0.14 & 1.06 & 0.01 & 0.15 & 0.15 & 1.09 & 0.05 & 0.00 \\
\hline C $-104^{b}$ & 2.68 & 0.00 & 0.06 & 0.65 & 0.02 & 0.20 & 0.20 & 0.29 & 0.28 & 0.28 \\
\hline $\mathrm{C}-107^{b}$ & 1.34 & 0.07 & 0.02 & 0.15 & 0.02 & 0.28 & 0.28 & 0.32 & 0.02 & 0.00 \\
\hline C-110 & 0.72 & 0.11 & 0.04 & 0.23 & 0.01 & 0.26 & 0.00 & 0.33 & 0.00 & 0.00 \\
\hline S- $104^{c}$ & 3.73 & 0.00 & 0.01 & 0.12 & 0.04 & 0.02 & 0.00 & 0.04 & 0.00 & 0.00 \\
\hline S-107 & 3.10 & 0.00 & 0.02 & 0.29 & 0.10 & 0.06 & 0.00 & 0.14 & 0.26 & 0.00 \\
\hline $\mathrm{T}-104^{b}$ & 0.62 & 0.10 & 0.04 & 0.01 & 0.02 & 0.17 & 0.00 & 0.24 & 0.00 & 0.00 \\
\hline T-107 & 2.17 & 0.07 & 0.08 & 0.32 & 0.01 & 0.48 & 0.34 & 0.29 & 0.00 & 0.00 \\
\hline $\mathrm{T}-110$ & 0.06 & 0.08 & 0.03 & 0.13 & 0.02 & 0.22 & 0.00 & 0.21 & 0.00 & 0.00 \\
\hline $\mathrm{T}-111$ & 0.02 & 0.14 & 0.06 & 0.11 & 0.04 & 0.18 & 0.18 & 0.25 & 0.00 & 0.00 \\
\hline TX-109 & 0.77 & 0.12 & 0.03 & 0.13 & 0.02 & 0.26 & 0.00 & 0.33 & 0.00 & 0.00 \\
\hline $\mathrm{TY}-103^{c}$ & 0.16 & 0.13 & 0.11 & 0.11 & 0.02 & 0.42 & 0.00 & 0.20 & 0.00 & 0.00 \\
\hline $\mathrm{TY}-105^{b}$ & 0.09 & 0.00 & 0.10 & 0.23 & 0.00 & 0.46 & 0.00 & 0.02 & 0.00 & 0.00 \\
\hline U-110 & 4.71 & 0.08 & 0.02 & 0.16 & 0.01 & 0.14 & 0.14 & 0.23 & 0.00 & 0.00 \\
\hline
\end{tabular}

${ }^{a}$ After a $100 \%$ dilution of the formulation based on the BBI.

${ }^{b}$ After a $25 \%$ dilution of the formulation based on the BBI.

${ }^{c}$ After a $75 \%$ dilution of the formulation based on the BBI.

Table 13. Hanford tanks with the largest quantities of sludge

\begin{tabular}{lc||lc}
\hline \multicolumn{1}{c|}{ Tank } & Sludge volume $($ gal $)$ & \multicolumn{1}{c}{ Tank } & Sludge volume (gal) \\
\hline T-111 & $4.5 \times 10^{5}$ & AW-105 & $2.6 \times 10^{5}$ \\
TX-109 & $3.8 \times 10^{5}$ & B-110 & $2.5 \times 10^{5}$ \\
T-110 & $3.7 \times 10^{5}$ & B-111 & $2.4 \times 10^{5}$ \\
A-103 & $3.7 \times 10^{5}$ & TY-105 & $2.3 \times 10^{5}$ \\
BX-107 & $3.5 \times 10^{5}$ & S-101 & $2.1 \times 10^{5}$ \\
T-104 & $3.2 \times 10^{5}$ & BX-109 & $1.9 \times 10^{5}$ \\
C-102 & $3.2 \times 10^{5}$ & U-110 & $1.9 \times 10^{5}$ \\
B-104 & $3.1 \times 10^{5}$ & AY-102 & $1.8 \times 10^{5}$ \\
S-104 & $2.9 \times 10^{5}$ & C-110 & $1.8 \times 10^{5}$ \\
S-107 & $2.9 \times 10^{5}$ & T-107 & $1.7 \times 10^{5}$ \\
AW-103 & $2.7 \times 10^{5}$ & BX-112 & $1.6 \times 10^{5}$ \\
C-104 & $2.6 \times 10^{5}$ & TY-103 & $1.6 \times 10^{5}$ \\
C-107 & $2.6 \times 10^{5}$ & & \\
\hline
\end{tabular}


process, while those from the REDOX process are located in tanks S-104 and S-107. The variety of waste is confirmed by the Sort on Radioactive Waste Type (SORWT) model (Hill et al., 1995), as shown in Table 14.

The BBI was used to develop waste simulants for these 22 tanks prior to any dilution due to retrieval activities. With six of the tank simulants, a combination of iron (III) nitrate and iron(III) oxide was used to minimize the total nitrate concentration. It should be noted that iron(III) nitrate is soluble in water while iron(III) oxide is insoluble. The simulant formulations were designed so that a significant fraction of each key component would be soluble at some point during the simulant preparation. Five of the sludge simulants contained zirconium dinitrate oxide, while two simulants had a combination of zirconium dinitrate oxide and zirconium dioxide. The tank C-104 and tank S-104 simulants required additional water to lower their densities to reasonable levels. Additional water was added to the simulants for tanks BY-112, C-104, C-107, TY-103, and TY-105 in order to lower the initial viscosity measurement at $65^{\circ} \mathrm{C}$ to below $20 \mathrm{cP}$. The final compositions of the 22 sludge simulants are shown in Table 12. The densities of the simulated sludge samples ranged from 1.15 to $1.55 \mathrm{~g} / \mathrm{mL}$. Only the simulants for tanks A-103, C-102, C-104, S-104, and U-110 would require further dilution prior to the waste transfer in order to meet the administrative control limit for density of $1.41 \mathrm{~g} / \mathrm{mL}$.

Table 14. Types of waste in the selected Hanford tanks

\begin{tabular}{|c|c|c|c|}
\hline Tank & $\begin{array}{l}\text { SORWT } \\
\text { group }\end{array}$ & Primary waste & Secondary waste \\
\hline $\begin{array}{l}\text { A-103 } \\
\text { AW-105 }\end{array}$ & $\mathrm{XI}$ & Double-shell slurry feed & Noncomplexed waste \\
\hline B-104 & XXV & Second decontamination cycle $\left(\mathrm{BiPO}_{4}\right)$ & Evaporator bottoms \\
\hline B-110 & XVI & Second decontamination cycle $\left(\mathrm{BiPO}_{4}\right)$ & High-level B plant waste (section 5) \\
\hline B-111 & XVI & Second decontamination cycle $\left(\mathrm{BiPO}_{4}\right)$ & High-level B plant waste (section 5) \\
\hline BX-107 & XII & First decontamination cycle $\left(\mathrm{BiPO}_{4}\right)$ & Tributyl phosphate (uranium extraction) \\
\hline BX-109 & $\mathrm{V}$ & Tributyl phosphate (uranium extraction) & Cladding waste \\
\hline BX-112 & VIII & First decontamination cycle $\left(\mathrm{BiPO}_{4}\right)$ & Evaporator bottoms \\
\hline C-102 & XXV & PUREX & Tributyl phosphate (uranium extraction) \\
\hline C-104 & XXV & Cladding waste & Organic solvent wash water (PUREX) \\
\hline C-107 & $\mathrm{X}$ & First decontamination cycle $\left(\mathrm{BiPO}_{4}\right)$ & Cladding waste \\
\hline C- 110 & XII & Tributyl phosphate (uranium extraction) & Organic solvent wash water (PUREX) \\
\hline S-104 & IV & REDOX & \\
\hline S-107 & I & REDOX & Evaporator bottoms \\
\hline $\mathrm{T}-104$ & XXV & First decontamination cycle $\left(\mathrm{BiPO}_{4}\right)$ & \\
\hline $\mathrm{T}-107$ & $\mathrm{X}$ & First decontamination cycle $\left(\mathrm{BiPO}_{4}\right)$ & Cladding waste \\
\hline $\mathrm{T}-110$ & $\mathrm{XV}$ & Second decontamination cycle $\left(\mathrm{BiPO}_{4}\right)$ & Final decontamination stage $\left(\mathrm{BiPO}_{4}\right)$ \\
\hline $\mathrm{T}-111$ & $\mathrm{XV}$ & Second decontamination cycle $\left(\mathrm{BiPO}_{4}\right)$ & Final decontamination stage $\left(\mathrm{BiPO}_{4}\right)$ \\
\hline TX-109 & II & Evaporator bottoms & First decontamination cycle $\left(\mathrm{BiPO}_{4}\right)$ \\
\hline TY-103 & XXII & Tributyl phosphate (uranium extraction) & $\begin{array}{l}\text { First decontamination cycle }\left(\mathrm{BiPO}_{4}\right) \text { - } \\
\text { Ferrocyanide-scavenged waste }\end{array}$ \\
\hline TY-105 & XXV & Tributyl phosphate (uranium extraction) & \\
\hline $\mathrm{U}-110$ & $\mathrm{X}$ & First decontamination cycle $\left(\mathrm{BiPO}_{4}\right)$ & Cladding waste \\
\hline
\end{tabular}




\subsection{EXPERIMENTAL PROCEDURE AND RESULTS}

Because the minimum temperatures at the start and end of a slurry transfer are 50 and $45^{\circ} \mathrm{C}$, respectively, the temperatures of primary interest for this study ranged from 65 to $40^{\circ} \mathrm{C}$. If a slurry transfer is interrupted and the waste is permitted to cool, the lowest possible temperature of the slurry is $15^{\circ} \mathrm{C}$, which represents the temperature of the buried transfer line with no additional heat. In previous viscosity studies, no effort was made to differentiate between the viscosities of the liquid and the slurry. In this study, viscosity measurements that focused primarily on either the liquid or the solids were made.

After the 20-mL samples in Table 12 were prepared, they were placed in an Aquatherm water bath shaker. After the samples were maintained at $80^{\circ} \mathrm{C}$ for the first week, the temperature of the samples was lowered to $65^{\circ} \mathrm{C}$ for the second week. At the end of the second week, the initial viscosity measurements were made at $65^{\circ} \mathrm{C}$. While the samples remained in the water bath shaker, they were rotated at a rate of $100 \mathrm{rpm}$. However, the rotation did not prevent any solids from settling to the bottom of the bottle. Prior to each viscosity measurement, the height of the settled solids and the total height of the sample were measured. Each sample was placed on a vortex mixer to resuspend all of the solids before $16 \mathrm{~mL}$ of the sample was transferred into the preheated small-sample adapter for the Brookfield DV-III rheometer. The volume below the spindle is $2.6 \mathrm{~mL}$, which is $16 \%$ of the total sample volume. Because solids settled into this void space during most of the viscosity tests, the viscosity measurements should represent primarily the liquid phase of the slurry. The sample was then permitted to equilibrate for $15 \mathrm{~min}$. For each sample, two viscosity tests were performed in an effort to determine the effects of shear rate and time. In the first test, the shear rate was varied from 12 to 122 to $12 \mathrm{~s}^{-1}$. Each particular shear rate was maintained for a period of $2 \mathrm{~min}$ before it was increased or decreased by $12 \mathrm{~s}^{-1}$. In the other test, a shear rate of $61 \mathrm{~s}^{-1}$ was normally applied to the sample for $5 \mathrm{~min}$. If high-viscosity solids were observed, then a lower shear rate (as indicated) was used. The viscosity results from the 5-min tests are presented in Table 15.

The height measurement of the gravity-settled solids was converted to the volume percent, which is given in Table 16 . If the viscosity measurement at $65^{\circ} \mathrm{C}$ was greater than $20 \mathrm{cP}$, the sample was diluted with deionized water until the measurement was below $20 \mathrm{cP}$. The amount of dilution water required because of either a high viscosity measurement at $65^{\circ} \mathrm{C}$ or a high initial density is given at the bottom of Table 12 . At the end of the $65^{\circ} \mathrm{C}$ tests, the samples were allowed to equilibrate at $60^{\circ} \mathrm{C}$ for 3.5 days prior to next set of viscosity measurements. An equilibration period for the next-lower temperature was maintained for a minimum of 3.5 days, and the temperature was reduced in increments of $5^{\circ} \mathrm{C}$ until it reached $40^{\circ} \mathrm{C}$. The samples were then equilibrated at $50^{\circ} \mathrm{C}$ for 1 week. After each sample was transferred to the rheometer at $50^{\circ} \mathrm{C}$, it was cooled to $15^{\circ} \mathrm{C}$ over a 2 -h period. More viscosity measurements were then taken. Because the solids in the slurry simulants were not adequately represented by the initial results, additional tests, which focused on the solids, were repeated at 50 and $45^{\circ} \mathrm{C}$ with no equilibration period between the temperatures.

Stainless steel spacers were placed in the bottom of the sample chamber to minimize the void space. The viscosity results, which are more representative of the slurries, are also shown in Table 14. 
Table 15. Viscosity of the FY 2002 slurry samples

(Viscosity in centipoises)

\begin{tabular}{|c|c|c|c|c|c|c|c|c|c|}
\hline $\begin{array}{l}\text { Sample } \\
\text { number }\end{array}$ & $65^{\circ} \mathrm{C}$ & $60^{\circ} \mathrm{C}$ & $55^{\circ} \mathrm{C}$ & $50^{\circ} \mathrm{C}$ & $45^{\circ} \mathrm{C}$ & $40^{\circ} \mathrm{C}$ & $15^{\circ} \mathrm{C}$ & $\begin{array}{l}50^{\circ} \mathrm{C}, \\
\text { solids }\end{array}$ & $\begin{array}{l}45^{\circ} \mathrm{C}, \\
\text { solids }\end{array}$ \\
\hline H1 & 2.4 & 2.6 & 2.6 & 2.6 & 2.8 & 3.0 & 6.1 & 2.6 & 2.7 \\
\hline $\mathrm{H} 2$ & 1.9 & 2.6 & 2.8 & 2.6 & 2.6 & 2.8 & 3.8 & $12.1^{b}$ & $16.0^{b}$ \\
\hline $\mathrm{H} 3$ & 2.3 & 2.5 & 2.7 & 3.8 & 3.4 & 3.6 & 6.0 & $23.3^{b}$ & $28.3^{d}$ \\
\hline H4 & 2.2 & 2.2 & 2.8 & 2.8 & 3.1 & 3.1 & 5.1 & 4.8 & 6.2 \\
\hline H5 & 4.9 & 5.5 & 5.6 & 6.1 & 6.6 & 6.6 & 10.8 & $48.8^{c}$ & $55.2^{c}$ \\
\hline H6 & 6.9 & 7.0 & 7.4 & 7.9 & 8.3 & 8.5 & 20.5 & 8.9 & 11.7 \\
\hline $\mathrm{H} 7$ & 4.0 & 4.1 & 5.0 & 5.1 & 5.1 & 5.1 & 8.0 & $47.7^{c}$ & $55.1^{c}$ \\
\hline H8 & 2.2 & 2.2 & 2.8 & 4.8 & 4.8 & 4.8 & 5.2 & $>6000^{a}$ & $>6000^{a}$ \\
\hline A-103 & 2.8 & 6.2 & 5.0 & 5.0 & 5.1 & 5.1 & 18.8 & 5.1 & 5.3 \\
\hline AW-105 & 0.8 & 0.9 & 0.9 & 0.9 & 1.0 & 1.0 & 1.7 & 2.1 & 2.8 \\
\hline B-104 & 1.7 & 1.7 & 2.0 & 2.0 & 2.0 & 2.2 & 3.4 & 5.5 & 5.8 \\
\hline B-110 & 10.7 & 6.1 & 4.6 & 4.1 & 3.6 & 3.2 & 3.7 & 10.8 & 10.9 \\
\hline B-111 & 3.3 & 2.8 & 2.6 & 2.6 & 2.5 & 2.5 & 3.1 & 7.0 & 7.4 \\
\hline BX-107 & 3.4 & 3.6 & 6.2 & 6.4 & 6.6 & 7.2 & 8.4 & $26.2^{c}$ & $34.4^{c}$ \\
\hline BX-109 & 4.1 & 5.9 & 5.4 & 5.7 & 6.6 & 6.6 & 6.8 & 7.0 & 9.0 \\
\hline BX-112 & 10.1 & 7.0 & 5.1 & 5.3 & 4.6 & 3.8 & 4.8 & 6.6 & 8.0 \\
\hline C-102 & 5.2 & 6.1 & $>6000^{a}$ & $>6000^{a}$ & $>6000^{a}$ & $>6000^{a}$ & $>6000^{a}$ & $>6000^{a}$ & $>6000^{a}$ \\
\hline C-104 & 11.2 & 6.5 & 3.0 & 3.3 & 4.0 & 2.7 & 4.5 & $>6000^{a}$ & $>6000^{a}$ \\
\hline C-107 & 8.8 & 4.3 & 4.2 & 3.6 & 1.2 & 1.4 & 4.0 & $3200^{a}$ & $3400^{a}$ \\
\hline C-110 & 6.9 & 6.8 & 3.9 & 2.9 & 2.9 & 2.6 & 4.0 & 9.4 & 9.7 \\
\hline S-104 & 5.3 & 5.2 & 5.5 & 5.1 & 5.0 & 5.2 & 11.8 & 8.3 & 11.7 \\
\hline S-107 & 2.8 & 2.8 & 2.9 & 3.3 & 3.3 & 3.3 & 5.6 & $45.8^{c}$ & $53.0^{c}$ \\
\hline $\mathrm{T}-104$ & 3.2 & 2.9 & 1.1 & 1.1 & 1.7 & 1.4 & 2.5 & 5.2 & 5.6 \\
\hline $\mathrm{T}-107$ & 7.3 & 4.7 & 4.5 & 2.7 & 4.3 & 2.8 & 4.4 & $>6000^{a}$ & $>6000^{a}$ \\
\hline $\mathrm{T}-110$ & 1.8 & 2.1 & 1.6 & 1.6 & 1.5 & 1.7 & 2.4 & 2.8 & 4.3 \\
\hline $\mathrm{T}-111$ & 3.3 & 3.4 & 4.7 & 5.0 & 5.0 & 5.0 & 6.2 & 7.8 & 11.6 \\
\hline TX-109 & 1.2 & 1.5 & 4.7 & 4.7 & 4.7 & 4.9 & 6.0 & $44.3^{c}$ & $49.0^{c}$ \\
\hline TY-103 & 3.2 & 7.1 & 9.0 & 7.1 & 6.9 & 5.9 & 6.6 & $55.1^{c}$ & $58.8^{c}$ \\
\hline TY-105 & 7.3 & 2.8 & 3.0 & 2.7 & 2.5 & 2.6 & 4.5 & 5.6 & 10.2 \\
\hline U-110 & 4.3 & 3.9 & 2.7 & 2.7 & 2.8 & 2.7 & 4.9 & $>6000^{a}$ & $>6000^{a}$ \\
\hline
\end{tabular}

${ }^{a}$ Shear rate of $0.12 \mathrm{~s}^{-1}$.

${ }^{b}$ Shear rate of $30.5 \mathrm{~s}^{-1}$.

${ }^{c}$ Shear rate of $6.1 \mathrm{~s}^{-1}$.

${ }^{d}$ Shear rate of $24.4 \mathrm{~s}^{-1}$. 
Table 16. Volume percent of gravity-settled solids prior to the slurry viscosity tests

\begin{tabular}{|c|c|c|c|c|c|c|c|c|}
\hline $\begin{array}{l}\text { Sample } \\
\text { number }\end{array}$ & $65^{\circ} \mathrm{C}$ & $60^{\circ} \mathrm{C}$ & $55^{\circ} \mathrm{C}$ & $50^{\circ} \mathrm{C}$ & $45^{\circ} \mathrm{C}$ & $40^{\circ} \mathrm{C}$ & 50 to $15^{\circ} \mathrm{C}$ & $\begin{array}{l}50^{\circ} \mathrm{C}, \\
\text { solids }\end{array}$ \\
\hline H1 & $<4$ & 4 & 4 & 8 & 8 & 8 & 4 & 4 \\
\hline $\mathrm{H} 2$ & 32 & 36 & 32 & 36 & 36 & 36 & 32 & 32 \\
\hline $\mathrm{H} 3$ & 36 & 36 & 36 & 32 & 32 & 32 & 32 & 32 \\
\hline $\mathrm{H} 4$ & 32 & 32 & 28 & 28 & 28 & 28 & 28 & 24 \\
\hline H5 & 48 & 48 & 44 & 44 & 40 & 40 & 36 & 40 \\
\hline H6 & 36 & 36 & 32 & 32 & 32 & 28 & 28 & 28 \\
\hline $\mathrm{H} 7$ & 32 & 32 & 32 & 32 & 36 & 36 & 32 & 28 \\
\hline H8 & 28 & 28 & 32 & 32 & 32 & 32 & 28 & 28 \\
\hline A-103 & 36 & 36 & 32 & 32 & 28 & 28 & 28 & 28 \\
\hline AW-105 & 20 & 20 & 20 & 20 & 20 & 24 & 20 & 24 \\
\hline B-104 & 32 & 32 & 32 & 36 & 32 & 32 & 32 & 32 \\
\hline B-110 & 68 & 64 & 64 & 64 & 64 & 64 & 60 & 60 \\
\hline B-111 & 56 & 56 & 56 & 56 & 56 & 52 & 56 & 56 \\
\hline BX-107 & 36 & 36 & 36 & 40 & 36 & 36 & 36 & 36 \\
\hline BX-109 & 48 & 57 & 67 & 67 & 67 & 67 & 67 & 67 \\
\hline BX-112 & 52 & 52 & 44 & 44 & 44 & 44 & 44 & 44 \\
\hline C-102 & 40 & 40 & 48 & 48 & 48 & 44 & 44 & 44 \\
\hline C-104 & 41 & 41 & 38 & 38 & 38 & 34 & 34 & 38 \\
\hline C-107 & 41 & 34 & 34 & 34 & 34 & 34 & 34 & 34 \\
\hline C-110 & 44 & 36 & 36 & 36 & 36 & 36 & 36 & 36 \\
\hline S-104 & 30 & 30 & 30 & 30 & 27 & 27 & 27 & 27 \\
\hline S-107 & 36 & 36 & 36 & 36 & 36 & 36 & 36 & 36 \\
\hline $\mathrm{T}-104$ & 32 & 32 & 28 & 28 & 28 & 28 & 28 & 28 \\
\hline $\mathrm{T}-107$ & 44 & 41 & 41 & 41 & 38 & 38 & 38 & 38 \\
\hline $\mathrm{T}-110$ & 36 & 36 & 36 & 36 & 36 & 36 & 36 & 36 \\
\hline $\mathrm{T}-111$ & 52 & 48 & 44 & 44 & 44 & 44 & 44 & 44 \\
\hline TX-109 & 32 & 32 & 32 & 28 & 28 & 28 & 28 & 28 \\
\hline TY-103 & 72 & 66 & 66 & 66 & 66 & 66 & 66 & 63 \\
\hline TY-105 & 50 & 47 & 47 & 44 & 44 & 44 & 44 & 44 \\
\hline U-110 & 31 & 28 & 31 & 28 & 28 & 28 & 28 & 28 \\
\hline
\end{tabular}

Eight of the samples exceeded the maximum viscosity prior to a slurry transfer; therefore, the effects of dilution with deionized water were examined. After each dilution with $5 \mathrm{~mL}$ of water, the samples were permitted to equilibrate for a minimum of 3.5 days. Viscosity measurements were made at 50 and $45^{\circ} \mathrm{C}$. If the viscosity of the diluted sample exceeded $20 \mathrm{cP}$, then the sample was diluted with an additional $5 \mathrm{~mL}$ of water. The equilibration period and viscosity measurements were repeated until the viscosity of the solids was below $20 \mathrm{cP}$. The effects of the water dilutions are shown in Table 17. The water dilutions for the individual Hanford tanks are based on the initial formulation from the BBI. Prior to any viscosity measurements, the simulants for tanks C-104 and C-107 were diluted by $25 \%$, while the formulation for the tank TY-103 sludge was diluted by $75 \%$. 
Table 17. Effects of water dilutions on the high-viscosity samples

\begin{tabular}{|c|c|c|c|c|c|c|}
\hline $\begin{array}{l}\text { Sample } \\
\text { number }\end{array}$ & Primary phase & $\begin{array}{c}\text { Temperature } \\
\left({ }^{\circ} \mathrm{C}\right)\end{array}$ & $\begin{array}{l}\text { Viscosity }-25 \% \\
\text { dilution }(\mathrm{cP})\end{array}$ & $\begin{array}{c}\text { Viscosity }-50 \% \\
\text { dilution }(\mathrm{cP})\end{array}$ & $\begin{array}{c}\text { Viscosity }-75 \% \\
\text { dilution }(\mathrm{cP})\end{array}$ & $\begin{array}{l}\text { Viscosity }-100 \% \\
\text { dilution }(\mathrm{cP})\end{array}$ \\
\hline H3 & Solids & 50 & 3.9 & & & \\
\hline H3 & Solids & 45 & 4.8 & & & \\
\hline H5 & Solids & 50 & 8.8 & & & \\
\hline H5 & Solids & 45 & 9.8 & & & \\
\hline $\mathrm{H} 7$ & Solids & 50 & 6.9 & & & \\
\hline $\mathrm{H} 7$ & Solids & 45 & 7.3 & & & \\
\hline $\mathrm{H} 8$ & Solids & 50 & $>6000^{a}$ & 2.3 & & \\
\hline H8 & Solids & 45 & $>6000^{a}$ & 2.3 & & \\
\hline BX-107 & Solids & 50 & 4.2 & & & \\
\hline BX-107 & Solids & 45 & 5.1 & & & \\
\hline C-102 & Liquid & 50 & 4.7 & & & \\
\hline C-102 & Liquid & 45 & 8.5 & & & \\
\hline C-102 & Solids & 50 & $>6000^{a}$ & $>6000^{a}$ & 4.0 & \\
\hline C-102 & Solids & 45 & $>6000^{a}$ & $>6000^{a}$ & $16.2^{b}$ & \\
\hline C-104 & Solids & 50 & & $>6000^{a}$ & $4000^{a}$ & 3.7 \\
\hline C-104 & Solids & 45 & & $>6000^{a}$ & $4000^{a}$ & 3.9 \\
\hline C-107 & Solids & 50 & & $1400^{a}$ & 6.5 & \\
\hline C-107 & Solids & 45 & & $2600^{a}$ & 6.8 & \\
\hline T-107 & Solids & 50 & $350^{c}$ & 8.1 & & \\
\hline T-107 & Solids & 45 & $410^{c}$ & 8.6 & & \\
\hline TY-103 & Solids & 50 & & & & 7.9 \\
\hline TY-103 & Solids & 45 & & & & 9.0 \\
\hline U-110 & Solids & 50 & $55.7^{d}$ & 5.4 & & \\
\hline U-110 & Solids & 45 & $58.3^{d}$ & 10.3 & & \\
\hline
\end{tabular}

\subsection{DISCUSSION}

As shown in Table 17, a maximum water dilution of $100 \%$ was needed to produce sludge slurries that could be safely transferred. Since the retrieval effort is expected to dilute the sludge by $300 \%$, pipeline plugs should not occur during the transfer if the sludge is sufficiently blended, if a phosphate plug cannot form, and if the solids in the slurry are small enough to be easily transported. In fact, these viscosity results clearly suggest that the $300 \%$ water dilution would be excessive. However, the perceived transfer limit for aluminum is $1 \mathrm{M}$. The aluminum concentrations in 26 tanks are greater than 4 mol per liter of waste; therefore, the aluminum concentration after the $300 \%$ dilution would still exceed the perceived limit. Because these 26 tanks contain 2,400,000 gal of waste, and the amount of dilution water required to meet the limit of $1 M$ aluminum is $12,900,000$ gal. If the aluminum limit could be increased to $1.5 \mathrm{M}$, the required amount of dilution water for these tanks would be only 7,800,000 gal. This potential reduction of 5,100,000 gal of dilution water should lead to significant cost savings, since this dilution water will eventually be evaporated prior to vitrification. In addition, the higher transfer limit for aluminum may be needed due to the limited amount of tank space.

Finally, waste transfers with aluminum concentrations in excess of $1 M$ are likely due to the large amounts of aluminum in certain tanks. For example, 1,600,000 and $1,400,000$ gal of dilution water would be needed to reduce the aluminum concentrations in tanks C-105 and S-101, respectively, to $1 M$. These quantities of dilution water exceed the tank capacities. Therefore, a further evaluation of these viscosity results and Hanford operational data is needed before the perceived aluminum limit of $1 \mathrm{M}$ can be increased. 
As shown in Table 12, dilution water was added to 7 of the 22 Hanford sludge simulants prior to the start of the viscosity measurements. The diluted simulants for tanks BX-109, S-104, T-104, and TY-103 required no additional dilution water after the viscosity measurements were initiated. As the samples were cooled and evaluated, seven of the sludge simulants produced viscosity measurements in excess of $20 \mathrm{cP}$. While the aluminum concentrations of these high-viscosity simulants ranged from 4.71 to $0.16 \mathrm{M}$, most had aluminum concentrations greater than $1 M$. However, the tank S-104 and tank S-107 simulants, with aluminum concentrations of 3.73 and $3.10 \mathrm{M}$, respectively, did not produce any high-viscosity measurements. Therefore, aluminum concentration is not solely responsible for the high-viscosity measurements. The chemical compositions of the simulants with aluminum concentrations greater than $2 M$ were compared. The primary differences between the simulants that produced high-viscosity measurements and those that did not were the concentrations of iron and silicon. For the two high-aluminum samples with no high-viscosity measurements, the maximum concentrations of iron and silicon were 0.06 and $0.14 M$, respectively. In contrast, the minimum concentrations of iron and silicon for the high-aluminum samples with high-viscosity measurements were 0.28 and $0.23 \mathrm{M}$, respectively. In addition, a low-aluminum sample with iron and silicon concentrations of 0.36 and $0.25 M$ failed to generate any high-viscosity measurements. Therefore, it appears that samples with high-viscosity measurements required sufficient concentrations of aluminum, iron, and silicon. It should be noted that relatively low concentrations of aluminum, iron, and silicon can be problematic. For example, after a 75\% dilution of the formulation based on the BBI, the tank TY-103 simulant produced high-viscosity measurements. The concentrations of aluminum, iron, and silicon in this simulant were 0.16 , 0.42 , and $0.20 \mathrm{M}$, respectively. The only notable exception to these observations involves the simulant for tank BX-109, which was diluted by $100 \%$ prior to the viscosity measurements. The initial concentrations of aluminum, iron, and silicon for the tank BX-109 simulant were $0.12,0.58$, and $0.04 M$, respectively. Thus, high concentrations of iron with low concentrations of aluminum and silicon may also be problematic. These findings should be confirmed by Hanford operational data. Finally, even though potentially problematic conditions have been identified, the Hanford tank farm operators should not encounter these conditions if waste is diluted by $300 \%$ prior to the transfers.

\section{SIMULATIONS OF SALTWELL PUMPING TRANSFERS AT HANFORD}

\subsection{BACKGROUND}

During the past few years, the interim stabilization program has performed the majority of the waste transfers at Hanford. The primary objective of this program is to reduce the levels of supernatants and interstitial liquids in the single-shell tanks through saltwell pumping. These transfers of filtered liquids to double-shell tanks have led to numerous pipeline plugs. For example, the tank S-102 saltwell recirculation loop became plugged. When attempts to remove this plug were unsuccessful, a second recirculation loop was added to the tank. This second loop also became plugged. If the second loop is abandoned, then a plugged loop must be removed before a new loop can be installed. In 
addition to costly schedule delays and the generation of even more contaminated waste, the tank farm operators run the risk of exposure to radiation during the installation of new equipment.

Since the recent pipeline plugs have involved saltwell pumping, the initial viscosity studies (Hunt et al., 1999; Hunt et al., 2000b; Hunt et al., 2002) at ORNL focused on simulants that had a low initial solids content. Most of the identified pipeline plugs were attributed to sodium phosphate; as a result, earlier viscosity studies evaluated conditions that can lead to this type of plug. The main factors in the formation of sodium phosphate plugs are the concentrations of sodium phosphate and sodium fluoride and temperature. The potentially problematic concentrations of sodium phosphate and sodium fluoride shown in Table 8 have been discussed earlier. High-viscosity solids due to sodium phosphate were observed at temperatures between 20 and $50^{\circ} \mathrm{C}$, with the vast majority detected between 20 and $30^{\circ} \mathrm{C}$. The rate of cooling was also shown to be a significant factor, with high-viscosity solids more likely to appear as the rate of cooling increased. These viscosity results were used to develop an artificial neural network, which predicts the highest possible viscosity for these thermodynamically unstable chemical systems. The primary objectives of this FY2002 effort were to improve the neural network predictions through a comparison of the effects of nitrate and nitrite on the sodium phosphate plugs and to evaluate the plug-forming potential of aluminum hydroxide and sodium carbonate.

\subsection{TEST MATRIX}

In the previous viscosity studies (Hunt et al., 1999; Hunt et al., 2000b; Hunt et al., 2002), nearly all of the samples contained aluminum, fluoride, hydroxide, nitrate, phosphate, silicon, and sulfate. The BBI of the Hanford tanks was examined to determine reasonable high and low concentrations for each of the seven components. Nearly all of these concentrations were reduced by a factor of 2 in order to produce samples with reasonable specific gravities. In contrast to the earlier samples, the only common components in the FY 2002 samples were aluminum and hydroxide. Nitrite was substituted for nitrate in approximately half of the samples so that the effects of nitrate and nitrite on sodium phosphate could be compared. In addition, higher concentrations of aluminum, carbonate, and hydroxide were used in some of the current samples. However, these concentrations were still below the corresponding maximum concentrations from the BBI analysis. The higher concentrations of aluminum and carbonate were used in an effort to produce highviscosity solids resulting from aluminum hydroxide and sodium carbonate, respectively. The compositions of the saltwell pumping simulants are presented in Table 18. The G16 sample in Table 18 represents dissolved saltcake from Hanford tank S-112. It was assumed that the retrieval operation would use 1,551,000 gal of water to dissolve 517,000 gal of saltcake, which is a ratio of 3 to 1 . 
Table 18. Chemical compositions of the Hanford saltwell pumping simulants

(Concentrations in molarity)

\begin{tabular}{|c|c|c|c|c|c|c|c|c|}
\hline $\begin{array}{l}\text { Sample } \\
\text { number }\end{array}$ & $\mathrm{Al}(\mathrm{OH})_{3}$ & $\mathrm{Na}_{2} \mathrm{CO}_{3}$ & $\mathrm{NaF}$ & $\mathrm{NaOH}$ & $\mathrm{NaNO}_{2}$ & $\mathrm{NaNO}_{3}$ & $\mathrm{Na}_{3} \mathrm{PO}_{4} \cdot 12 \mathrm{H}_{2} \mathrm{O} \cdot 0.25 \mathrm{NaOH}$ & $\mathrm{Na}_{2} \mathrm{SO}_{4}$ \\
\hline G1 & 2.0 & 0.0 & 0.0 & 5.0 & 0.0 & 4.0 & 0.0 & 0.0 \\
\hline G2 & 1.5 & 0.0 & 0.0 & 5.0 & 0.0 & 4.0 & 0.0 & 0.0 \\
\hline G3 & 2.0 & 0.4 & 0.0 & 5.0 & 0.0 & 4.0 & 0.0 & 0.0 \\
\hline G4 & 2.0 & 0.0 & 0.1 & 5.0 & 0.0 & 4.0 & 0.0 & 0.0 \\
\hline G5 & 2.0 & 0.0 & 0.0 & 5.0 & 0.0 & 4.0 & 0.2 & 0.0 \\
\hline G6 & 2.0 & 0.0 & 0.1 & 3.0 & 0.0 & 3.0 & 0.2 & 0.0 \\
\hline G7 & 1.5 & 0.4 & 0.1 & 4.0 & 0.0 & 4.0 & 0.0 & 0.0 \\
\hline G8 & 1.5 & 0.0 & 0.0 & 4.0 & 0.0 & 4.0 & 0.2 & 0.0 \\
\hline G9 & 2.0 & 0.0 & 0.0 & 5.0 & 4.0 & 0.0 & 0.0 & 0.0 \\
\hline G10 & 1.5 & 0.0 & 0.0 & 4.0 & 4.0 & 0.0 & 0.0 & 0.0 \\
\hline G11 & 1.0 & 0.0 & 0.0 & 3.0 & 4.0 & 0.0 & 0.0 & 0.0 \\
\hline G12 & 1.0 & 0.0 & 0.0 & 1.0 & 4.0 & 0.0 & 0.5 & 0.0 \\
\hline G13 & 0.0 & 0.6 & 0.0 & 4.0 & 1.0 & 0.0 & 0.5 & 0.0 \\
\hline G14 & 0.0 & 0.6 & 0.0 & 4.0 & 4.0 & 0.0 & 0.5 & 0.0 \\
\hline G15 & 0.0 & 0.6 & 0.2 & 4.0 & 1.0 & 0.0 & 0.5 & 0.0 \\
\hline G16 & 0.32 & 0.27 & 0.0 & 1.9 & 0.47 & 1.65 & 0.11 & 0.17 \\
\hline
\end{tabular}

\subsection{EXPERIMENTAL PROCEDURE AND RESULTS}

The saltwell pumping simulants were prepared in a similar manner to the slurry simulants, and the samples were equilibrated at 80,65 , and $50^{\circ} \mathrm{C}$ for a period of 1 week at each temperature. The volume percent of solids and the viscosity of these samples were measured in the same way that was described previously for the slurry simulants. The results of the measurements of viscosity and volume percent of solids are shown in Tables 19 and 15 , respectively. After the initial viscosity measurements at $50^{\circ} \mathrm{C}$, the samples were allowed to equilibrate at $45^{\circ} \mathrm{C}$ for 3.5 days prior to next set of measurements. An equilibration period for the next-lower temperature was maintained for a minimum of 3.5 days, and the temperature was reduced in increments of $5^{\circ} \mathrm{C}$ until it reached $15^{\circ} \mathrm{C}$.

After the gradual-cooling experiments were completed, the saltwell pumping samples were again heated to $60^{\circ} \mathrm{C}$ for approximately 1 week. After the equilibration period, the volume percent of solids was determined, and the result is shown in Table 20. The hot sample was mixed and transferred into the rheometer's small-sample adapter, which was also heated to $60^{\circ} \mathrm{C}$. The temperature of the water bath, which controls the temperature of the small-sample adapter, was reduced to $30^{\circ} \mathrm{C}$ in an effort to simulate a pump failure. The initial rate of cooling was slightly more than $0.7^{\circ} \mathrm{C} / \mathrm{m}$, and the cooldown period was approximately $2 \mathrm{~h}$. After the sample was permitted to equilibrate for $1 \mathrm{~h}$, two viscosity tests were performed in an effort to determine the effects of shear rate and time. The viscosity result at a constant shear rate, which was normally $61 \mathrm{~s}^{-1}$, is given in Table 19. After these tests of a simulated pump failure at $60^{\circ} \mathrm{C}$ were completed, the samples were equilibrated for 1 week at $50^{\circ} \mathrm{C}$. The procedure, which simulated a pump failure, was repeated, and viscosity measurements were made after the sample was permitted to equilibrate at $20^{\circ} \mathrm{C}$ for $1 \mathrm{~h}$. 
Table 19. Viscosity of the FY 2002 saltwell pumping samples

(Viscosity in centipoises)

\begin{tabular}{|c|c|c|c|c|c|c|c|c|c|c|}
\hline $\begin{array}{l}\text { Sample } \\
\text { number }\end{array}$ & $50^{\circ} \mathrm{C}$ & $45^{\circ} \mathrm{C}$ & $40^{\circ} \mathrm{C}$ & $35^{\circ} \mathrm{C}$ & $30^{\circ} \mathrm{C}$ & $25^{\circ} \mathrm{C}$ & $20^{\circ} \mathrm{C}$ & $15^{\circ} \mathrm{C}$ & 60 to $30^{\circ} \mathrm{C}$ & 50 to $20^{\circ} \mathrm{C}$ \\
\hline G1 & 7.1 & 8.0 & 8.3 & 8.9 & 9.0 & 9.1 & 10.1 & 11.1 & 4.9 & 7.3 \\
\hline G2 & 6.3 & 6.9 & 7.1 & 7.4 & 7.8 & 8.7 & 8.8 & 9.5 & 4.9 & 6.0 \\
\hline G3 & 8.3 & 8.8 & 9.0 & 10.1 & 10.1 & 10.7 & 11.3 & $12.2^{c}$ & 6.2 & 8.1 \\
\hline G4 & 8.0 & 8.3 & 8.4 & 9.0 & 10.1 & 10.2 & 10.2 & 11.6 & 5.2 & 7.3 \\
\hline G5 & 8.4 & 8.8 & 11.3 & $12.0^{a}$ & $12.0^{a}$ & $28^{c}$ & 10.1 & 10.4 & $4200^{d}$ & $>6000^{d}$ \\
\hline G6 & 4.7 & 5.3 & 5.4 & 5.2 & 5.7 & 5.7 & 6.4 & 7.1 & 3.8 & 6.0 \\
\hline G7 & 5.6 & 6.5 & 7.0 & 7.0 & 8.0 & 8.2 & 8.2 & 9.0 & 4.6 & 6.3 \\
\hline G8 & 5.8 & 6.2 & 8.8 & $13.3^{a}$ & $14.1^{a}$ & $120^{b}$ & 7.6 & 8.1 & $420^{b}$ & $1000^{d}$ \\
\hline G9 & 6.1 & 7.4 & 7.5 & 7.7 & 7.7 & 7.9 & 8.8 & 10.1 & 4.5 & 5.8 \\
\hline G10 & 4.4 & 4.7 & 5.0 & 5.6 & 5.9 & 6.5 & 71 & 7.7 & 4.3 & 5.6 \\
\hline G11 & 3.0 & 3.2 & 3.3 & 3.7 & 4.0 & 4.3 & 4.9 & 5.6 & 3.0 & 3.9 \\
\hline G12 & 2.7 & 2.8 & 2.2 & 2.4 & 2.5 & $450^{b}$ & $220^{b}$ & $35^{c}$ & $>6000^{d}$ & $>6000^{d}$ \\
\hline G13 & 2.8 & 2.9 & 2.6 & 2.6 & 2.6 & $390^{b}$ & 3.0 & 3.1 & 1.9 & $950^{d}$ \\
\hline G14 & 3.9 & 4.1 & 3.5 & $330^{b}$ & $510^{b}$ & $500^{b}$ & $410^{b}$ & $300^{b}$ & $200^{b}$ & $1300^{d}$ \\
\hline G15 & 2.6 & 2.6 & 2.6 & 2.7 & 3.0 & 3.2 & 3.4 & 3.7 & 2.5 & 2.9 \\
\hline G16/S-112 & 1.8 & 2.2 & 2.3 & 2.4 & 2.4 & 2.6 & 2.7 & 3.0 & 2.2 & 2.6 \\
\hline
\end{tabular}

Table 20. Volume percent of settled solids prior to saltwell pumping tests

\begin{tabular}{lrrrrrrrrrr}
\hline $\begin{array}{l}\text { Sample } \\
\text { number }\end{array}$ & $50^{\circ} \mathrm{C}$ & $45^{\circ} \mathrm{C}$ & $40^{\circ} \mathrm{C}$ & $35^{\circ} \mathrm{C}$ & $30^{\circ} \mathrm{C}$ & $25^{\circ} \mathrm{C}$ & $20^{\circ} \mathrm{C}$ & $15^{\circ} \mathrm{C}$ & 60 to & 50 to \\
$30^{\circ} \mathrm{C}$ & $20^{\circ} \mathrm{C}$ \\
\hline G1 & & & & & & & & & $<5$ \\
G2 & $<5$ & $<5$ & $<5$ & $<5$ & $<5$ & $<5$ & $<5$ & $<5$ & $<5$ & $<5$ \\
G3 & 5 & 5 & 5 & 5 & 5 & 5 & 5 & 5 & 5 & $<5$ \\
G4 & $<5$ & $<5$ & $<5$ & $<5$ & $<5$ & $<5$ & $<5$ & $<5$ & $<5$ & $<5$ \\
G5 & $<5$ & 10 & 10 & 20 & 20 & 20 & 20 & 15 & $<5$ & 5 \\
G6 & $<5$ & 5 & 10 & 10 & 10 & 10 & 10 & 10 & $<5$ & 15 \\
G7 & $<5$ & $<5$ & $<5$ & $<5$ & $<5$ & $<5$ & $<5$ & $<5$ & $<5$ & $<5$ \\
G8 & $<5$ & 5 & 25 & 30 & 30 & 25 & 20 & 20 & $<5$ & 10 \\
G9 & $<5$ & $<5$ & $<5$ & $<5$ & $<5$ & $<5$ & $<5$ & $<5$ & $<5$ & $<5$ \\
G10 & $<5$ & $<5$ & $<5$ & $<5$ & $<5$ & $<5$ & $<5$ & $<5$ & $<5$ & $<5$ \\
G11 & $<5$ & $<5$ & $<5$ & $<5$ & $<5$ & $<5$ & $<5$ & $<5$ & $<5$ & $<5$ \\
G12 & 25 & 30 & 25 & 25 & 25 & 30 & 25 & 30 & 15 & 10 \\
G13 & 35 & 35 & 30 & 30 & 30 & 25 & 25 & 25 & 10 & 15 \\
G14 & 35 & 35 & 35 & 40 & 35 & 35 & 30 & 30 & 10 & 15 \\
G15 & 25 & 30 & 30 & 30 & 30 & 30 & 30 & 30 & 15 & 10 \\
G16/S-112 & $<5$ & $<5$ & 5 & 5 & 5 & 5 & 5 & 5 & $<5$ & 5 \\
\hline
\end{tabular}




\subsection{DISCUSSION}

High-viscosity solids were detected in 5 of the 16 samples. Each of these five samples had a phosphate concentration of $0.2 \mathrm{M}$ or greater and a fluoride concentration of $0.0 \mathrm{M}$. The new results are consistent with earlier results, which were used to determine potentially problematic phosphate concentrations with respect to fluoride concentrations, as shown in Table 8 (Hunt et al., 2002). Two other samples had phosphate and fluoride concentrations in the ranges shown in Table 8. Sample G6, which had a phosphate concentration of $0.2 \mathrm{M}$ and a fluoride concentration of $0.1 \mathrm{M}$, did not generate any highviscosity solids. This experimental result is in agreement with the prediction of a safe fluoride concentration based on Table 8. The other high-phosphate sample, G15, contained phosphate and fluoride concentrations of 0.5 and $0.2 \mathrm{M}$, respectively. This combination of concentrations is on the borderline for a potential transfer problem. However, during the FY 2001 viscosity study (Hunt et al., 2002), the potential for a transfer problem was shown to decrease as the carbonate concentration increases. The high-carbonate concentration in sample G15 probably prevented the formation of high-viscosity solids. It is believed that hydrogen bonding with the carbonate adversely impacts the sodium phosphate crystals. The impact of carbonate on high-viscosity solids can be seen with samples G12, G13, and G14. The phosphate and fluoride concentrations in these three samples were 0.5 and $0.0 \mathrm{M}$, respectively. The highest viscosity for the sample without any carbonate (G12) was greater than $6000 \mathrm{cP}$, while the highest viscosities for the two samples with carbonate concentrations of $0.6 M$ (G13 and G14) were 950 and $1300 \mathrm{cP}$, respectively.

While the carbonate concentration can significantly influence the viscosities of these saltwell pumping simulants, the substitute of sodium nitrite for sodium nitrate produced only a small decrease in the viscosities. This observation is not surprising, since the viscosities of a $4 M$ sodium nitrate solution and a $4 M$ sodium nitrite solution are both $1.8 \mathrm{cP}$ at $20^{\circ} \mathrm{C}$.

These results suggest that the primary contribution of sodium nitrite and sodium nitrate is to the ionic strength of the simulant.

Finally, the attempts to produce an aluminum hydroxide or sodium carbonate plug under normal operating conditions for saltwell pumping were not successful. Therefore, the formation of aluminum and carbonate plugs would most likely occur during a water wash or an off-normal condition such as a suspended waste transfer. For aluminum, the solubility of gibbsite is very $\mathrm{pH}$ dependent. It has been speculated that a drop in $\mathrm{pH}$ during water flushes led to gibbsite precipitation and, eventually, to a plug. The initial $\mathrm{pH}$ of saltwell pumping solution can be expected to be in the range of 14 to 11 when water is used. During dissolution tests on actual saltcake from Hanford tank S-112 (Herting and Bechtold, 2002), the $\mathrm{pH}$ values of the dissolved saltcake samples ranged from 14 to 11 . An ORNL study (Wesolowski, 1992) has determined the gibbsite solubility in sodium hydroxide solutions in the same $\mathrm{pH}$ and temperature range. For example, gibbsite solubilities at $25^{\circ} \mathrm{C}$ are $6.8 \times 10^{-3}$ and $7.0 \times 10^{-4} \mathrm{~m}$ for hydroxide concentrations of $9.3 \times 10^{-2}$ and $9.6 \times 10^{-3} \mathrm{~m}$, respectively. As the $\mathrm{pH}$ continues to decrease to 6 , the solubility of gibbsite also steadily decreases. At $25^{\circ} \mathrm{C}$, the solubilities of gibbsite at $\mathrm{pH}$ values of 10 and 8 are approximately $1 \times 10^{-5}$ and $1 \times 10^{-7} \mathrm{M}$, respectively (Snoeyink and Jenkins, 1980). During water flushes of a transfer line, the $\mathrm{pH}$ of the solution in the line and the concentration of soluble aluminum will decrease at a similar rate. Therefore, a gibbsite plug is unlikely to occur during a water flush unless the waste is supersaturated with aluminum or the temperature of the waste in the 
transfer line drops significantly. As shown in a subsequent section, supernatant from one of the tanks at the SRS was supersaturated with respect to aluminum. Hanford tank operators have indicated that such supersaturated solutions were routinely generated as a result of aluminum precipitation kinetics. An ORNL study (Wesolowski, 1992) has shown that the concentration of soluble aluminum is reduced by $50 \%$ when the temperature is decreased from 50 to $25^{\circ} \mathrm{C}$ with no change in $\mathrm{pH}$. These results indicate that the solution in the transfer line could be or could become supersaturated with respect to aluminum. For carbonate, the solubilities of sodium carbonate and its various hydrated forms decrease as the temperature decreases. At $25^{\circ} \mathrm{C}$, the ESP predicts that any sodium carbonate solids would be in the form of sodium carbonate monohydrate. The solubilities of sodium carbonate monohydrate are 0.42 and 0.27 $M$ in hot and cold water, respectively (Weast and Astle, 1981). The effects of dilution water from saltwell pumping can be expected to far exceed the small reduction in carbonate solubility due to a lower temperature. Therefore, the precipitation of sodium carbonate monohydrate in the transfer line is unlikely unless the water is permitted to evaporate.

While the necessary conditions for gibbsite precipitation are known to exist in the tank farms at Hanford and the SRS, only one transfer problem has been attributed to gibbsite precipitation to date. Therefore, other existing factors must be reducing the potential for the formation of this type of plug. First, the precipitation kinetics of gibbsite is known to be slow, as demonstrated by the presence of supersaturated solutions in the tanks, and the transfer time is usually very much shorter than the hold time in the tanks. The slow kinetics and the quick waste transfer should dramatically reduce the potential amount of gibbsite precipitation. Researchers at the Pacific Northwest National Laboratory and the SRS are evaluating the precipitation of aluminum-containing species in tank wastes for the Environmental Management Science Program. Second, the gibbsite solids that were formed from supersaturated simulants of the SRS supernatants were very fine and easily suspended, and they did not appear to agglomerate. Under normal flow conditions, the gibbsite solids would be easily transferred to the receipt tank. In sharp contrast, saltcake dissolution tests at MSU have indicated that the gibbsite particles will agglomerate in a relatively static environment over several days. Therefore, sufficient time for gibbsite precipitation and agglomeration in a static environment would be needed for a gibbsite plug to form. Due to the potential importance of agglomeration during waste transfers, researchers at AEA Technology are studying particle size distributions of tank waste simulants as a function of flow rate (Francis et al., 2001).

\section{ENHANCEMENTS TO VISCOSITY PREDICTIONS}

\subsection{BACKGROUND}

In 2001, an artificial neural network (ANN) was designed to predict the viscosity of a solution that contained aluminum, carbonate, fluoride, hydroxide, nitrate, phosphate, silicon, sodium, and sulfate (Hunt et al., 2002). Since the completion of this initial model, another

data set, which is shown in Tables 18 and 19, was obtained. This additional data set allowed the creation of a more accurate viscosity prediction model. A new set of viscosity ANN 
models was developed using the above-listed components as inputs. Some new sample data points contained measurements of nitrite. These measurements were combined with those for nitrate for purposes of data modeling. ANNs are capable of modeling the nonlinearity in the relationships between component concentrations and viscosity. The anatomy of the brain provides a metaphor for ANN architecture, in which computational nodes and links resemble neurons and synapses. ANNs are nonlinear universal function approximators (Hornik et al., 1989), and it is not assumed that the measurements are related by a particular functional form such as a polynomial or exponential. ANNs can be used for prediction through an arbitrary nonlinear input-output mapping or for classification purposes (i.e., to determine if the data point belongs to a single class such as high or low viscosity). A supervised learning paradigm is often used for prediction where input-output mappings are nonlinear. The classical statistical technique for prediction is multiple linear regression; however, this technique is not recommended if the true relationship is nonlinear. A more thorough introduction to ANNs can be found elsewhere (Bishop, 1995; Jain et al., 1996; Lippmann, 1987).

\subsection{METHODS}

A sufficiently complex ANN model with a large number of nodes and weights can be trained to provide an exact fit to a finite set of sample points. There is always a danger that a complex model will overfit the data and that the model may generalize poorly to samples that have not been previously encountered by the model. If the model generalizes poorly, it will have little value as an explanatory device. Therefore, the performance of an ANN model with respect to a set of viscosity training data cannot be used to determine the predictive capabilities of the model. A set of test data that was not used to train the model must be used to estimate the accuracy of the model predictions. If the ANN model overfits the new data, test performance will usually be substantially lower than training performance. Often data availability is limited, and most of the available data must be used to train the model. When data are limited, a technique known as k-fold cross-validation is an efficient training procedure, because every sample has an opportunity to serve as both training and test data.

The viscosity ANN model was developed in Matlab using extensions to the Netlab toolkit (Nabney, 2002) for neural networks. The model contained eight predictor compounds and a single output variable, which is viscosity. Using k-fold cross-validation, the entire data set of 87 samples was divided into 9 randomly selected, nearly equal-sized, mutually exclusive subsets. Each subset was checked to ensure that it contained a mixture of lowviscosity and high-viscosity samples. An independent ANN was trained with 8/9 of the entire data set, while the test set with the other $1 / 9$ of the data was used to estimate the generalization (test) error of each model. An estimate of the overall test error is obtained by pooling test errors from each of the nine subsets.

After several different candidate architectures were tried, a network with seven hidden nodes was selected because it appeared to minimize training/generalization error. This architecture is designated by the notation " $8 \times 7 \times 1$," which indicates that there are eight predictor variables (compounds), seven hidden nodes, and a single output node. Both input and output data were transformed by using a nonlinear function in the $[0,1)$ interval. The functional form ( $\mathrm{g}$ ) selected for the data transformation is shown in Eq. (3): 


$$
g(X)=\frac{X^{a}}{X^{a}+b}
$$

where variables $a$ and $b$ are free parameters that are fixed by the actual data vector $(X)$ in order to determine desired anchor points at both ends of the transformation. Outputs are required to be within this interval, and inputs are typically better behaved if normalized in this fashion. The predicted variable was defined as peak viscosity across the entire temperature range for both fast and slow cooling rates.

\subsection{RESULTS}

Results of ANN performance in Table 21 are given in transformed units. Classification predictions of the entire data set by the overall ANN model were nearly perfect. Generalization performance was also reasonably good. However, the test mean squared error was more than 10 times the magnitude of the training mean squared error, which suggests some overfitting of the viscosity data by the ANN.

Early attempts to model viscosity with ANN models were successful only in discriminating between two classes (i.e., high and low viscosity). Figure 10 shows that the overall ANN was able to predict raw viscosity values quite well in most instances. An inspection of the log-log plot in Fig. 10 demonstrates that the overall ANN registered an exemplary performance with the qualitative estimates of raw viscosity values. Most data points were reasonably close to the dotted line, which indicates perfect agreement between observed values and model predictions. The viscosity samples naturally cluster into two groups, where a viscosity value of $50 \mathrm{cP}$ serves as a clear boundary between high- and lowviscosity clusters.

Solid lines divide the scatterplot in Fig. 10 into four quadrants using this same class boundary. The upper-right and lower-left quadrants are regions in which the samples were correcty classified as either high or low viscosity, respectively. However, in the upper-left and lower-right quadrants, the ANN would have made an incorrect classification. The upperleft quadrant represents a false alarm, which could lead to an unneeded processing step by the tank farm operators. In contrast, any sample in the lower-right quadrant could lead to a plugged pipeline without advanced warning. However, none of the samples were incorrectly classified, and all were well within class boundaries.

Table 21. ANN performance on viscosity predictions for saltwell pumping simulants

\begin{tabular}{lcc}
\hline & Training (entire data set) & Test (overall) \\
\hline Mean squared error & 0.00288 & 0.0459 \\
Percent of variance explained (\%) & 97.6 & 61.1 \\
Classification performance $(\%)$ & 100 & 87.8 \\
\hline
\end{tabular}




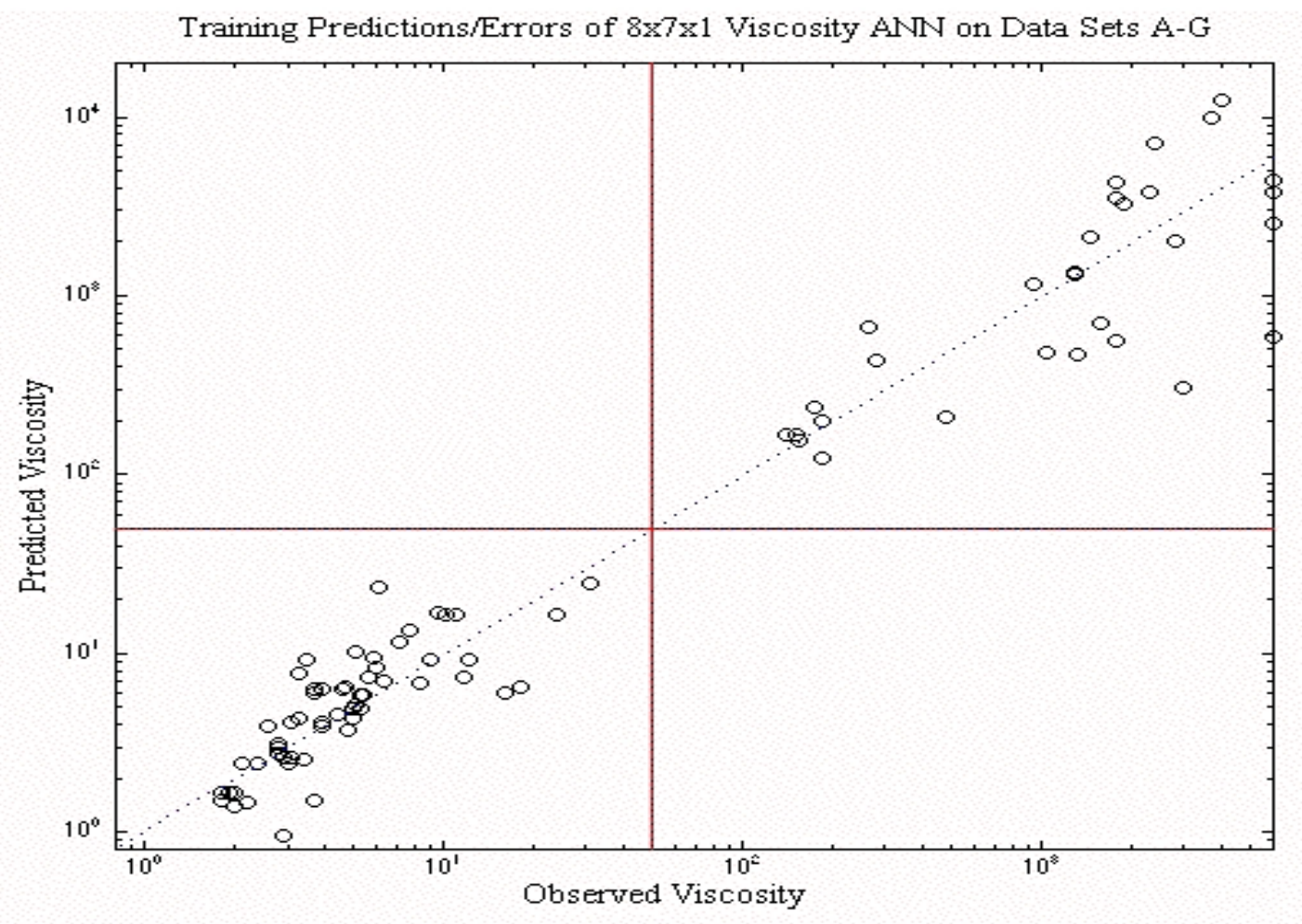

Fig. 10. Training performance: observed vs predicted viscosity for all samples.

Generalization performance for each sample is illustrated in Fig. 11. Substantial departures of predicted values from the ideal (dotted) regression line were observed. However, in most instances the predicted trend is in the right direction. Classification performance was even more impressive than regression performance; classifications of high vs low viscosity were correct in nearly $88 \%$ of all cases. The samples that were incorrectly classified are identified in Fig. 11. The false positives appear in the upper-left quadrant, while the false negatives are in the lower-right quadrant. A false negative is a much more serious error since it could lead to an unexpected pipeline plug. Of the six false positives, three had phosphate and fluoride concentrations that could not be determined to be either a "safe" or "potentially unsafe" transfer condition based on the concentrations in Table 8. While the other three false positives had a phosphate concentration of $0.025 \mathrm{M}$ or less, they did have high concentrations of aluminum or carbonate, which have been discussed earlier as potential concerns. Nearly all of the false negatives would have been identified as problematic based on the potentially unsafe concentrations given in Table 8 . The only exception was sample B6, which had a phosphate concentration of $0.9 M$ and a fluoride concentration of $0.3 \mathrm{M}$. It is very unlikely that the Hanford tank operators will transfer such a highly concentrated solution. This evaluation clearly indicates that the neural network in conjunction with the information in Table 8 should be able to identify nearly all of the potentially unsafe transfers. 


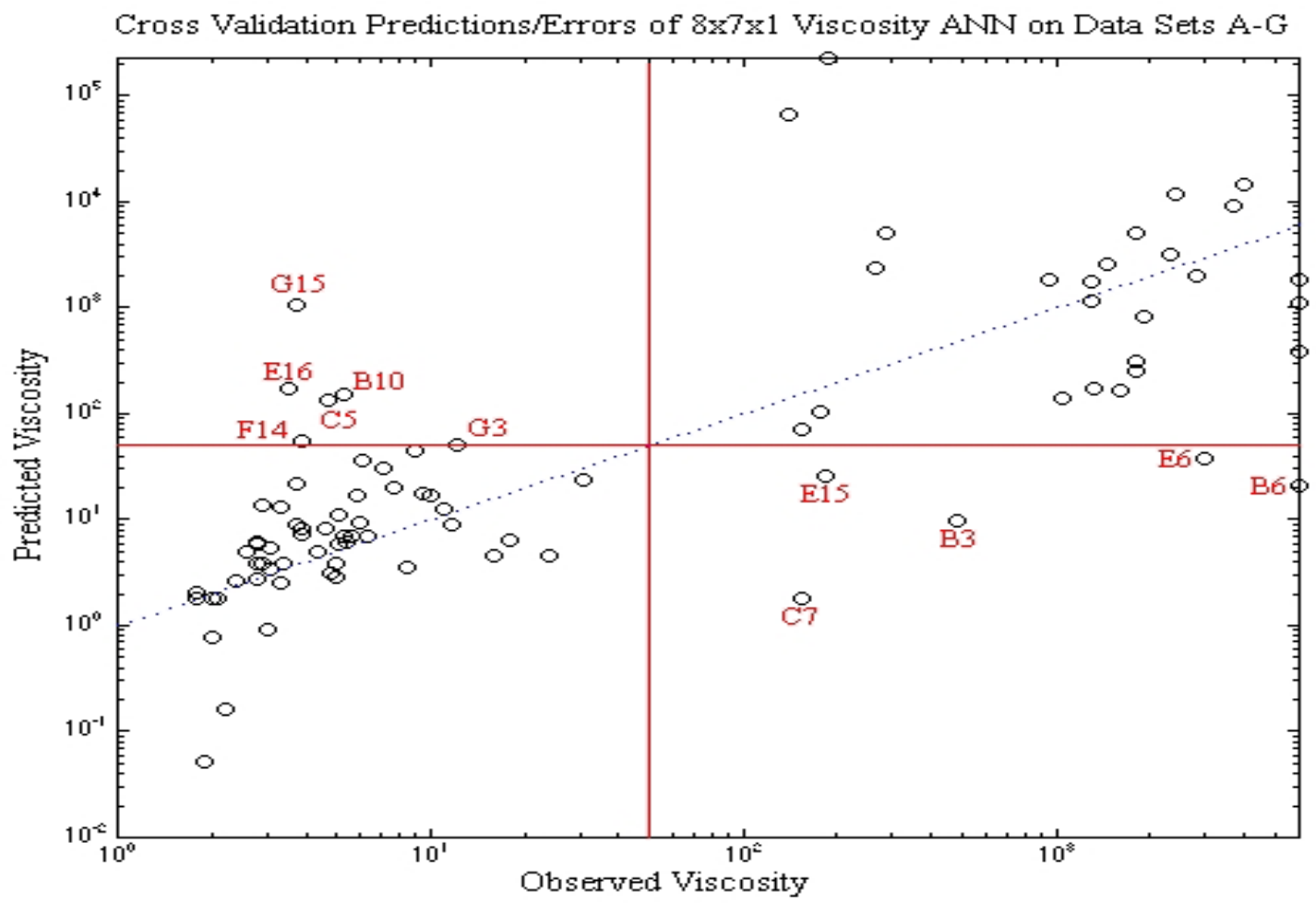

Fig. 11. Generalization performance: observed vs predicted viscosity for all samples.

An estimate of the importance or sensitivity of each compound to the viscosity of the individual sample was needed. In a linear regression, global sensitivity can be estimated from the standardized beta coefficients in the linear model itself, but no corresponding method exists for ANNs. In previous research (Bishop, 1995), local sensitivity values were computed using Eq. 4:

$$
\mathrm{S}_{1}(i)=\delta \mathrm{V} / \delta \mathrm{C}_{i}
$$

This index shows the rate of change in viscosity with respect to concentration of the $i$ th component as measured at a single point $\mathrm{C}_{i}$. Since the functional form of viscosity is not known, the value of each $C_{i}$ was slightly perturbed, and the change in values of viscosity was observed. A global index can be obtained by taking an average of the absolute values of the local sensitivity values. This index seems to be biased toward predictive variables expressed over a larger range, since such variables tend to be associated with larger absolute deviations when perturbed by small changes in the input. Therefore, a second estimate of the importance of each compound was needed.

Another, more principled, view of sensitivity or importance examines effects of the presence or absence of a variable instead of the effects of small perturbations about local values. The effect of a variable is "removed" by substituting its mean value for all samples. It is believed that important variables held constant to their mean values produce large increases in model error. Conversely, if a variable has little effect on model predictions, substituting its mean value should not greatly affect model error. Suppose $\mathrm{MSE}_{i}^{+}$is the mean squared error resulting from using observed values of the $i$ th variable in the model, and 
$\mathrm{MSE}_{i}^{-}$is the mean squared error that one obtains when the mean value of the $i$ th variable is substituted for all samples. The difference $\left(\mathrm{MSE}_{i}^{+}-\mathrm{MSE}_{i}^{-}\right)$is a global indicator of the increase in mean squared error caused by removing the effect of a variable. We normalize the difference by dividing the total mean squared error increase across all variables. The global error-based sensitivity index is shown in Eq. (5) (Moody, 1994):

$$
\mathrm{S}_{\mathrm{e}}(i)=\operatorname{abs}\left(\mathrm{MSE}_{i}^{+}-\mathrm{MSE}_{i}^{-}\right) / \Sigma\left(\mathrm{MSE}_{i}^{+}-\mathrm{MSE}_{i}^{-}\right) \text {. }
$$

The sum of the individual $\mathrm{S}_{\mathrm{e}}(i)$ was 1 . The global normalized error-based sensitivities to viscosity for the eight compounds to viscosity were determined. The compounds that are most important to the degree of viscosity are phosphate, fluoride, and sulfate. As expected, phosphate is the single most important compound contributing to the viscosity of the samples.

To understand the effects on viscosity in greater detail, continuous ANN model predictions of viscosity were made across the entire range of concentrations for each compound. The model predictions of the main effects for each compound are shown in Fig. 12. In each plot, a single explanatory variable was systematically varied, while reasonable values were used for other explanatory variables. The actual values of the other explanatory variables were selected using kernel regression, which is a nonparametric estimation technique. The smoothness of the predictions was not fixed but instead was determined by the bandwidth in the kernel regression. Predictions can be very smooth if a wide bandwidth is selected. Alternatively, they can be forced, in an attempt to pass all the actual data points through within a narrow bandwidth. In this effort, the bandwidth was selected to follow a hybrid of smoothing and data fitting. The bandwidth associated with each compound was independently selected to minimize the generalization error of the kernel estimates. Actual data points and model predictions are included in Fig. 12 for comparison purposes. The solid lines in Fig. 12 show the viscosity prediction of each compound, given kernel estimates of the other predictor variables. The prediction line is not really a fit to the data; therefore, it is not expected to pass through the center of mass in the data cloud, because the effects of the other explanatory variables were not considered. An examination of Fig. 12 suggests that the predictions of the viscosity ANN model are not highly smoothed.

A simple or monotonic relationship was not observed between any compound and viscosity based on smoothed predictions. It was conjectured that viscosity cannot be understood simply in terms of the primary effects of each compound. Complex interactions among several compounds must be involved in the final determination of the viscosity. This independent evaluation of model predictions confirmed earlier observations that the formation of sodium phosphate and double salts with sodium fluoride such as sodium fluoride-sodium phosphate plays a critical role in the viscosity of the Hanford saltwell pumping simulants. 

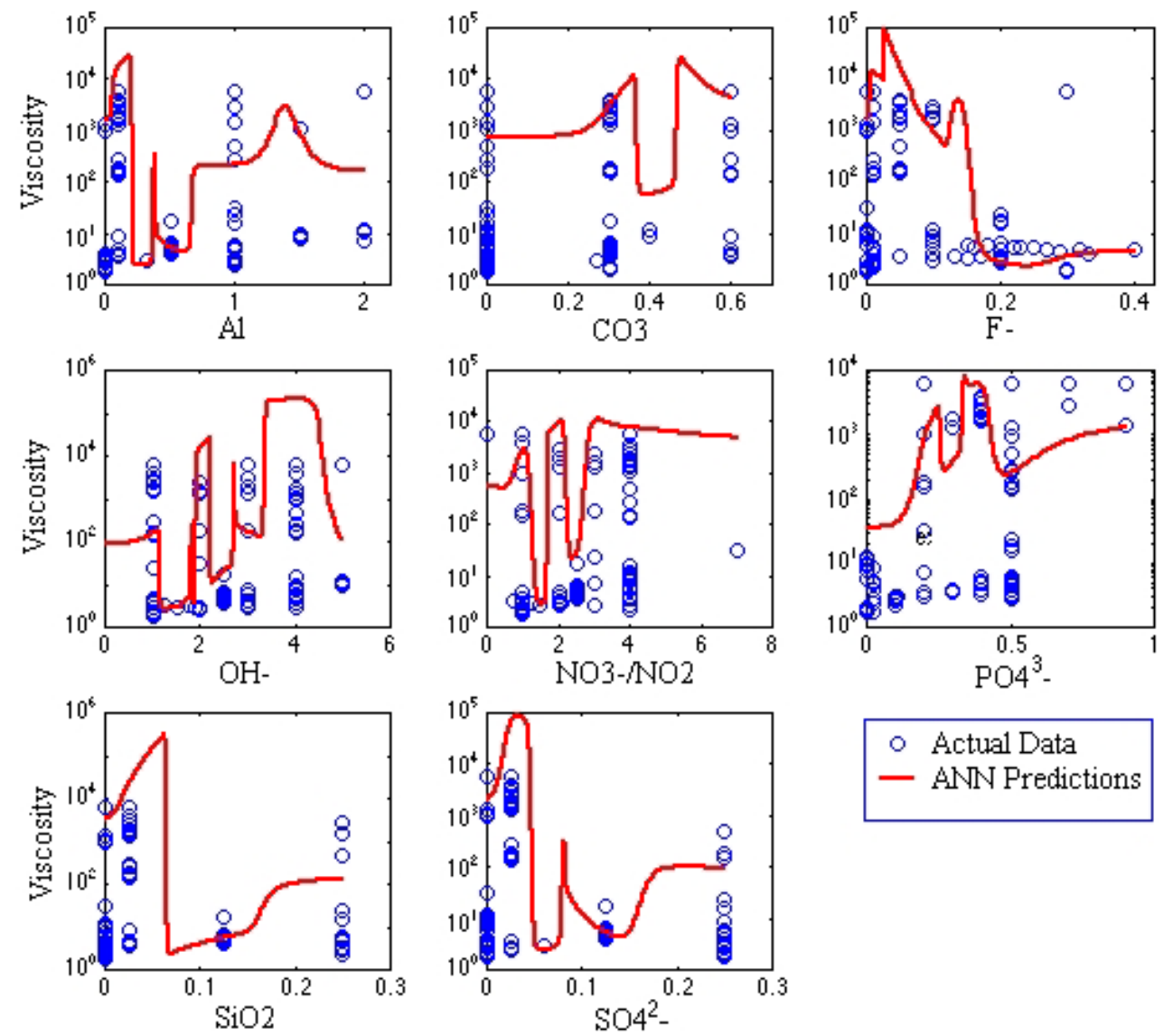

- Actual Data

- ANN Predictions

Fig. 12. Scatterplots of compound concentrations vs viscosity.

\subsection{WEB-BASED ANN VISCOSITY MODEL FOR SALTWELL PUMPING}

The ANN predictive model is able to make viscosity predictions from arbitrary combinations of component concentrations. The input parameter space of the model is far denser than the 87 sample data points that were used to train this ANN. Although the model predictions within the tested concentration ranges should be reliable, the model can also extrapolate beyond the ranges of the training data. It is expected that Hanford process engineers will provide an independent validation of the model and will evaluate its extrapolation capabilities.

The ANN model was translated from the Matlab functions in its development environment to ANSI C code. A simple web page was constructed to allow users to provide input to the ANN viscosity model. A form on the main page invites the user to enter concentrations for each of the eight compounds. After the submit button is pressed, a Perl script is invoked. Values of the entered variables are then passed to the executable program. The $\mathrm{C}$ program computes the viscosity prediction, which is then displayed on the results page. Naturally, it is expected that the ANN viscosity prediction will be most accurate if the 
user enters values for all eight compound concentrations. If any values are omitted, the program will substitute the mean values for that compound from the training set. In the event that a listed compound is not represented in a user sample or solution, the user is requested to enter a value of zero.

Interested users may access a preliminary version of the ANN viscosity model at http://www.ornl.gov/ViscosityANN/viscosity1.html. Please revisit this URL to use the latest model, which may include debugging fixes, updates to the program, and user interface modifications.

\section{STRATEGIES TO REMOVE THE GIBBSITE PLUG AT HANFORD}

\subsection{BACKGROUND}

Recent transfers at Hanford between the U and SY tank farms have resulted in significant blockage of a 3-in. transfer line, which is approximately $1500 \mathrm{ft}$ long, with small variations in the slope of the pipe. As a result of the blockage, the flow rate has been reduced to $1-2 \mathrm{gal} / \mathrm{min}$ at a pump head of $65 \mathrm{psi}$. Attempts to remove the plug with water backflushes have only been marginally successful as the flow rate could be increased only to $9 \mathrm{gal} / \mathrm{min}$. The transfers that have led to this partially plugged line have involved liquids from saltwell pumping activities. These solutions are high in aluminum and low in potentially complicating chemicals such as silicon. Therefore, the Hanford tank farm operators believed that the plug is probably gibbsite and that a flush with caustic will be needed to improve the flow rate. Hanford personnel requested that this effort evaluate the effects of various caustic dissolution strategies.

\subsection{CHEMISTRY}

Since the precipitation evidently occurred from homogenous solution at fairly low temperature, the most likely solid is gibbsite, $\mathrm{Al}(\mathrm{OH})_{3}$. Recently, ORNL researchers (Palmer, 2002) measured dissolution rates of gibbsite slurries in various concentrations of sodium hydroxide. The complete process can be represented by the reaction steps in Eqs. (6) and (7):

$$
\mathrm{Al}(\mathrm{OH})_{3}(\mathrm{~s}) \leftrightarrow \mathrm{Al}(\mathrm{OH})_{3}^{0}(a q)
$$

and

$$
\mathrm{Al}(\mathrm{OH})_{3}^{0}(a q)+\mathrm{OH}^{-} \frac{\tilde{k}_{1}}{k_{2}} \mathrm{Al}(\mathrm{OH})_{4}^{-}
$$

The first reaction step represents pure dissolution, which is a mass transfer process that depends on the surface area of the solid, its crystal structure, and the fluid flow rate around the solid particles. The second reaction step is a homogeneous chemical reaction. While a different mechanism such as a surface reaction of hydroxide ion on gibbsite may be 
involved, it was assumed that Eqs. (6) and (7) adequately describe the process. In addition, the assumption was made that the reaction in Eq. (6) quickly reaches steady state. Therefore, the concentration of neutral $\mathrm{Al}(\mathrm{OH})_{3}(\mathrm{aq})$ is approximately constant, and Eq. (7) controls the overall rate of dissolution. If these assumptions are not correct, then changes in the mixing pattern or the amount of solids present would significantly alter the rate of dissolution.

However, virtually no information is available about the mass transfer processes in Eq. (6). Therefore, additional tests would be required before Eq. (6) could be used in these approximations. Under these assumptions, the rate of the process is governed by Eqs. (8) and (9):

$$
r_{1}=\tilde{k}_{1}\left[\mathrm{OH}^{-}\right]\left[\mathrm{Al}(\mathrm{OH})_{3}^{0}\right]=k_{1}\left[\mathrm{OH}^{-}\right]
$$

and

$$
r_{2}=k_{2}\left[\mathrm{Al}(\mathrm{OH})_{4}^{-}\right]
$$

Assuming that only hydroxide is present in the initial solution $\left[\mathrm{OH}^{-}\right]_{\mathrm{t}=0}=\mathrm{C}_{0}$, then aluminate concentration is shown in Eq. (10):

$$
C(t)=\frac{k_{1} C_{0}}{k_{1}+k_{2}}\left[1-\exp \left(k_{1}+k_{2}\right) t\right]
$$

where $C(t)=\left[\mathrm{Al}(\mathrm{OH})_{4}{ }^{-}\right]$. The maximum aluminate concentration is shown in Eq. (11):

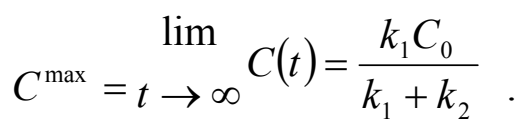

The experimental results from the ORNL study (Palmer, 2002) were fit to Eq. (10), which produced rate constants as shown in Table 22.

Table 22. Rate constants for gibbsite dissolution

\begin{tabular}{ccc}
\hline Temperature $\left({ }^{\circ} \mathrm{C}\right)$ & $\mathrm{k}_{1}\left(\right.$ day $\left.^{-1}\right)$ & $\mathrm{k}_{2}\left(\right.$ day $\left.^{-1}\right)$ \\
\hline 30 & 0.05 & 0.46 \\
63 & 1.68 & 6.8 \\
\hline
\end{tabular}




\subsection{PIPE BLOCKAGE}

The two types of blockage were considered: close-packed particles and a reduction in pipe diameter with only a small channel for fluid transport. Although the actual blockage is probably some hybrid combination of unknown characteristics, a simple analysis of these two configurations nevertheless yields considerable insight.

\subsubsection{Packed-Particle Blockage}

In the case of close-packed particulates, flow through beds of spheres (Denn, 1980) is approximately described by Eq. (12), which is called the Ergun equation:

$$
f_{p}=\left(150 / \operatorname{Re}_{p}\right)+1.75,
$$

where $f_{p}$ and $\operatorname{Re}_{p}$ are the particle friction factor and Reynolds number, respectively. The data necessary to calculate these quantities are given in Table 23. Since pressure drop, flow rate and fluid properties are known, only the void fraction and particle diameter must be estimated in order to calculate the length of plugged pipe. As shown in Table 23, two different void fractions $(\varepsilon), 0.1$ and 0.4 , were used to estimate the length of plugged pipe. The minimum void fraction for close-packed spheres is about 0.1 . In the ORNL experiments, Palmer's estimated particle surface area of $0.3 \mathrm{~m}^{2} / \mathrm{g}$, which is for uniform spherical particles, yields a particle diameter $\left(D_{p}\right)$ of $8.3 \times 10^{-6} \mathrm{~m}$. However, there is no assurance that the particles in the Hanford plug are similar in size. The assumed void fractions in Table 23 indicate that the plugged region of the pipe spans much less than $1 \mathrm{~m}$.

Table 23. Data for packed particle bed

\begin{tabular}{llcc}
\hline Variable & \multicolumn{1}{c}{ Definition } & Void fraction of 0.4 & Void fraction of 0.1 \\
\hline$D_{p}$ & Particle diameter, $\mathrm{m}$ & $1.00 \times 10^{-4}$ & $1.00 \times 10^{-5}$ \\
$\mathrm{Q}$ & Volume of flow rate, $\mathrm{m}^{3}$ & $1.30 \times 10^{-4}$ & $1.30 \times 10^{-4}$ \\
$\mathrm{~A}$ & Cross-section of flow area, $\mathrm{m}^{2}$ & $8.2 \times 10^{-2}$ & $1.8 \times 10^{-2}$ \\
$v$ & Superficial velocity, $\mathrm{m} / \mathrm{s}$ & $7.14 \times 10^{-3}$ & $7.14 \times 10^{-3}$ \\
$\rho$ & Fluid density, $\mathrm{kg} / \mathrm{m}^{3}$ & $1.22 \times 10^{3}$ & $1.22 \times 10^{3}$ \\
$\Delta p$ & Pressure drop, Pa & $4.50 \times 10^{5}$ & $4.50 \times 10^{5}$ \\
$\eta$ & Fluid viscosity, Pa-s & $5.0 \times 10^{-3}$ & $3.0 \times 10^{-3}$ \\
$\operatorname{Re}_{p}$ & Packed bed Reynolds number $^{a}$ & $4.4 \times 10^{-1}$ & $2.9 \times 10^{-1}$ \\
$f_{p}$ & Packed bed friction factor ${ }^{b}$ & $3.46 \times 10^{2}$ & $5.18 \times 10^{2}$ \\
$L$ & Length of bed, m & $2.23 \times 10^{-1}$ & $1.55 \times 10^{-4}$ \\
\hline
\end{tabular}

$$
\begin{aligned}
& { }^{a} \operatorname{Re}_{p}=\frac{D_{p} v_{p} \rho}{(1-\varepsilon) \eta} . \\
& { }^{b} f_{p}=\frac{D_{p} \varepsilon^{3}}{\rho v^{2}(1-\varepsilon)} \frac{(\Delta p)}{L} .
\end{aligned}
$$




\subsubsection{Small-Channel Blockage}

A circular channel was evaluated in which the diameter was assumed to be reduced by deposited solids on the wall. In this case, the traditional friction factor $(f)$ and Reynolds number $(\mathrm{Re})$ are related as shown in Eqs. (13a) and $(13 \mathrm{~b})$ for laminar $(\operatorname{Re}<2100)$ and turbulent $(\operatorname{Re} \geq 2100)$ flow, respectively:

and

$$
f=16 / \operatorname{Re}
$$

$$
f=0.079 \mathrm{Re}^{-1 / 4} .
$$

Since the pressure drop, flow rate and fluid properties are known, only an estimate of the channel diameter is needed in order to calculate the blockage length. Several pipe diameters were considered, and estimates for the blockages are provided in Table 24. For a pipe diameter $(D)$ of $2 \mathrm{~cm}$, the flow is laminar; however, the correct blockage length is longer than the pipe itself. If the diameter is reduced to $1.5 \mathrm{~cm}$, the flow is barely turbulent $(\operatorname{Re}>2100)$ and the blockage is about half the length of the pipe. Diameters of 1 and $0.5 \mathrm{~cm}$ produced blockages of lengths that were physically possible. Thus, the actual pipe blockage probably has one or more channels through the gibbsite with flow areas between 0.5 and $1.0 \mathrm{~cm}$ diameter. The total gibbsite, which is shown in last row in Table 24, is based on the assumption that the pipe is totally filled with gibbsite with the exception of the flow channel. This quantity represents a maximum value, and the actual plug probably contains only a fraction of this amount.

\begin{tabular}{|c|c|c|c|c|c|}
\hline Variable & Definition & $0.5 \mathrm{~cm}$ & $\begin{array}{c}\text { Pipe } \\
1.0 \mathrm{~cm}\end{array}$ & $\begin{array}{c}\text { Diameter } \\
1.5 \mathrm{~cm}\end{array}$ & $2.0 \mathrm{~cm}$ \\
\hline$Q^{\prime}$ & Flow rate, $\mathrm{m}^{3} / \mathrm{s}$ & $1.30 \times 10^{-4}$ & $1.30 \times 10^{-4}$ & $1.30 \times 10^{-4}$ & $1.30 \times 10^{-4}$ \\
\hline$V$ & Flow velocity, m/s & 6.62 & 1.66 & 0.736 & 0.414 \\
\hline$\rho$ & Fluid density, $\mathrm{g} / \mathrm{cm}^{3}$ & 1.220 & 1.220 & 1.220 & 1.220 \\
\hline$\Delta p$ & Pressure drop, $\mathrm{Pa}$ & $4.50 \times 10^{5}$ & $4.50 \times 10^{5}$ & $4.50 \times 10^{5}$ & $4.50 \times 10^{5}$ \\
\hline$\eta$ & Fluid viscosity, $\mathrm{Pa}-\mathrm{s}$ & $5.0 \times 10^{-3}$ & $5.0 \times 10^{-3}$ & $5.0 \times 10^{-3}$ & $5.0 \times 10^{-3}$ \\
\hline \multirow[t]{2}{*}{$\mathrm{Re}$} & Reynolds number $^{a}$ & $8.08 \times 10^{3}$ & $4.04 \times 10^{3}$ & $2.69 \times 10^{3}$ & $2.02 \times 10^{3}$ \\
\hline & Flow regime & Turbulent & Turbulent & Turbulent & Laminar \\
\hline$f$ & Friction factor ${ }^{b}$ & $8.53 \times 10^{-3}$ & $9.91 \times 10^{-3}$ & $1.10 \times 10^{-2}$ & $7.92 \times 10^{-2}$ \\
\hline \multirow[t]{2}{*}{$\mathrm{L}$} & Blockage length, m & 2.52 & $6.79 \times 10^{1}$ & $4.66 \times 10^{2}$ & $2.72 \times 10^{3}$ \\
\hline & Residence time, $\mathrm{s}$ & $3.18 \times 10^{-1}$ & $4.10 \times 10^{1}$ & $6.34 \times 10^{2}$ & $6.57 \times 10^{3}$ \\
\hline $\mathrm{N}$ & Total gibbsite, mol & $3.56 \times 10^{2}$ & $9.45 \times 10^{3}$ & $6.34 \times 10^{4}$ & $3.58 \times 10^{5}$ \\
\hline \multicolumn{6}{|c|}{$\operatorname{Re}=\frac{D V \rho}{}$} \\
\hline \multicolumn{6}{|c|}{$k e=\bar{\eta}$} \\
\hline$f=\frac{D \Delta}{}$ & & & & & \\
\hline
\end{tabular}

Table 24. Data for restricted pipe flow 


\subsection{DISSOLUTION OF THE GIBBSITE PLUG}

The restricted pipe flow with a $1.0-\mathrm{cm}$ diameter was selected as a representative case in the effort to evaluate various processes to remove the gibbsite plug. These plug removal simulations utilized the dissolution rates in Table 22 and compared the effects of continuous flow with those of batch additions of the sodium hydroxide.

\subsubsection{Continuous Flow}

One possibility is to pump caustic solution continuously through the pipe. This process was simulated through the division of the blocked portion of the pipe into multiple control volumes $\left(V_{i}\right)$. For each subvolume, the rate equations are shown in Eqs. (14a), (14b), and (14c):

$$
\begin{gathered}
A_{i}=Q\left[\left(A_{i-1} / V_{i-1}\right)-\left(A_{i} / V_{i}\right)\right]+k_{1} O_{i}-k_{2} A_{i}, \\
G_{i} /\left(10^{3} V_{i}\right)=-k_{1} O_{i}+k_{2} A_{i},
\end{gathered}
$$

and

where

$$
O_{i}=Q\left[\left(O_{i-1} / V_{i-1}\right)-\left(Q_{i} / V_{i}\right)\right]-k_{1} O_{i}+k_{2} A_{i}
$$

$A_{i}=\left[\mathrm{Al}(\mathrm{OH})_{4}{ }^{-}\right](\mathrm{mol} / \mathrm{L})$,

$O_{i}=\left[\mathrm{OH}^{-}\right](\mathrm{mol} / \mathrm{L})$,

$G_{i}=$ amount of gibbsite $\mathrm{Al}(\mathrm{OH})_{3}(\mathrm{~mol})$,

$Q=$ flow rate $\left(\mathrm{m}^{3} / \mathrm{s}\right)$,

$k_{1}, k_{2}=$ reaction rate constants from Eqs. (9), (10), and (11) $\left(\mathrm{s}^{-1}\right)$.

As the gibbsite dissolves, the volume of liquid increases and creates more room for additional caustic. Therefore, the change in volume must be considered.

The dissolution of the gibbsite blockage is simulated when Eqs. (14a), (14b), and (14c) are solved simultaneously. Results for several cases are shown in Table 25. The maximum flow rate was $10.9 \mathrm{~m}^{3} /$ day. It is possible that turbulent flow increases the dissolution rates that are given in Table 22. Therefore, it was necessary to increase the reaction rate constants through the use of a multiplier as shown in Eq. (15):

and

$$
k_{1}{ }^{\prime}=k_{1} \alpha
$$

$$
k_{2}{ }^{\prime}=k_{2} \alpha \text {. }
$$


The dissolution time in Table 25 ranges from a few hours to several months.

The dissolution time was very dependent on the nature of the plug and the assumptions regarding the flow and reaction rates. For example, the dissolution of a $68-\mathrm{m}$ plug with an initial flow diameter of $1 \mathrm{~cm}$ would take at least 8 months at $30^{\circ} \mathrm{C}$ even if the reaction multiplier was 10 . The dissolution time was reduced considerably when the temperature was increased to $63^{\circ} \mathrm{C}$. However, the quickest dissolution time for the 68-m plug was 8 days. As expected, the use of sodium hydroxide increases with flow rate. Comparable simulations were performed on a $2.5-\mathrm{m}$ plug with an initial flow diameter of $0.5 \mathrm{~cm}$. Since the dissolution time is directly related to the amount of gibbsite to be dissolved, the dissolution times for the $2.5-\mathrm{m}$ plug were considerably shorter than those for the $68-\mathrm{m}$ plug. At $30^{\circ} \mathrm{C}$, the dissolution time can be as short as 10 days. If the dissolution rate is not enhanced by the continuous flow, the dissolution time may be as long as 3.5 months. At $63^{\circ} \mathrm{C}$, the dissolution time is reduced to a few hours or a few days. In addition, a much smaller quantity of the caustic is consumed than in the case of the long plug.

Although the exact nature of the actual plug is not known, the actual dissolution time will probably be between the dissolution times for the long and short plugs as shown in Table 25. The actual value may well involve precipitation over a long distance of pipe, although severe restriction may occur only in a small region. Furthermore, it is quite likely that the plug will be disrupted well before all the gibbsite is dissolved, in which case the caustic flow would clear particulates even after it became saturated.

Table 25. Dissolution results with a continuous flow of sodium hydroxide

\begin{tabular}{ccccccc}
\hline $\begin{array}{c}\text { Pipe restriction } \\
(\mathrm{cm})\end{array}$ & $\begin{array}{c}\text { Plug length } \\
(\mathrm{m})\end{array}$ & $\begin{array}{c}\text { Temperature } \\
\left({ }^{\circ} \mathrm{C}\right)\end{array}$ & $\begin{array}{c}\text { Flow rate } \\
\left(\mathrm{m}^{3} / \text { day }\right)\end{array}$ & $\begin{array}{c}\text { Reaction } \\
\text { multiplier }\end{array}$ & $\begin{array}{c}\text { Dissolution } \\
\text { time (days) }\end{array}$ & $\begin{array}{c}\text { Caustic used } \\
(\mathrm{mol})\end{array}$ \\
\hline 1 & 68 & 30 & 0.109 & 10 & 350 & $2.9 \times 10^{5}$ \\
1 & 68 & 30 & 1.09 & 10 & 248 & $2.2 \times 10^{6}$ \\
1 & 68 & 30 & 10.9 & 10 & 238 & $2.1 \times 10^{7}$ \\
1 & 68 & 63 & 0.109 & 1 & 130 & $1.0 \times 10^{5}$ \\
1 & 68 & 63 & 1.09 & 1 & 76 & $6.6 \times 10^{5}$ \\
1 & 68 & 63 & 10.9 & 1 & 71 & $6.2 \times 10^{6}$ \\
1 & 68 & 63 & 0.109 & 10 & 67 & $4.6 \times 10^{4}$ \\
1 & 68 & 63 & 1.09 & 10 & 13 & $1.0 \times 10^{5}$ \\
1 & 68 & 63 & 10.9 & 10 & 8 & $6.5 \times 10^{5}$ \\
0.5 & 2.5 & 30 & 0.0109 & 1 & 105 & $8.8 \times 10^{3}$ \\
0.5 & 2.5 & 30 & 0.109 & 1 & 74 & $6.4 \times 10^{4}$ \\
0.5 & 2.5 & 30 & 1.09 & 1 & 71 & $6.2 \times 10^{5}$ \\
0.5 & 2.5 & 30 & 10.9 & 1 & 71 & $6.1 \times 10^{6}$ \\
0.5 & 2.5 & 30 & 0.0109 & 10 & 42 & $3.3 \times 10^{3}$ \\
0.5 & 2.5 & 30 & 0.109 & 10 & 10 & $8.8 \times 10^{3}$ \\
0.5 & 2.5 & 63 & 1.09 & 10 & 7.4 & $6.4 \times 10^{4}$ \\
0.5 & 2.5 & 63 & 10.9 & 10 & 7.1 & $6.2 \times 10^{5}$ \\
0.5 & 2.5 & 63 & 0.0109 & 1 & 20 & $1.4 \times 10^{3}$ \\
0.5 & 2.5 & 63 & 0.109 & 1 & 3.9 & $3.0 \times 10^{3}$ \\
0.5 & 2.5 & 63 & 1.09 & 1 & 2.3 & $1.9 \times 10^{4}$ \\
0.5 & 2.5 & 63 & 10.9 & 1 & 2.1 & $1.8 \times 10^{5}$ \\
0.5 & 2.5 & 63 & 0.0109 & 10 & 18 & $1.2 \times 10^{3}$ \\
0.5 & 2.5 & 63 & 0.109 & 10 & 2.0 & $1.4 \times 10^{3}$ \\
0.5 & 2.5 & 63 & 1.09 & 10 & 0.38 & $3.0 \times 10^{3}$ \\
0.5 & 2.5 & 63 & 10.9 & 10 & 0.23 & $2.0 \times 10^{4}$ \\
\hline
\end{tabular}


The considerable benefits of the higher temperature include increases in both the amount and rate of dissolution. The caustic solution should be as hot as possible during the field deployment. In addition, it appears that the maximum flow rate, $10.9 \mathrm{~m}^{3} /$ day, has little advantage over a much slower flow rate of $1.09 \mathrm{~m}^{3} /$ day. In virtually every case, the dissolution times are similar, but the higher flow rate requires a good deal more caustic. However, when the flow rate was reduced to $1 \%$ of the maximum flow rate, or $0.109 \mathrm{~m}^{3} /$ day, the dissolution of the plug was noticeably slower in many situations.

\subsubsection{Batch Dissolution}

The other obvious alternative to continuous-flow dissolution is batch dissolution, in which the caustic solution is pumped into the pipe and permitted to dissolve the plug in a static environment. After a period of time, the initial caustic solution will be removed, and another batch of sodium hydroxide will be transferred into the pipe. It was assumed that each batch dissolves a fraction of the equilibrium amount, which was given by Eqs. (10) and (11). This fraction is given in Eq. (16):

$$
F=\frac{C}{C^{\max }}=1-\exp \left[-\left(k_{1}+k_{2}\right) t\right]
$$

where $C$ and $C^{\max }$ are the actual aluminate concentration and maximum aluminate concentration, respectively. The time required for each batch dissolution is given Eq. (17):

$$
t=\frac{-\ln (1-F)}{k_{1}+k_{2}} .
$$

With a series of identical batches, a plug can be completely dissolved. Several different batch strategies were evaluated, and the results are shown in Table 26. These results neglect any dissolution that might occur during the transient phase of pumping caustic into or along the pipe. In reality, this transient dissolution may be substantial, but this part of the analysis focused solely on the batch effects.

A comparison of the dissolution results in Tables 25 and 26 clearly shows that the batch effects are quite different from those achieved via continuous flow. In the batch cases, the short plug actually takes longer to dissolve than the long plug. This effect is due largely to the smaller amount of caustic contacting the plug. It is assumed that fresh caustic is instantly distributed throughout the plugged portion at the introduction of each new batch. When transportation time is neglected for batch cases, the long plug can be dissolved at $63^{\circ} \mathrm{C}$ in much less time than with continuous dissolution. However, it should be noted that other batch dissolutions generally took longer than their continuous analogues. 
Table 26. Dissolution results with batch additions of sodium hydroxide

\begin{tabular}{cccccc}
\hline $\begin{array}{c}\text { Plug length } \\
(\mathrm{m})\end{array}$ & $\begin{array}{c}\text { Temperature } \\
\left({ }^{\circ} \mathrm{C}\right)\end{array}$ & $\begin{array}{c}\mathrm{F} \text { (fraction of } \\
\text { equilibrium })\end{array}$ & $\begin{array}{c}\text { Time per batch } \\
(\mathrm{min})\end{array}$ & $\begin{array}{c}\text { Number of } \\
\text { batches }\end{array}$ & $\begin{array}{c}\text { Total dissolution } \\
\text { time (days) }\end{array}$ \\
\hline 2.5 & 30 & 0.40 & $1440(1$ day $)$ & 543 & 543 \\
68 & 30 & 0.40 & $1440(1$ day $)$ & 405 & 405 \\
2.5 & 30 & 0.042 & 120 & 5135 & 432 \\
68 & 30 & 0.042 & 120 & 3829 & 322 \\
2.5 & 63 & 0.035 & 6.0 & 3051 & 12.8 \\
68 & 63 & 0.035 & 6.0 & 2275 & 9.5 \\
2.5 & 63 & 0.163 & 30 & 663 & 13.8 \\
68 & 63 & 0.163 & 30 & 495 & 10.3 \\
2.5 & 63 & 0.88 & 360 & 125 & 31.3 \\
68 & 63 & 0.88 & 360 & 94 & 23.5 \\
\hline
\end{tabular}

\subsection{RECOMMENDATIONS AND CONCLUSIONS}

These results indicate that a continuous dissolution at high temperature and low flow rate is likely the best approach. The highest temperature that is practical will increase both the dissolution rate and amount. A flow of $1 \mathrm{~m}^{3} /$ day will likely yield the same dissolution rate as a flow of $10 \mathrm{~m}^{3} /$ day, while the slower flow rate will consume only a fraction of the caustic.

However, a rate much below $1 \mathrm{~m}^{3} /$ day might impact the dissolution rate significantly. A continuous flow is recommended since it ensures that caustic is replenished, higher temperature is maintained, and flow turbulence is induced, all of which enhances the dissolution rate.

\section{POTENTIAL ALUMINUM SATURATION AT SAVANNAH RIVER}

\subsection{SEEDING TESTS WITH SAVANNAH RIVER SUPERNATANTS}

An experimental effort at the SRS was initiated to determine if several SRS supernatants were supersaturated with respect to aluminum. SRS personnel added gibbsite seeds to supernatant samples from tanks 30,32 , and 34 at $25^{\circ} \mathrm{C}$. A fourth supernatant sample, which contained a mixture of supernatants from tanks 37 and 44, was also seeded with gibbsite. The aluminum concentration of each sample was measured prior to the seeding and 120 days after the seeding. These experiments provided an excellent opportunity to evaluate the predictive capabilities of thermodynamic models at the SRS and ORNL. The initial chemical analyses of each sample, which are shown in Table 27, were used as inputs for thermodynamic models to predict the effects of the gibbsite seeds. Model predictions from both sites were made before the experimental results from the seeding tests were available. 
Table 27. Chemical compositions and properties of Savannah River supernatants (Compositions in molarity unless otherwise indicated)

\begin{tabular}{lcccc}
\hline $\begin{array}{c}\text { Chemical component/ } \\
\text { property }\end{array}$ & Tank 30 & Tank 32 & Tank 34 & $\begin{array}{c}\text { Composite of } \\
\text { tanks 37 and 44 }\end{array}$ \\
\hline Sodium & 5.497 & 4.306 & 5.600 & 5.350 \\
Potassium & 0.028 & 0.013 & 0.029 & 0.037 \\
Free hydroxide & 2.510 & 1.860 & 3.360 & 3.900 \\
Nitrate & 1.490 & 1.420 & 1.140 & 0.650 \\
Nitrite & 0.570 & 0.570 & 0.460 & 0.510 \\
Aluminate & 0.360 & 0.360 & 0.200 & 0.170 \\
Sulfate & 0.000 & 0.000 & 0.010 & 0.002 \\
Carbonate & 0.290 & 0.050 & 0.218 & 0.072 \\
Phosphate & 0.005 & 0.003 & 0.004 & 0.003 \\
Silicon & 0.000 & 0.000 & 0.000 & 0.000 \\
Water & 50.023 & 51.572 & 51.050 & 52.262 \\
& & & & \\
Total solids, kg/L & 0.341 & 0.283 & 0.312 & 0.275 \\
Water, kg/L & 0.901 & 0.929 & 0.920 & 0.942 \\
Density, g/mL & 1.242 & 1.212 & 1.232 & 1.217 \\
pH & $>14$ & $>14$ & $>14$ \\
\hline
\end{tabular}

\subsection{SOLGASMIX PREDICTIONS OF ALUMINUM CONCENTRATIONS}

At ORNL, the SOLGASMIX code has been used to predict the aluminum concentrations in several supernatant simulants for the SRS (Weber, 2001a). In addition, SOLGASMIX calculations have been used to predict the formation of aluminosilicate deposits in the SRS evaporator system (Weber, 2001b). For these new SOLGASMIX predictions for the gibbsite seed tests, it was assumed that the supernatants contain only the chemical components shown in Table 27. For each supernatant, the amount of water (or kilograms of water per kilogram of waste) was calculated using the molecular weight of each component and the density from Table 27 . The molal concentrations were then used as input for calculation of phase equilibrium at $25^{\circ} \mathrm{C}$ using the modified SOLGASMIX code. As shown in Table 28, the SOLGASMIX predictions indicated that the tank 34 supernatant and the supernatant composite from tanks 37 and 44 were undersaturated with respect to aluminum as well as other chemical components. In contrast, the SOLGASMIX model predicted that 19 and $46 \%$ of the aluminum in tanks 30 and 34, respectively, should precipitate in the form of gibbsite. The experimental results from the SRS seeding tests are also listed in Table 28. The test results and the SOLGASMIX predictions were in agreement for three of the four seeding tests. At the SRS, the tank 34 supernatant and the composite supernatant from tanks 37 and 44 showed increases in aluminum concentration after 120 days, which indicates dissolution of the gibbsite seed crystals. These experimental results are consistent with the SOLGASMIX predictions that the supernatants were not saturated with respect to aluminum. The seeding test with tank 32 supernatant showed a 
decrease in aqueous aluminum concentration, which confirmed the SOLGASMIX calculation that the supernatant was supersaturated with respect to aluminum. The seeded sample from tank 30 indicated no change in aluminum concentration after 120 days, and the supernatant remained very near saturation throughout the experiment. Because the SOLGASMIX code predicted that the solution was slightly supersaturated, a small amount of aluminum should have precipitated. However, part of the apparent discrepancy may be a result of the to very slow precipitation of aluminum in slightly supersaturated solution. In conclusion, the results of the seeding tests validate the use of the SOLGASMIX code to predict the aluminum phase equilibria in the SRS supernatants.

Table 28. Test results and SOLGASMIX predictions for aluminum concentrations

\begin{tabular}{lll}
\hline \multicolumn{1}{c}{ Tank } & \multicolumn{1}{c}{ Test results } & \multicolumn{1}{c}{ SOLGASMIX predictions } \\
\hline 30 & No change in [Al] & Gibbsite precipitation (19\%) \\
32 & Decrease in [Al] to $0.24 M$ (still falling) & Gibbsite precipitation (46\%) \\
34 & Increase in [Al] to $0.43 M$ (still rising) & No gibbsite precipitation \\
37 and 44 & Increase in [Al] to $0.42 M$ & No gibbsite \\
\hline
\end{tabular}

\section{ACKNOWLEDGMENTS}

This work was sponsored by the U.S. Department of Energy through the Office of Science and Technology's Tanks Focus Area. The Environmental Simulation Program predictions were performed at Mississippi State University in the Diagnostic Instrumentation and Analysis Laboratory. Additional support from the Department of Energy through Cooperative Agreement DE-FC26-98FT40395 is gratefully acknowledged. The remainder of this effort was performed at Oak Ridge National Laboratory under the auspices of the Computational Science and Engineering Division and the Nuclear Science and Technology Division. Oak Ridge National Laboratory is managed by UT-Battelle, LLC, under contract DE-AC00OR22725. 


\section{REFERENCES}

Alexander, G. B., W. M. Heston, and R. K. Iler. 1954. "The Solubility of Amorphous Silica in Water," J. Phys. Chem. 58, 453.

Bishop, C. M. 1995. Neural Networks for Pattern Recognition, Oxford University Press, New York.

Colton, N. G. 1996. Status Report: Pretreatment Chemistry Evaluation-Wash and Leach Factors for the Single-shell Tank Waste Inventory, PNL-11290, Pacific Northwest National Laboratory, Richland, Washington.

Colton, N. G., E. A. Daymo, W. L. Kuhn, and A. R. Felmy. 1998. Literature Review: Events, Phenomena, and Studies Pertinent to the Technical Risks in the Waste Feed Delivery Project, Pacific Northwest National Laboratory, Richland, Washington.

Denn, M. M. 1980. Process Fluid Mechanics, Prentice-Hall, Englewood Cliffs, New Jersey.

Francis, A., J. Henshaw, C. Kemp, and S. W. Swanton. 2001. Particle Sizing Studies on Tanks C-103 and C-104 Simulants Under Varying Flow Conditions, AEAT/R/NS/0516, AEA Technology, Harwell, England.

Herting, D. L. 1999. U-Farm Cooling Test Results, Final Report, Numatec Hanford Corporation Internal Memo \#82800-99-039, Richland, Washington.

Herting, D. L. 2000. Saltcake Dissolution FY 2000 Status Report, HNF-7031, Fluor Hanford, Richland, Washington.

Herting, D. L., and D. B. Bechtold. 2002. Tank 241-S-112 Saltcake Dissolution Laboratory Test Report, RPP-10984, Fluor Hanford, Richland, Washington.

Herting, D. L., D. W. Edmonson, J. R. Smith, T. A. Hill, and C. H. Delegard. 1999. Saltcake Dissolution FY 1999 Status Report, HNF-5193, Fluor Hanford, Richland, Washington.

Hill, J. G., G. S. Anderson, and B. C. Simpson. 1995. The Sort on Radioactive Waste Type Model: A Method to Sort Single-Shell Tanks into Characteristic Groups, PNL-9814, Pacific Northwest National Laboratory, Richland, Washington.

Hornik, K., M. Stinchcombe, and H. White. 1989. "Multilayer Feedforward Networks Are Universal Approximators," Neural Networks 2, 359.

Hunt, R. D., E. C. Beahm, C. W. Chase, J. L. Collins, T. A. Dillow, and C. F. Weber. 1999. Prevention of Solids Formation: Results of the FY 1999 Studies, ORNL/TM-1999/263, Oak Ridge National Laboratory, Oak Ridge, Tennessee. 
Hunt, R. D., C. P. McGinnis, C. F. Weber, T. D. Welch, and J. R. Jewett. 2000a. FY 2000 Saltcake Dissolution and Feed Stability Workshop, ORNL/TM-2000/202, Oak Ridge National Laboratory, Oak Ridge, Tennessee.

Hunt, R. D., T. A. Dillow, J. R. Parrott, Jr., J. C. Schryver, C. F. Weber, and T. D. Welch. 2000b. Waste Preparation and Transport Chemistry: Results of the FY 2000 Studies, ORNL/TM-2000/298, Oak Ridge National Laboratory, Oak Ridge, Tennessee.

Hunt, R. D., J. S. Lindner, A. J. Mattus, J. C. Schryver, and C. F. Weber. 2002. Waste Preparation and Transport Chemistry: Results of the FY 2001 Studies, ORNL/TM-2001/289, Oak Ridge National Laboratory, Oak Ridge, Tennessee.

Jain, A. K., J. Mao, and K. M. Mohiuddin. 1996. “Artificial Neural Networks: A Tutorial," Computer 29, 31.

Kinrade, S. D., and T. W. Swaddle. 1988. "Silicon-29 NMR Studies of Aqueous Silicate Solutions. 1. Chemical Shifts and Equilibria," Inorg. Chem. 27, 4253.

Lippmann, R. P. 1987. "An Introduction to Computing with Neural Nets," IEEE ASSP Mag. 4(2), 4 .

Marshall, W. L. 1980. "Amorphous Silica Solubilities-I. Behavior in Aqueous Sodium Nitrate Solution, 25-300 C, 0-6 Molal," Geochim. Cosmochim. Acta 44, 907.

McCormick, A. V., A. T. Bell, and C. J. Radke. 1987. "Quantitative Demonstration of Siliceous Species in Sodium Silicate Solutions by Silicon-29 NMR Spectroscopy," Zeolites 7, 183.

McKay, R. L. 1993. Letter Report for Westinghouse Hanford Company: TWRS Retrieval Technology Project, Slurry Transport_-Plugging Investigation, Pacific Northwest National Laboratory, Richland, Washington.

Moody, J. 1994. "Prediction Risk and Architecture Selection for Neural Networks," in From Statistics to Neural Networks: Theory and Pattern Recognition Applications, V. Cherkassky, J. H. Friedman and H. Wechsler (eds.), NATO ASI Series F, Vol. 136, Springer-Verlag, New York.

Nabney, I. 2002. Netlab: Algorithms for Pattern Recognition, Springer-Verlag, New York.

Palmer, D. A. (ORNL). 2002. Personal communication.

Snoeyink, V. L., and D. Jenkins. 1980. Water Chemistry, John Wiley \& Sons, New York.

Svensson, I. L., S. Sjoberg, and L. O. Ohman. 1986. "Polysilicate Equilibria in Concentrated Sodium Silicate Solutions," J. Chem. Soc. Faraday Trans. 1 82, 3635. 
Weast, R. C., and M. J. Astle. 1981. CRC Handbook of Chemistry and Physics, CRC Press, Boca Raton, Florida.

Weber, C. F. 2001a. Thermodynamic Modeling of Savannah River Evaporators, ORNL/TM-2001/102, Oak Ridge National Laboratory, Oak Ridge, Tennessee.

Weber, C. F. 2001b. Phase Equilibrium Studies of Savannah River Tanks and Feed Streams for the Salt Waste Processing Facility, ORNL/TM-2001/109, Oak Ridge National Laboratory, Oak Ridge, Tennessee.

Wesolowski, D. J. 1992. "Aluminum Speciation and Equilibria in Aqueous Solution: I. The Solubility of Gibbsite in the System Na-K-Cl-OH-Al $(\mathrm{OH})_{4}$," Geochim. Cosmochim. Acta 56, 1065.

Wilmarth, W. R., and R. A. Peterson. 2000. Analysis of Surface and Variable Depth Samples from Tank 43H, WSRC-TR-2000-00208, Westinghouse Savannah River Company, Aiken, South Carolina. 
ORNL/TM-2002/300

\section{INTERNAL DISTRIBUTION}

1-2. R. D. Hunt

3. R. T. Jubin

4. ORNL Laboratory Records-CRL, RC, OSTI

\section{ELECTRONIC DISTRIBUTION ONLY}

5. D. G. Baide, CH2M Hill Hanford Group, Daniel_G_Dan_Baide@rl.gov

6. W. B. Barton, CH2M Hill Hanford Group, W_B_Blaine_Barton@rl.gov

7. J. W. Cammann, CH2M Hill Hanford Group, Jerry_W_Cammann@rl.gov

8. B. A. Carteret, Pacific Northwest National Laboratory, betty.carteret@pnl.gov

9. J. S. Garfield, Numatec Hanford Company, John_S_Garfield@rl.gov

10. K. A. Gasper, CH2M Hill Hanford Group, Kenneth_A_Ken_Gasper@rl.gov

11. K. D. Gerdes, U.S. Department of Energy, kurt.gerdes@em.doe.gov

12. T. S. Gutman, U.S. Department of Energy, thomas.gutmann@srs.gov

13. J. Henshaw, AEA Technology, jim.henshaw@aeat.co.uk

14. J. N. Herndon, ORNL, herndonjn@ornl.gov

15. D. L. Herting, Fluor Hanford, Daniel_L_Herting@rl.gov

16. D. J. Hill, ORNL, hilldj@ornl.gov

17. D. T. Hobbs, Westinghouse Savannah River Company, david.hobbs@srs.gov

18. J. O. Honeyman, Numatec Hanford Company, James_O_Jim_Honeyman@rl.gov

19. C. M. Kendrick, ORNL, kendrickcm@ornl.gov

20. R. A. Kirkbride, Numatec Hanford Company, Randy_A_Kirkbride@rl.gov

21. B. E Lewis, Jr., ORNL, lewisbejr@ornl.gov

22. J. S. Lindner, MSU, lindner@dial.msstate.edu

23. R. D. Lopez, Florida International University, rlopez@hcet.fiu.edu

24. G. T. MacLean, Fluor Federal Services, Graham_T_MacLean@rl.gov

25. A. J. Mattus, ORNL, mattusaj@ornl.gov

26. B. M. Mauss, U.S. Department of Energy, Billie_M_Mauss@rl.gov

27. C. P. McGinnis, ORNL, mcginniscp@ornl.gov

28. J. R. Noble-Dial, U.S. Department of Energy, nobledialjr@oro.doe.gov

29. M. J. Plodinec, MSU, plodinec@dial.msstate.edu

30. D. A. Reynolds, CH2M Hill Hanford Group, Daniel_A_Reynolds@rl.gov

31. J. C. Schryver, ORNL, schryverjc@ornl.gov

32. R. Srivastava, Florida International University, Rajiv.Srivastava@fiu.edu

33. R. R. Thompson, CH2M Hill Hanford Group, R_R_Rex_Thompson@rl.gov

34. R. K. Toghiani, MSU, Rebecca@che.msstate.edu

35. W. B. van Pelt, Westinghouse Savannah River Company, bill.van-pelt@srs.gov

36. C. F. Weber, ORNL, webercf@ornl.gov

37. T. D. Welch, ORNL, welchtd@ornl.gov

38. W. R. Wilmarth, Westinghouse Savannah River Company, bill.wilmarth@srs.gov 